NIST Technical Note 1889v2

\title{
CFAST - Consolidated Model of Fire Growth and Smoke Transport (Version 7) Volume 2: User's Guide
}

Richard D. Peacock

Paul A. Reneke

Glenn P. Forney

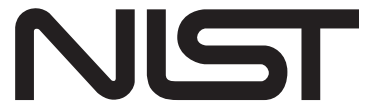

National Institute of Standards and Technology U.S. Department of Commerce 



\section{NIST Technical Note 1889v2}

\section{CFAST - Consolidated Model of Fire Growth and Smoke Transport (Version 7) Volume 2: User's Guide}

Richard D. Peacock Paul A. Reneke Glenn P. Forney

This publication is available free of charge from: http://dx.doi.org/10.6028/NIST.TN.1889v2

October 2015 CFAST Version 7.0.0

GIT Revision: Gitv7-0-g4eddb8a

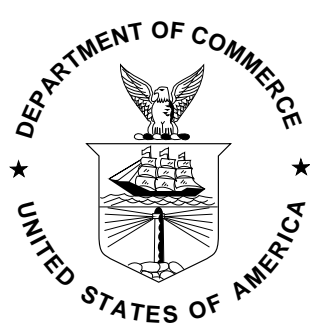

U.S. Department of Commerce Penny Pritzker, Secretary 



\section{Disclaimer}

The U. S. Department of Commerce makes no warranty, expressed or implied, to users of CFAST and associated computer programs, and accepts no responsibility for its use. Users of CFAST assume sole responsibility under Federal law for determining the appropriateness of its use in any particular application; for any conclusions drawn from the results of its use; and for any actions taken or not taken as a result of analyses performed using these tools. CFAST is intended for use only by those competent in the field of fire safety and is intended only to supplement the informed judgment of a qualified user. The software package is a computer model which may or may not have predictive value when applied to a specific set of factual circumstances. Lack of accurate predictions by the model could lead to erroneous conclusions with regard to fire safety. All results should be evaluated by an informed user.

National Institute of Standards and Technology Technical Note 1889v1

Natl. Inst. Stand. Technol. Tech. Note 1889v2, 94 pages (October 2015)

CODEN: NTNOEF

This publication is available free of charge from: http://dx.doi.org/10.6028/NIST.TN.1889v1 


\section{Intent and Use}

The algorithms, procedures, and computer programs described in this report constitute a methodology for predicting some of the consequences resulting from a prescribed fire. They have been compiled from the best knowledge and understanding currently available, but have important limitations that must be understood and considered by the user. The program is intended for use by persons competent in the field of fire safety and with some familiarity with personal computers. It is intended as an aid in the fire safety decision-making process. 


\section{Abstract}

CFAST is a two-zone fire model capable of predicting the environment in a multi-compartment structure subjected to a fire. It calculates the time-evolving distribution of smoke and gaseous combustion products as well as the temperature throughout a building during a user-prescribed fire. This report describes the use of the model, including installing and running the software, the computer platforms upon which it is supported and examples to verify correct installation. 


\section{Acknowledgments}

Continuing support for CFAST is via internal funding at NIST. In addition, support is provided by other agencies of the U.S. Federal Government, most notably the Nuclear Regulatory Commission Office of Nuclear Regulatory Research and the U.S. Department of Energy. The U.S. NRC Office of Nuclear Regulatory Research has funded key validation experiments, the preparation of the CFAST manuals, and the continuing development of sub-models that are of importance in the area of nuclear power plant safety. Special thanks to Mark Salley and David Stroup for their efforts and support.

Support to refine the software development and quality assurance process for CFAST has been provided by the U.S. Department of Energy (DOE). The assistance of Subir Sen and Debra Sparkman in understanding DOE software quality assurance programs and the application of the process to CFAST is gratefully acknowledged. Thanks are also due to Allan Coutts, Washington Safety Management Solutions for his insight into the application of fire models to nuclear safety applications and detailed review of the CFAST document updates for DOE. 


\section{Contents}

Disclaimer

Intent and Use $\quad$ v

$\begin{array}{lll}\text { Abstract } & \text { vii }\end{array}$

$\begin{array}{lc}\text { Acknowledgments } & \text { ix }\end{array}$

1 Getting Started $\quad 1$

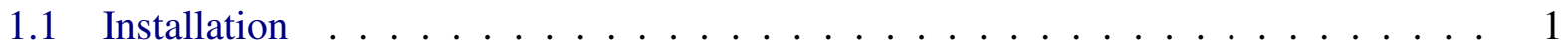

1.2 Basic Features . . . . . . . . . . . . . . . . . . . 2

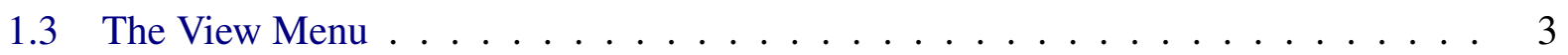

1.4 The Help Menu . . . . . . . . . . . . . . . . . . . . . . 4

2 Simulation Environment $\quad 5$

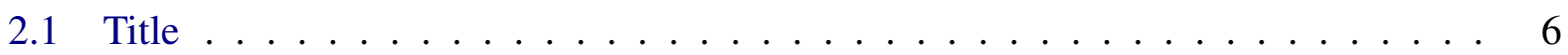

2.2 Simulation Times . . . . . . . . . . . . . . . . . . . . 6

2.3 Simulation Conditions . . . . . . . . . . . . . . . . . 6

3 Thermal Properties 9

3.1 Adding Thermal Properties . . . . . . . . . . . . . . . . 10

3.2 Editing Thermal Properties . . . . . . . . . . . . . . . . . 10

4 Compartments $\quad 11$

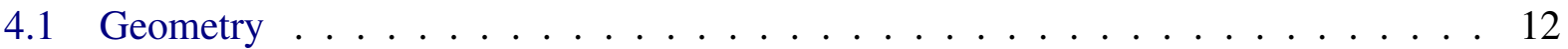

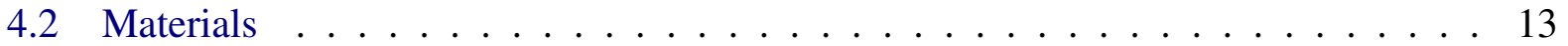

4.3 Modeling a Compartment as a Tall Shaft or Long Corridor . . . . . . . . . . . . 14

4.4 Defining Variable Compartment Area . . . . . . . . . . . . . . . . 14

5 Natural Ventilation $\quad 17$

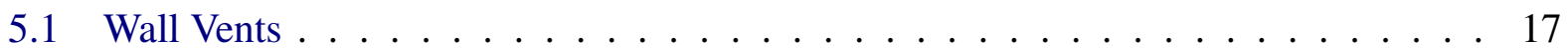

5.2 Ceiling/Floor Vents . . . . . . . . . . . . . . . . . 18

6 Mechanical Ventilation $\quad 21$

6.1 Connections to Compartments . . . . . . . . . . . . . . . . . . . . 22

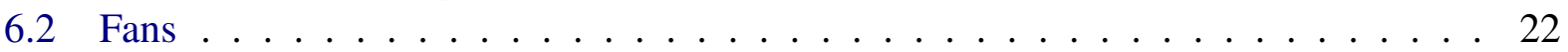




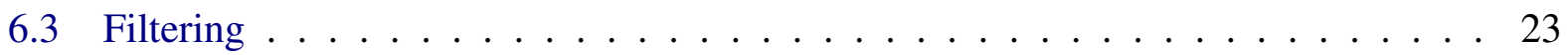

7 Fires 2

7.1 Adding Fires . . . . . . . . . . . . . . . . . . . . 25

7.2 Time-Dependent Properties . . . . . . . . . . . . . . . . . . . . 27

7.3 Special Topic: t-Squared Fires $\ldots \ldots \ldots \ldots . \ldots \ldots$

8 Defining Targets 2

9 Sprinklers and Detectors $\quad 31$

10 Surface Connections 33

11 Visualization 35

11.1 Adding Visualizations . . . . . . . . . . . . . . . . . . 35

11.2 Visualization Resolution . . . . . . . . . . . . . . . . . . 36

11.3 Output Options . . . . . . . . . . . . . . . . . . . . . 37

12 Output from CFAST 41

12.1 Compact Output . . . . . . . . . . . . . . . . . . . . 41

12.2 Detailed Outputs . . . . . . . . . . . . . . . . . . 41

12.2.1 Output for Initialization . . . . . . . . . . . . . . . . . . 42

12.2.2 Output for Main Variables . . . . . . . . . . . . . . . . . . 46

12.2.3 Output for Wall Surfaces, Targets, and Detectors/Sprinklers . . . . . . . . 47

12.2.4 Output for Gas Species . . . . . . . . . . . . . . . . . . . . 48

12.2.5 Output for Vent Flows . . . . . . . . . . . . . . . . . . 48

12.3 Spreadsheet Output . . . . . . . . . . . . . . . . . . . . . . . 49

12.3.1 Primary Output Variables (project_n.csv) $\ldots \ldots \ldots \ldots \ldots$

12.3.2 Species Output (project_s.csv) _ . . . . . . . . . . . . . . 51

12.3.3 Vent Flow (project_f.csv) . . . . . . . . . . . . . . . . . 51

12.3.4 Surface and Target Temperature and Heat Flux (project_w.csv) . . . . . . 52

12.4 Error Messages . . . . . . . . . . . . . . . . . . . . . 54

13 Scenario and Sofware Limits 59

$\begin{array}{lc}\text { References } & 61\end{array}$

$\begin{array}{lr}\text { Appendices } & 62\end{array}$

A Structure of the CFAST Input File $\quad 63$

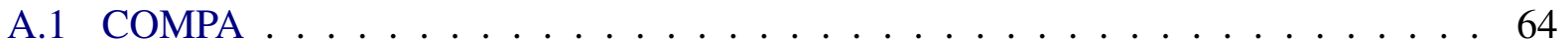

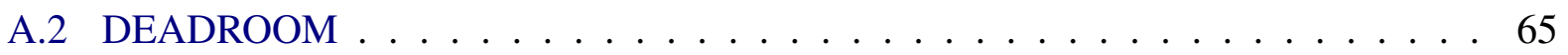

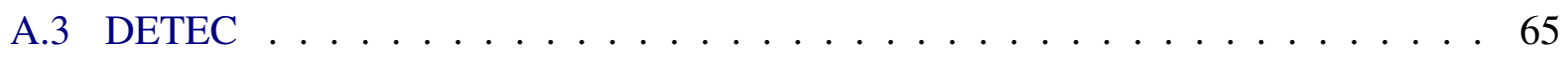

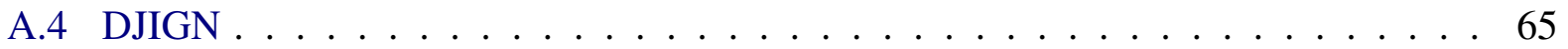

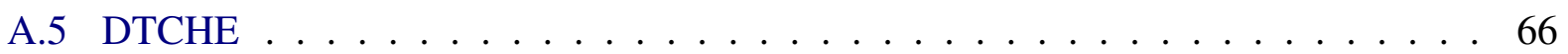

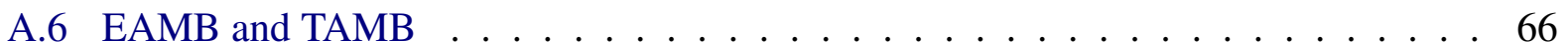




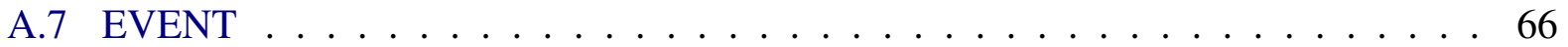

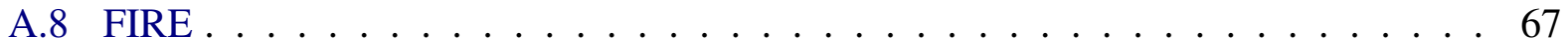

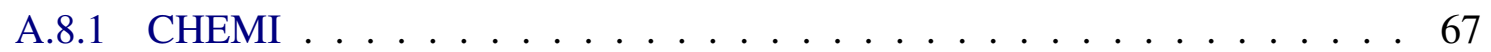

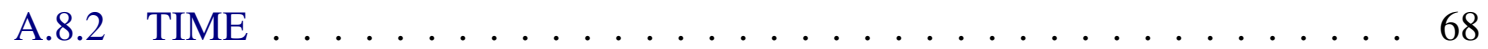

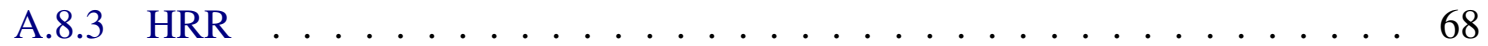

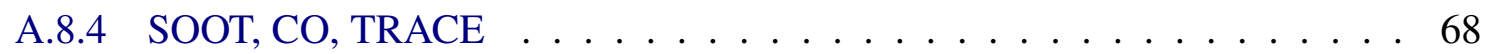

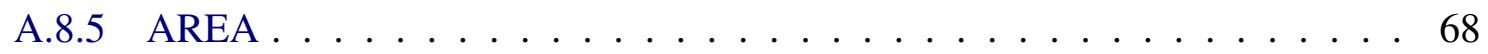

A.8.6 HEIGH . . . . . . . . . . . . . . . . . . 68

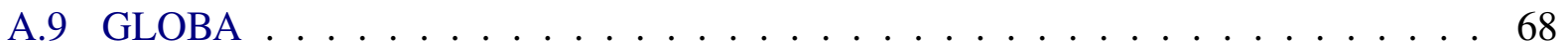

A.10 HALL . . . . . . . . . . . . . . . . . . . . . . . . . . . 69

A.11 HHEAT . . . . . . . . . . . . . . . . . . . . . . . . . . . . 69

A.12 HVENT . . . . . . . . . . . . . . . . . . . . . 70

A.13 INTER . . . . . . . . . . . . . . . . . . . . . . 70

A.14 ISOF . . . . . . . . . . . . . . . . . . . . . 70

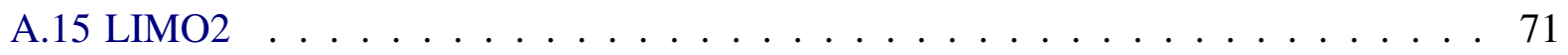

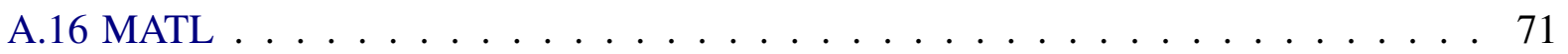

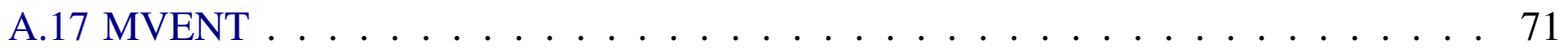

A.18 ONEZ . . . . . . . . . . . . . . . . . . . . . 71

A.19 ROOMA and ROOMH . . . . . . . . . . . . . . . . . . 72

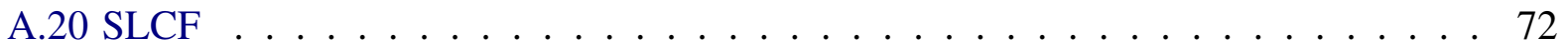

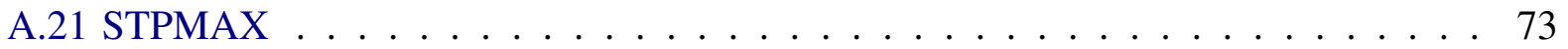

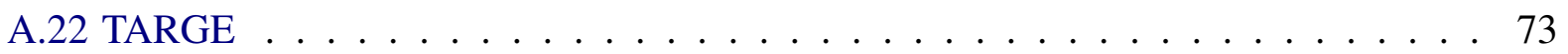

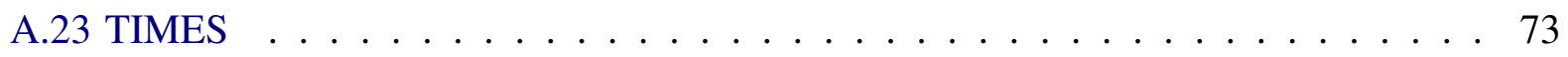

A.24 THRMF . . . . . . . . . . . . . . . . . . . . . 74

A.25 VERSN . . . . . . . . . . . . . . . . . . . . . 74

A.26 VHEAT . . . . . . . . . . . . . . . . . . . . . . . . 74

A.27 VVENT . . . . . . . . . . . . . . . . . . . . . . . . . 74

A.28 Running CFAST from a Command Prompt . . . . . . . . . . . . . 75 


\section{List of Figures}

1.1 The Primary CFAST Input Page $\ldots \ldots \ldots \ldots . \ldots \ldots$

1.2 The Standard CFAST Output Screen . . . . . . . . . . . . . . . . . 3

2.1 The CFAST Simulation Environment Tab $\ldots \ldots \ldots \ldots$

3.1 The CFAST Thermal Properties Tab . . . . . . . . . . . . . . . . . . . 9

3.2 Inserting Thermal Properties in CFAST $\ldots \ldots \ldots \ldots \ldots$

4.1 The CFAST Compartments Tab . . . . . . . . . . . . . . . . . 11

4.2 Compartment Orientation and Positioning in CFAST . . . . . . . . . . . 12

5.1 The CFAST Wall Vents Tab . . . . . . . . . . . . . . . . . . . . . 18

5.2 The CFAST Ceiling/Floor Vents Tab . . . . . . . . . . . . . . . . . . . . 19

6.1 The CFAST Mechanical Vents Tab . . . . . . . . . . . . . . . . . . . 21

7.1 The CFAST Fires Tab . . . . . . . . . . . . . . . . . . . . . . 26

7.2 Inserting T-squared Fires in CFAST $\ldots \ldots \ldots \ldots \ldots$

8.1 The CFAST Targets $\mathrm{Tab} \ldots \ldots \ldots$

9.1 The CFAST Detection/Suppression Tab $\ldots \ldots \ldots$

10.1 The CFAST Surface Connections Tab . . . . . . . . . . . . . . 33

11.1 The CFAST Visualizations Tab . . . . . . . . . . . . . . . . . 36

11.2 Smokeview Visualization of Gas Temperature with a Single Fire . . . . . . . . . 37

11.3 Smokeview Visualization of Gas Velocity with Two Fires . . . . . . . . . . . . 38

11.4 Smokeview Visualization of Detector Activation in a Corridor . . . . . . . . . 39 


\section{Chapter 1}

\section{Getting Started}

The Consolidated Model of Fire and Smoke Transport (CFAST) is documented by three publications, this user's guide, a technical reference guide [1] and a model evaluation guide [2]. The technical reference guide describes the underlying physical principles, provides a comparison with other models, and includes an evaluation of the model following the guidelines of ASTM E1355 [3]. The model evaluation guide documents verification and validation efforts for the model. This user's guide describes how to use the model.

\subsection{Installation}

CFAST was designed primarily for a personal computer running Microsoft Windows. However, the source code is written in Fortran and can be run as a stand alone command line application that reads input data from a text file. Details of how one runs CFAST without the Windows-based graphical user interface are found in Appendix A. All of the files associated with CFAST can be obtained at:

http://cfast.nist.gov

The CFAST distribution consists of a self-extracting set-up program for Windows-based personal computers. After downloading the set-up program, double-clicking on the file's icon walks you through a series of steps for installation of the program. The most important part of the installation is the creation of a folder ( $\mathrm{C}$ : $\backslash$ Program Files $\backslash$ CFAST by default) in which the CFAST executable files and supplemental data files are installed. Sample input files are found in the Examples folder.

CFAST input files are best created and run using a Windows-based input editor called CEdit. Sample input files are provided with the program for new users who are encouraged to first run the sample calculations before attempting to create an input file. To run the model, browse to the location of the CFAST sample input file (default location is in a folder called Examples in the installation folder, copy the file named standard. in to a location of your choice and then double click on the copied file. This should open the file in the CFAST input editor, CEdit, as shown in Fig. 1.1. The simple test case can be run from the program menu by clicking on the "Run" icon. The case should finish in a few seconds. To verify that the installation has been done correctly, the output of the model should appear as shown in Fig. 1.2. 


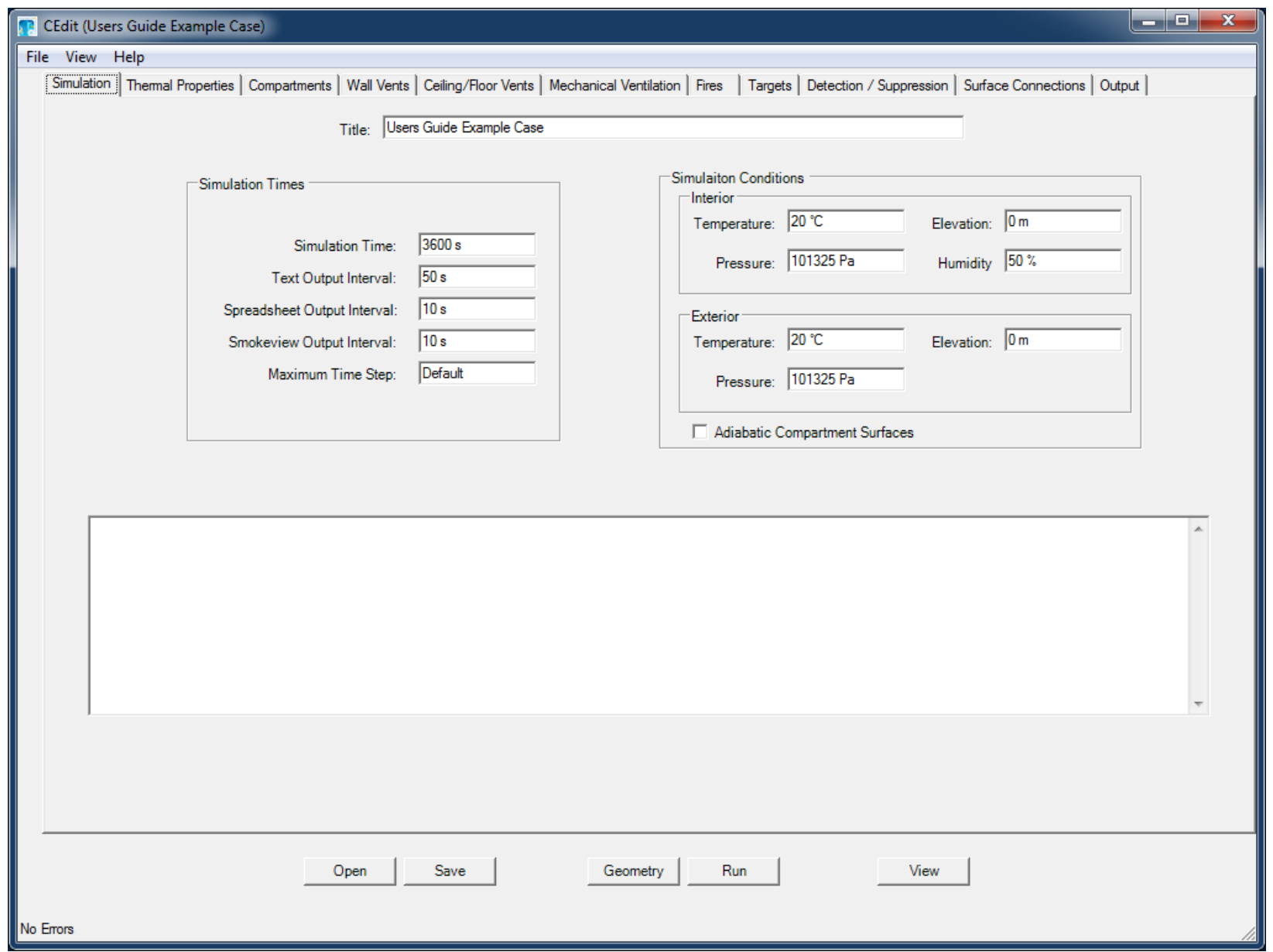

Figure 1.1: The Primary CFAST Input Page.

\subsection{Basic Features}

The input parameters are organized via tabs near the top of the CEdit screen, as shown in Fig. 1.1.

Simulation Environment includes simulation time, specification of model outputs, and ambient conditions. Also included on the page are a constantly updated list of errors, warnings, and messages about the input file specification or model simulation.

Thermal Properties defines the thermal conductivity, specific heat, density, thickness and emissivity values for all materials and fuel sources to be used in a simulation.

Compartments defines the size, construction characteristics, and position of the compartments in a simulation.

Wall Vents define doors and windows.

Ceiling/Floor Vents define holes in the ceiling/floor.

Mechanical Ventilation defines forced air ventilation. 


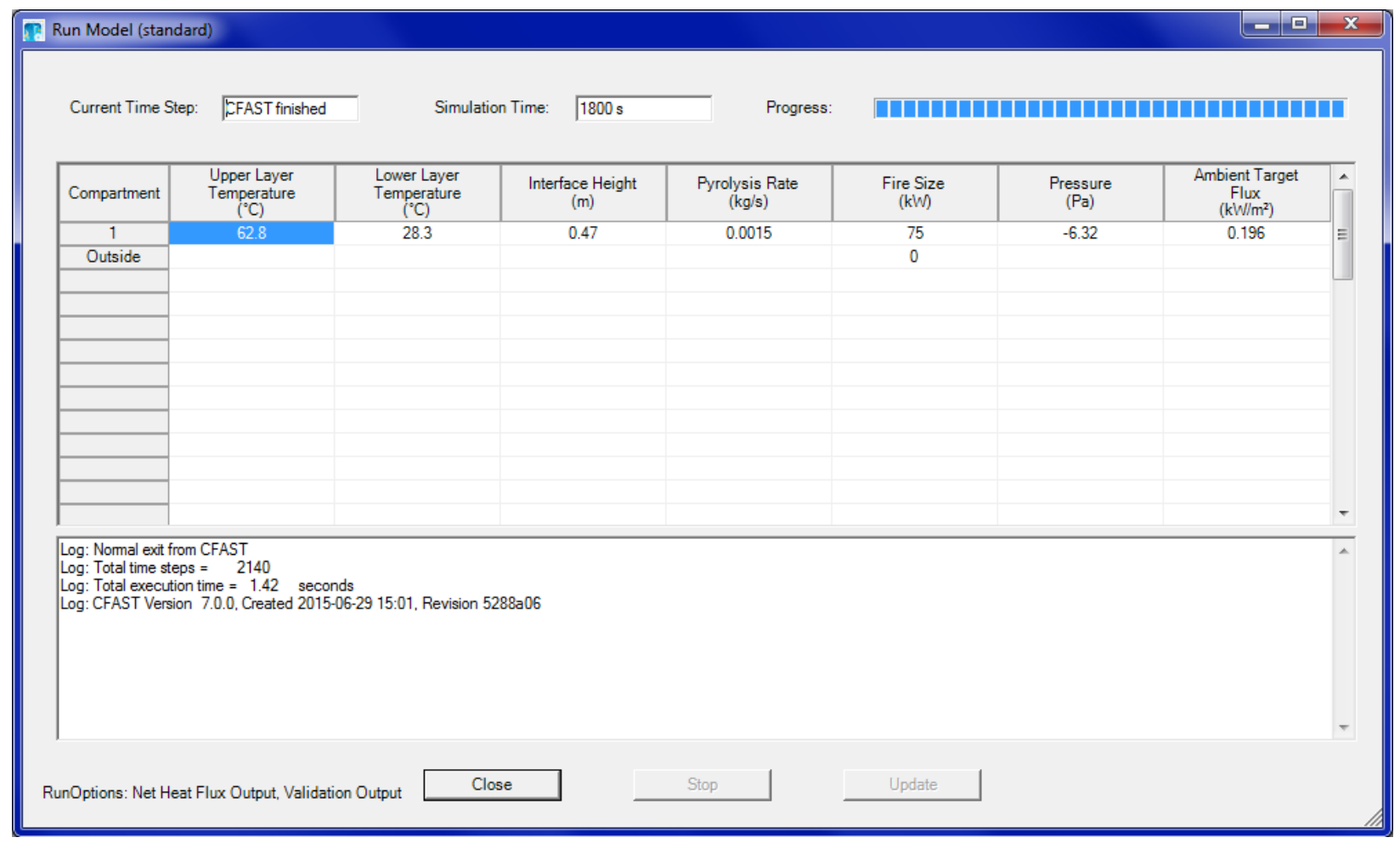

Figure 1.2: The Standard CFAST Output Screen.

Fires include user specification of the initial fire source and any additional burning objects in one or more of the compartments of the simulation.

Targets provide the ability to calculate the temperature and net heat flux to objects placed and oriented arbitrarily in the structure.

Detection / Suppression defines any heat alarms and sprinklers in the compartments of the simulation.

Surface Connections allows for more detailed description of the connections between compartments in the simulation to better simulate the transfer of heat from compartment to compartment in the simulation.

Visualizations allows specification of one or more 2-D and 3-D visualizations to be added to the simulation for viewing with Smokeview. Note that these can require significant additional computational time than a basic CFAST simulation without visualizations.

\subsection{The View Menu}

The View menu allows you to view or print the input data file, output file (if the simulation has been run and a text output file generated) and the log file of the simulation. If one of the items does not exist on the user's hard disk, the selection is grayed out. 
Select Engineering Units allows you to select the units for input and output. By default, most outputs are in S.I. units, with temperature in Celsius.

\subsection{The Help Menu}

The Help menu accesses this user's guide, the CFAST web site, or an about dialog box that displays the user license and version of the program. 


\section{Chapter 2}

\section{Simulation Environment}

The Environment page defines the initial conditions and simulation time for the CFAST input file.

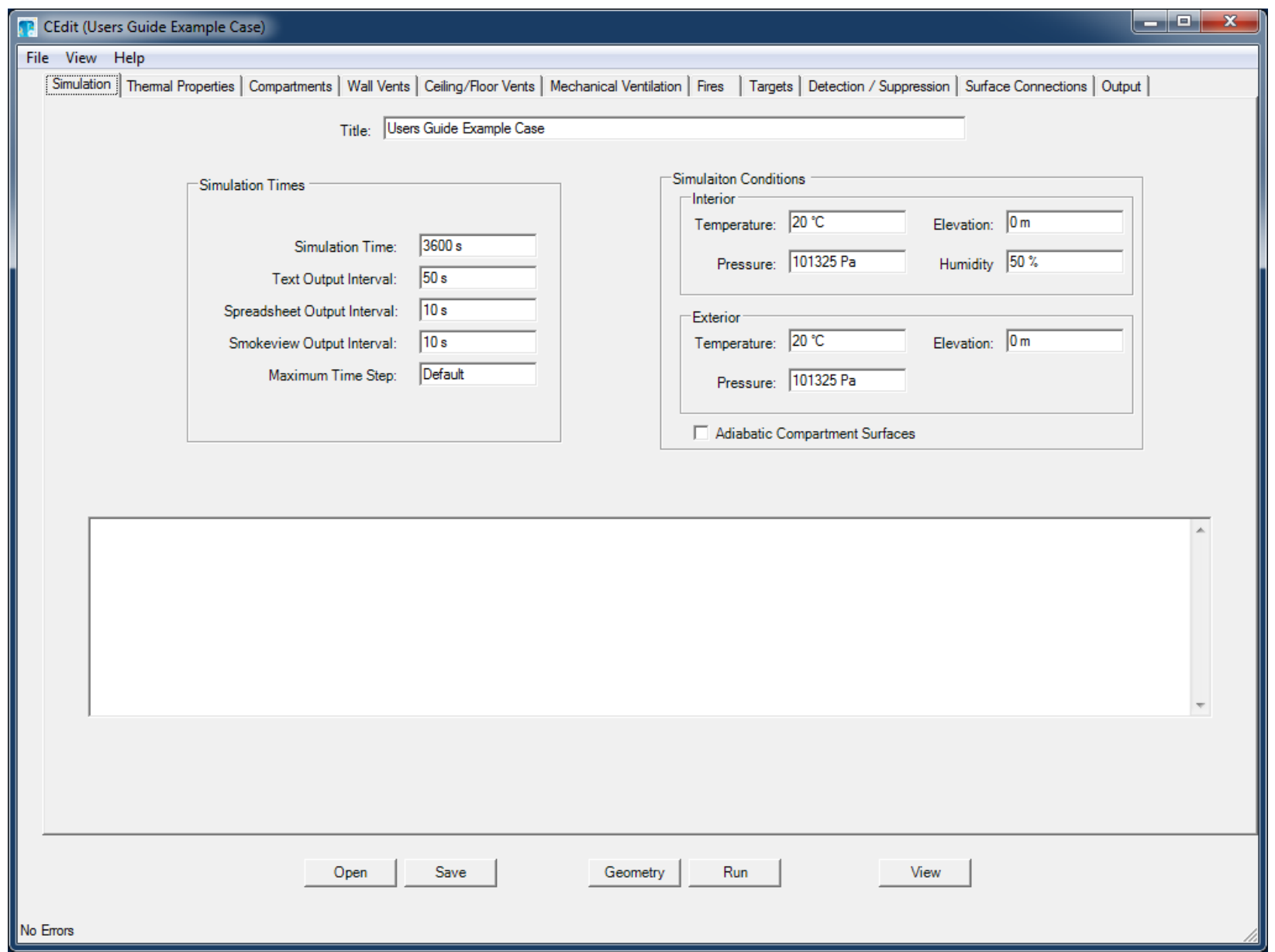

Figure 2.1: The CFAST Simulation Environment Tab. 


\subsection{Title}

The first thing to do when setting up an input file is to give the simulation a title. The title is optional and may consist of letters, numbers, and/or symbols and may be up to 50 characters. All output files will be tagged with this character string.

\subsection{Simulation Times}

Simulation Time (default units: s, default value, 900 s): The length of time over which the simulation takes place. The maximum value for this input is $86400 \mathrm{~s}$ (1 day).

Text Output Interval (default units: s, default value, $50 \mathrm{~s}$ ): The time interval between each printing of the output data. If equal to zero, no output values will appear.

Spreadsheet Output Interval (default units: s, default value, $10 \mathrm{~s}$ ): CFAST can output the results of the simulation in a comma-delimited spreadsheet file. This parameter defines the time interval between these outputs. A value greater than zero must be used if the spreadsheet file is desired.

Smokeview Output Interval (default units: s, default value: $10 \mathrm{~s}$ ): CFAST can output a subset of the results in a format compatible with the visualization program Smokeview. This input defines the time interval between outputs of the model results in a Smokeview-compatible format. A value greater than zero must be used if the Smokeview output is desired.

Maximum Time Step (default units: s, default value: $2 \mathrm{~s}$ ): CFAST will automatically adjust the time interval for the solution of the differential equation set up or down so that the simulation is as efficient as possible within the pre-defined error tolerances. This parameter places a maximum value for the equation solver and can normally be left at the default value. In cases (which are hopefully rare) where the model fails to converge on a solution, this value can be reduced which often will allow the simulation to successfully complete.

\subsection{Simulation Conditions}

Ambient conditions define the environment at which the scenario begins. Initial pressures in a structure are calculated simply as a lapse rate (related to the height above sea level) based on the NOAA/NASA tables [4]. It is convenient to choose the base of a structure to be at zero height and then reference the height of the structure with respect to that height. The temperature and pressure must then be measured at that position. Another possible choice would be the pressure and temperature at sea level, with the structure elevations then given with respect to mean sea level. This is also acceptable, but somewhat more tedious in specifying the construction of a structure. Either of these choices works though, so long as they are consistent. Usually, the station elevation is set to zero and the pressure to ambient. The effect of changing these values is minor. Note that the equations implemented in the model are not designed to handle negative elevations and altitudes. 
Temperature (default units: ${ }^{\circ} \mathrm{C}$, default value: $20{ }^{\circ} \mathrm{C}$ ): Initial ambient temperature inside or outside the structure at the station elevation.

Pressure (default units: Pa, default value: $101325 \mathrm{~Pa}$ ): Initial values for ambient atmospheric pressure inside and outside the structure at the station elevation. The default value is standard atmospheric pressure at sea level.

Elevation (defaults units: $\mathrm{m}$, default value: $0 \mathrm{~m}$ ): The height where the ambient pressure and temperature are specified. This is the reference height for calculating the density of the atmosphere as well as the temperature and pressure inside and outside of the structure as a function of height.

Humidity (default units \% RH, default value: $50 \%$ ): The initial relative humidity in the system, only specified for the interior. This is converted to kilograms of water per cubic meter as an initial condition for both the interior and exterior of the structure.

Adiabatic Compartment Surfaces When this box is checked, all of the compartment surfaces are assumed to be perfect insulators and the materials section of the compartments tab becomes grayed out. This feature is useful when designing an experiment in which it is safe to assume that there is no heat transfer to the walls of the compartments. 


\section{Chapter 3}

\section{Thermal Properties}

The Thermal Properties page defines the thermal conductivity, specific heat, density, thickness and emissivity values for all materials and fuel sources that will be used in a simulation.

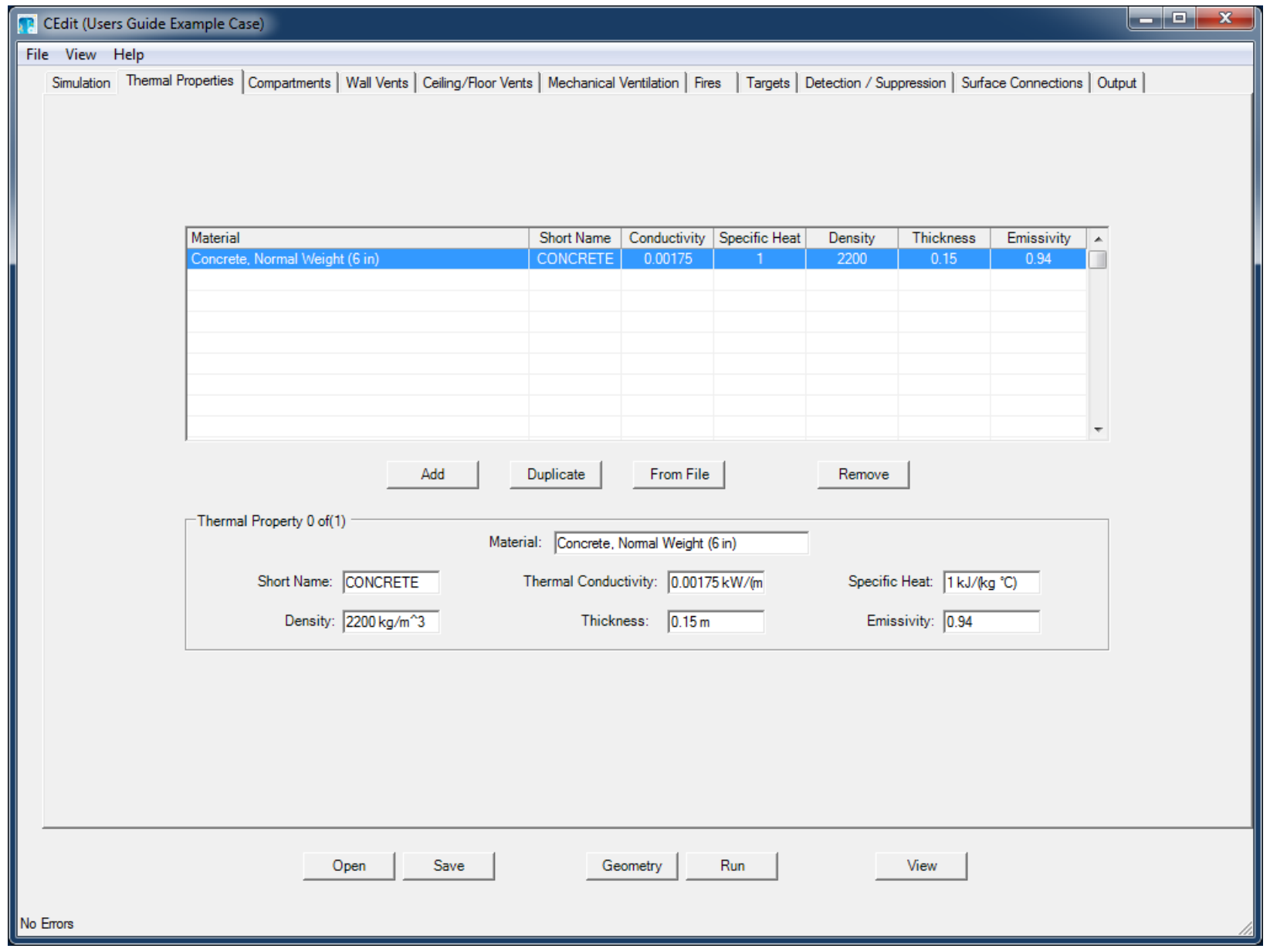

Figure 3.1: The CFAST Thermal Properties Tab. 


\subsection{Adding Thermal Properties}

By default, CEdit does not include predefined thermal properties for compartment materials. Thus, the user needs to define materials for use within a specific simulation. These may be from other simulations or input directly from reference sources or test results. Clicking the 'Add' button and assigning values to the following list of properties will create a set of thermal properties associated with a material used in a compartment or a fuel source in a fire.

Material A descriptive name for the material.

Short Name A one-word (no more than 8 characters) unique identifier for the material. This identifier should not contain any spaces and is used in other CFAST inputs to identify the particular material referenced.

Thermal Conductivity (default value: none, default units: $\mathrm{kW} /(\mathrm{m} \cdot \mathrm{K})$ ): Thermal conductivity for the material.

Specific Heat (default value: none, default units: $\mathrm{kJ} /(\mathrm{kg} \cdot \mathrm{K})$ ): Specific heat for the material.

Density (default value: none, default units: $\mathrm{kg} / \mathrm{m}^{3}$ ): Density for the material.

Thickness (default value: none, default units: $\mathrm{m}$ ): Thickness of the material. Note that if two materials with identical thermal properties but with different thicknesses are desired, two separate materials must be defined.

Emissivity (default value: 0.9, default units: none): Emissivity of the material surface. This is the fraction of radiation that is absorbed by the material.

\subsection{Editing Thermal Properties}

The 'From File' button allows you to insert thermal properties from existing CFAST input files to the current simulation.

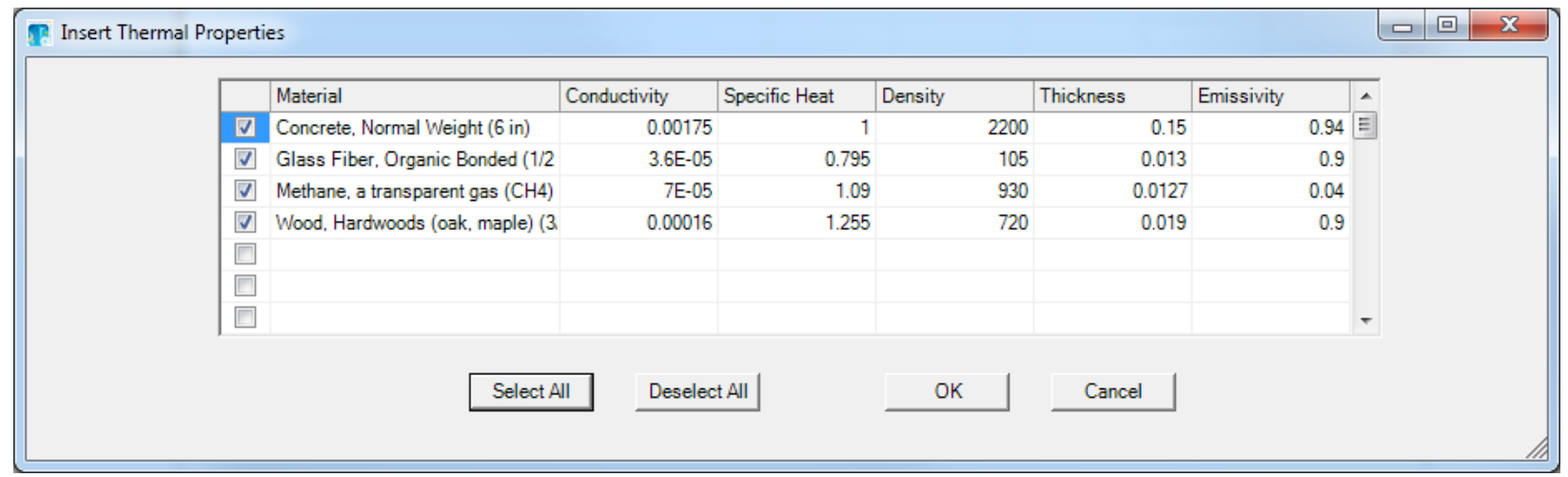

Figure 3.2: Inserting Thermal Properties in CFAST. 


\section{Chapter 4}

\section{Compartments}

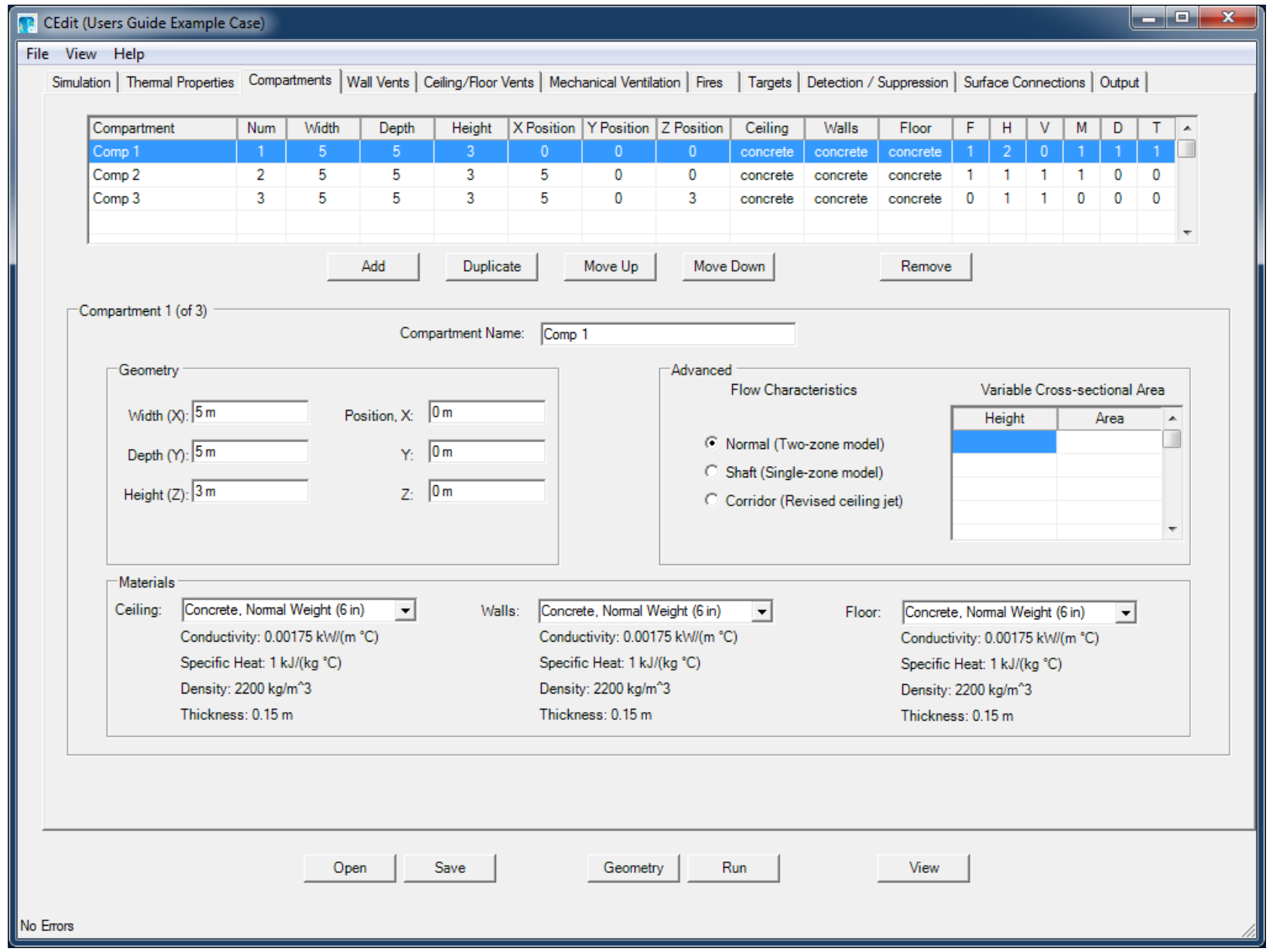

Figure 4.1: The CFAST Compartments Tab.

The Compartments page defines the size, position, materials of construction, and flow characteristics for the compartments in the simulation. Initially, only the simulation environment page and the 'Add' button on the compartment geometry and thermal properties pages are enabled; all 
other pages are not available to the user for detailed inputs until a compartment has been added to the simulation.

In order to model a fire scenario, the size and position of each compartment in the structure must be specified. For a compartment, the width, depth, compartment height and height of the floor of the compartment provide this specification. The maximum number of compartments for version 7 is thirty. The usual assumption is that compartments are rectangular parallelepipeds. However, the CFAST model can accommodate odd shapes as equivalent floor area parallelepipeds or with a cross-sectional area that varies with height.

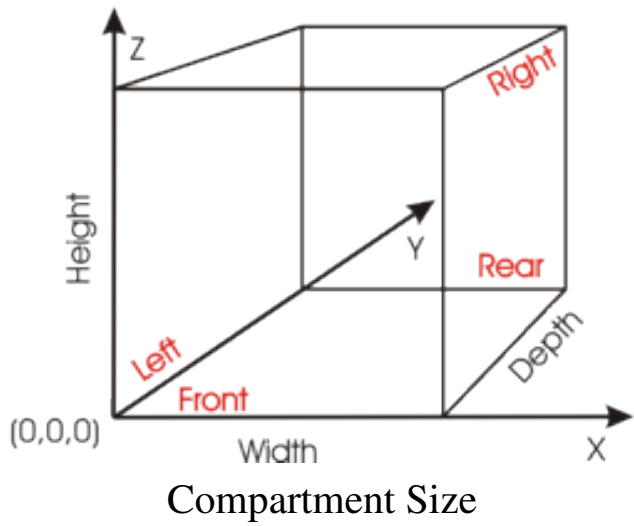

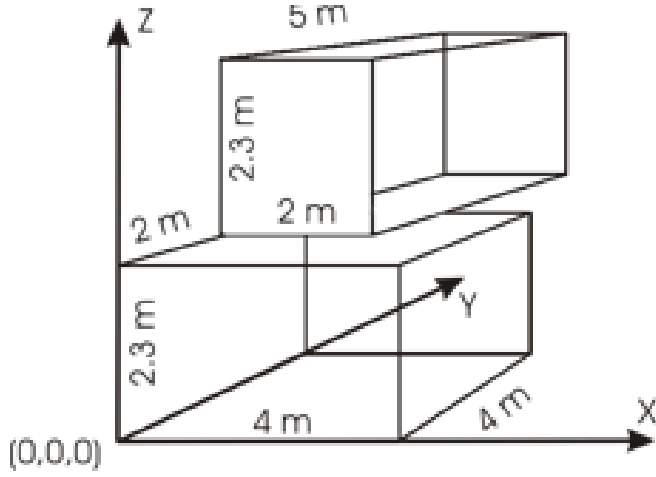

Compartment Position

Figure 4.2: Compartment Orientation and Positioning in CFAST.

At least one compartment must be specified in the input file. There are no defaults for compartment size. There are defaults for absolute positioning $(0,0,0)$. The fully mixed (single zone) and corridor models are turned off by default.

Compartments in CFAST are most typically defined by a width, depth, and height. If desired, compartments can be prescribed by the cross-sectional area of the compartment as a function of height from floor to ceiling for other shapes. The absolute position of the compartment with respect to a single structure reference point can be defined to ease visualization or to allow exact placement of vents and surfaces relative to other compartments in a detailed calculation. This specification is important for positioning the compartments for visualization in Smokeview.

Compartment Name: Compartments are identified by a unique alphanumeric name. This may be as simple as a single character or number, or a description of the compartment.

\subsection{Geometry}

Width specifies the width of the compartment as measured on the $X$ axis from the origin $(0,0,0)$ of the compartment.

Depth specifies the depth of the compartment as measured on the $\mathrm{Y}$ axis from the origin $(0,0,0)$ of the compartment.

Height specifies the height of the compartment as measured on the $\mathrm{Z}$ axis from the origin $(0,0,0)$ of the compartment. 
Absolute Width Position (Position X) specifies the absolute x coordinate of the lower, left, front corner of the room.

Absolute Depth Position (Position Y) specifies the absolute y coordinate of the lower, left, front corner of the room.

Absolute Floor Height (Position Z) specifies the height of the floor of each compartment with respect to station elevation specified by the internal ambient conditions reference height parameter. The reference point must be the same for all elevations in the input data. For example, the two rooms in the sample to the right in figure 4.2 would be located at $(0,0,0)$ and $(0,2,2.3)$.

\subsection{Materials}

To calculate heat loss through the ceiling, walls, and floor of a compartment, the properties of the bounding surfaces must be known. This includes the thermophysical properties of the surfaces and the arrangement of adjacent compartments if inter-compartment heat transfer is to be calculated.

The bounding surfaces are the ceilings, walls and floors that define a compartment. These are referred to as thermophysical boundaries, since each participates in conduction and radiation as well as defining the compartments, unless these phenomena are explicitly turned off.

The thermophysical properties of the surfaces which define compartments are described by specifying the thermal conductivity, specific heat, emissivity, density, and thickness of the enclosing surfaces for each material and then assigning the material to the ceiling, walls, and floor of a compartment. Thermal properties for materials are read from the CFAST input file. The thermophysical properties are specified at one condition of temperature, humidity, etc. Only a single layer per boundary is allowed (some previous versions allowed up to three).

Ceiling Material (default value: Gypsum Board): material name from the thermal properties data file used for the ceiling surface of the compartment.

Wall Material (default value: Gypsum Board): material name from the thermal properties data file used for the wall surfaces of the compartment.

Floor Material (default value: Off): material name from the thermal properties data file used for the floor surface of the compartment.

If the thermophysical properties of the enclosing surfaces are not included, CFAST will treat them as adiabatic (no heat transfer).

If a name is used which is not in the input file, the model should stop with an error message.

The back surfaces of compartments are assumed to be exposed to ambient conditions unless specifically specified (see the section on Surface Connections) to specify heat transfer connections between compartments). 


\subsection{Modeling a Compartment as a Tall Shaft or Long Corridor}

For tall compartments or those removed from the room of fire origin, the compartment may be modeled as a single, well-mixed zone rather than the default two-zone assumption. A single zone approximation is appropriate for smoke flow far from a fire source, where the two-zone layer stratification is less pronounced than in compartments near the fire or in situations where the stratification does not occur. Examples are elevators, shafts, complex stairwells, or compartments far from the fire.

By specifying the compartment as a corridor, the ceiling jet temperature is calculated with a different empirical correlation that results in a somewhat higher temperature near the ceiling. This will impact, for example, detectors, sprinkler, and targets near the ceiling in corridors.

Normal (Two-zone model) Conditions in the compartment are calculated with the normal twozone approach.

Shaft (Single-zone model) Conditions in the compartment are calculated as a single well-mixed zone.

Corridor (Revised ceiling jet) Conditions in the compartment are calculated with the normal two-zone approach. Ceiling jet temperatures in the compartment are calculated with a revised empirical correlation specific to corridors.

\subsection{Defining Variable Compartment Area}

The Compartment Geometry page includes two additional entries that may be used for defining compartment properties for spaces which are not rectangular in area. Values for a chosen compartment are entered in a spreadsheet.

Height Value(s) (default units: m, default values: none): Height off the floor of the compartment.

Area Value(s) (default units $\mathrm{m}^{2}$, default values: none): Cross-sectional area at the corresponding Height.

Once the total compartment volume is determined from the set of cross-sectional area and height inputs, an effective width and depth are calculated (maintaining the original user input for compartment height) so the compartment volume matches the actual total volume of the compartment. The aspect ratio (width/depth) is maintained.

Cross-sectional area values should be input in order by ascending height. If the first height value is not zero (i.e., at floor level), the cross-sectional area is assumed constant from the floor to the height specified in the first cross-sectional area value.

Similarly, if the last height value is not at the ceiling height, the cross-sectional area is assumed constant from the height specified in the last cross-sectional area value to the ceiling. Between any two adjacent cross-sectional area data values in the input list, the area is assumed to be a pyramidal section (which by definition maintains the same width to depth aspect ratio for the compartment from floor to ceiling). 
CFAST uses the variable cross-sectional area inputs to determine the layer height. The equations solved by CFAST determine the volume of the upper layer. For a normal rectangular room, this corresponds directly to a layer height. For a variable cross-sectional area compartment, a numerical integration of the area inputs beginning at the ceiling is used to determine the height at which the upper layer occupies the calculated volume of the upper layer. 


\section{Chapter 5}

\section{Natural Ventilation}

Natural ventilation can occur when two compartments are connected via open doorways or windows (Wall Vents); or when two compartments are connected via Floor/Ceiling Vents. If no vents are specified between two compartments, they are assumed to be isolated.

\subsection{Wall Vents}

Wall vents are doors or windows that connect compartments that physically overlap in elevation, or that connect to the outside. Horizontal flow connections may also be used to account for leakage between compartments or to the outdoors.

First Compartment First of the two compartments connected by a door or window.

Second Compartment Second of the two compartments connected by a door or window.

Sill (default units: m): Height of the bottom of the opening relative to the floor of the first compartment.

Soffit (default units: m): Height of the top of the opening relative to the floor of the first compartment.

Width (default units: $\mathrm{m}$ ): The width of the opening.

Initial Opening Fraction (default value: 1, fully open): Fraction between 0 and 1 of the vent width to indicate the door or window is partially open at the start of the simulation.

Change Opening Fraction At Time (default units: s) Time during the simulation at which to change the opening fraction.

Final Opening Fraction (default value: 1, fully open): Opening fraction at the end of the simulation.

Vent Offset (default units: $\mathrm{m}$, Default value: $0 \mathrm{~m}$ ): For visualization only, the horizontal distance between the near edge of the vent and the origin of the axis defined by the selected face (below) in the first compartment (Front and Rear are along the X-axis; left and right are along the Y-axis). 


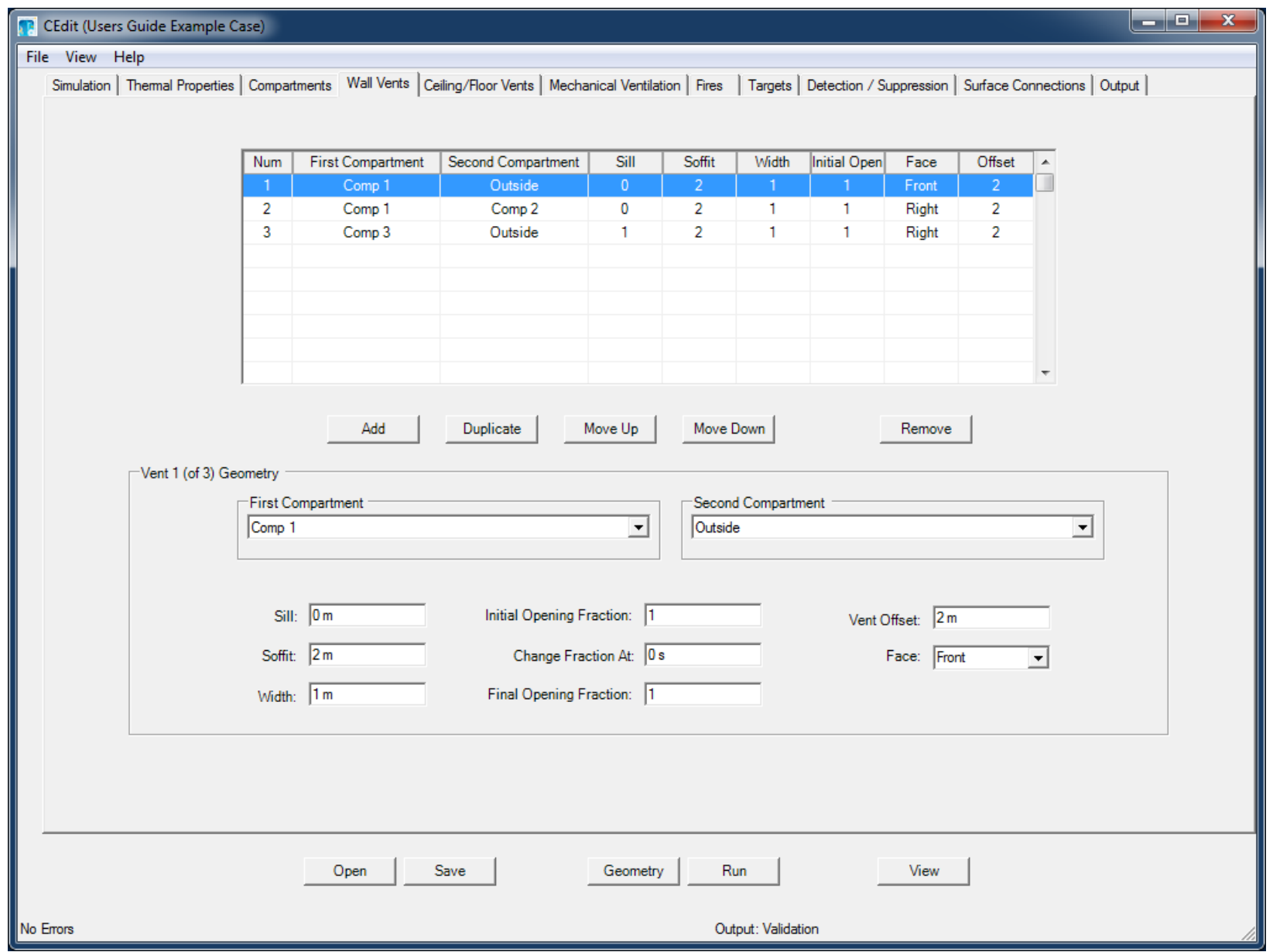

Figure 5.1: The CFAST Wall Vents Tab.

Face The wall on which the vent is positioned. Choices are Front, Rear, Right, Left and are relative to the $\mathrm{X}-\mathrm{Z}$ plane.

\subsection{Ceiling/Floor Vents}

Examples of these openings are scuddles in a ship, or a hole in the roof of a residence. Connections can exist between compartments or between a compartment and the outdoors. Combined buoyancy and pressure-driven flow through a vertical flow vent is possible when the connected spaces adjacent to the vent are filled with gases of different density in an unstable configuration, with the density of the top space larger than that of the bottom space. With a moderate cross-vent pressure difference, the instability leads to a bi-directional flow between the two spaces. For relatively large cross-vent pressure difference the flow through the vent is unidirectional.

Top Compartment The vent is located on the floor of this compartment.

Bottom Compartment The vent is located on the ceiling of this compartment. 


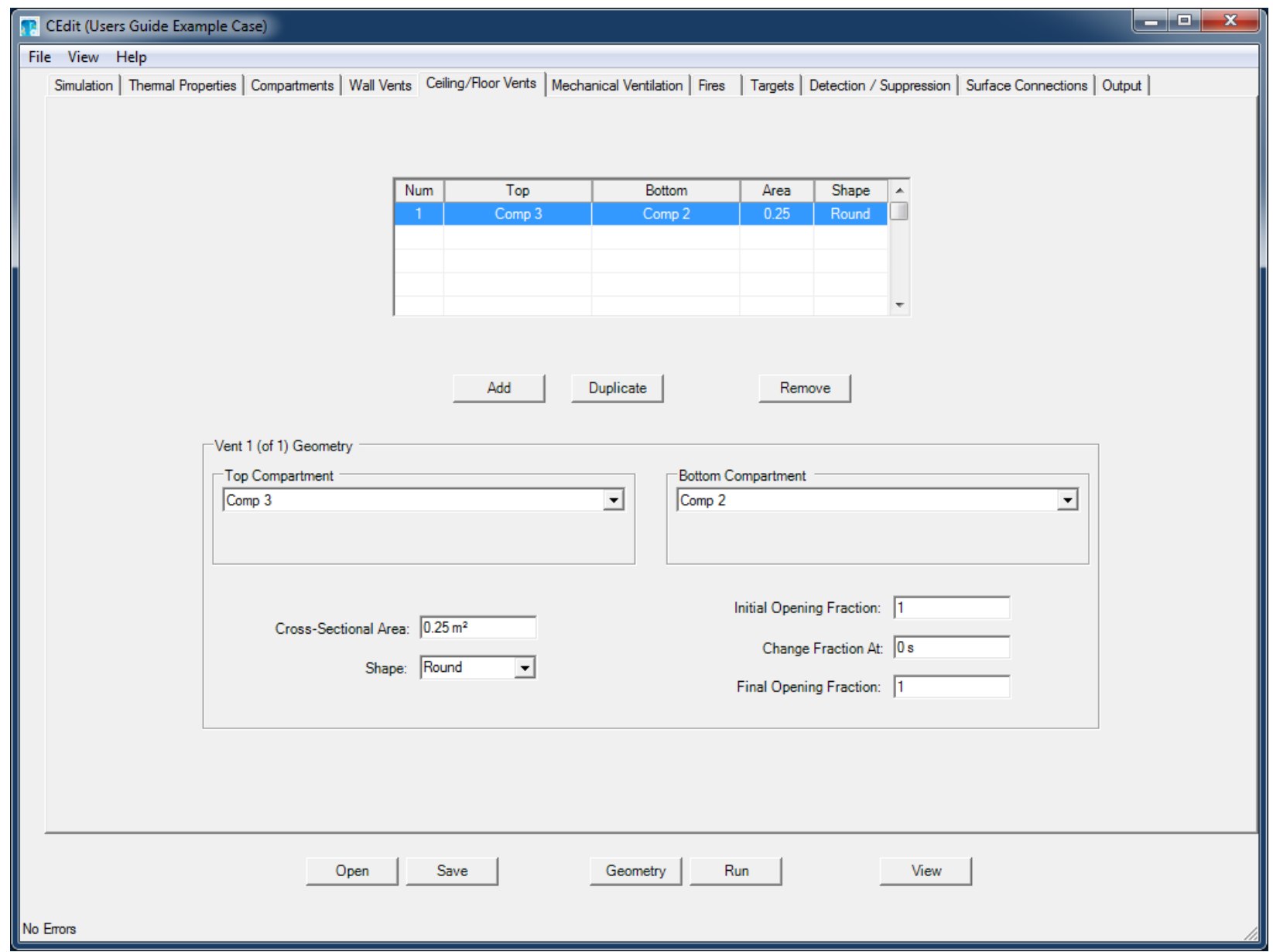

Figure 5.2: The CFAST Ceiling/Floor Vents Tab.

Cross-sectional Area (default units: $\mathrm{m}^{2}$ )

Shape The shape factor changes the calculation of the effective diameter of the vent and flow coefficients for flow through the vent.

Initial Opening Fraction By default, the vent is fully open. You may specify a fraction between 0 and 1 that allows the vent to be partially or fully closed at the beginning of the simulation.

Change Opening Fraction At Time (default units: s): Time during the simulation at which to change the opening fraction.

Final Opening Fraction Fractional area of the vent following the specified time.

CFAST allows only a single connection between any pair of compartments included in a simulation because the empirical correlation governing the flow was developed using only a single opening between connected compartments.

Vertical connections can only be created between compartments that could be physically stacked based on specified floor and ceiling elevations for the compartments. Some overlap between the absolute floor height of one compartment and the absolute ceiling height of another compartment 
is allowed. However, whether the compartments are stacked or overlap somewhat, the ceiling/floor absolute elevations must be within $0.01 \mathrm{~m}$ of each other. The check is not done when the connection is to the outside. 


\section{Chapter 6}

\section{Mechanical Ventilation}

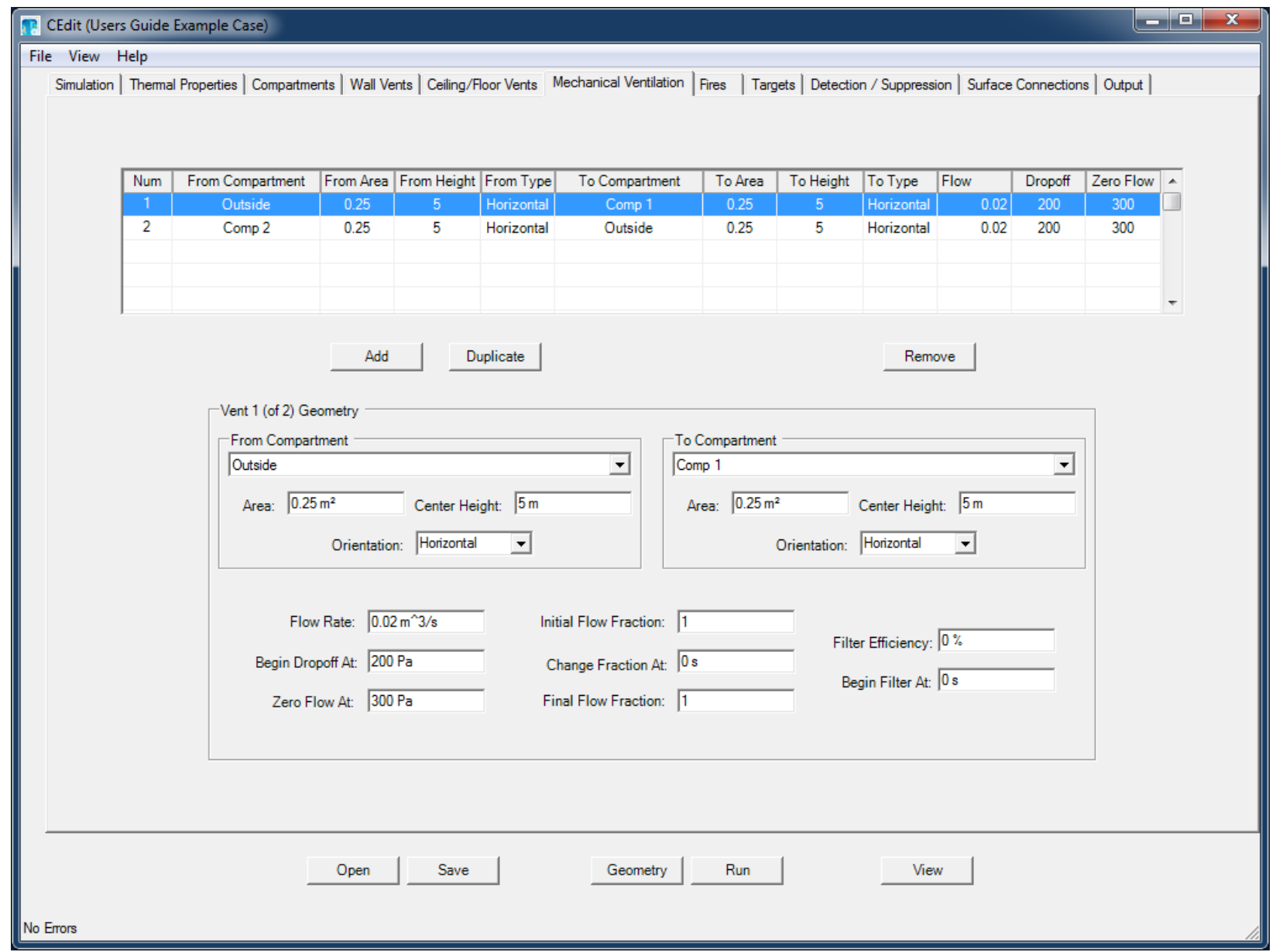

Figure 6.1: The CFAST Mechanical Vents Tab.

Fan-duct systems are commonly used in buildings for heating, ventilation, air conditioning, pressurization, and exhaust. Generally, systems that maintain comfortable conditions have either one or two fans. Residences often have a system with a single fan. Further information about these 
systems is presented in Klote and Milke [5] and the American Society of Heating, Refrigerating and Air Conditioning Engineers Handbook [6].

The model for mechanical ventilation is based on the theory of networks and is based on the model developed by Klote [7]. This is a simplified form of Kirchoff's law which says that flow into a node must be balanced by flow out of the node. The equations used describe the relationship between the pressure drop across a duct, the resistance of a duct, and the mass flow. The pressure can be changed by conditions in a compartment, or a fan in line in the duct system. Resistance arises from the finite size of ducts, roughness on duct surfaces, bends and joints. In CFAST, default values are used for the duct properties, and thus mechanical ventilation connections are simply described by the connections to the two compartments and a fan whose throughput is a constant volumetric flow up to a user-specified pressure drop across the fan, dropping to zero at high backwards pressure on the fan.

\subsection{Connections to Compartments}

From Compartment The compartment from which the fan flow originates.

To Compartment The compartment to which the fan flow terminates.

Area (default units: $\mathrm{m}^{2}$ ): Cross-sectional area of the opening.

Center Height (default units: m): Height of the midpoint of the duct opening above the floor.

Orientation A horizontal diffuser implies vertical flow through the ceiling or floor of the compartment. A vertical diffuser implies horizontal flow through a wall of the compartment.

\subsection{Fans}

CFAST does not include provisions for reverse flow through a fan, or a fan curve. Rather, you may specify a pressure above which the flow linearly decreases to zero.

Flow Rate (default units: $\mathrm{m}^{3} / \mathrm{s}$ ): Constant flow rate of the fan.

Begin Drop Off Pressure (default units: Pa, default value: $200 \mathrm{~Pa}$ ): Above this pressure, the flow begins a linear drop-off to zero.

Zero Flow Pressure (default units: Pa, default value: $300 \mathrm{~Pa}$ ): The pressure above which the flow is zero.

Initial Opening Fraction Value from 0 to 1 denoting the initial opening area.

Change Opening Fraction At Time (default units: s): Time during the simulation at which to change the opening fraction.

Final Opening Fraction following the specified time. 


\subsection{Filtering}

For mechanical vents, there are two species that can be filtered out of the gas flow: soot and the user-defined trace species. Filters are applied only to fan openings. The fan must have been defined before the filter can be applied. Initially filtering is off.

Filter Efficiency (default units: \%): Flow through mechanical vents may include filtering that removes a user-specified portion of soot and trace species mass from the flow through the vent. By default, there is no filtering applied; that is, all of the soot and trace species mass in the vent flow is passed through the vent. Within the user interface, this is specified as a filter efficiency of $0 \%$. If desired, you may specify the fraction of the soot and trace species mass to be removed as a percentage.

Begin Filtering At Time (default units: s): Time during the simulation at which the mechanical vent filtering begins.

If the simulation includes mechanical ventilation filtering, care should be taken in choosing trace species production rates to insure the production rate is small compared to the total pyrolysis rate since the filtering removes mass from the system. This will better allow appropriate conservation of mass in the solution of the system of differential equation. For large production rates of trace species, scaling factors can be used (e.g., divide by 1000) for the trace species production rate to reduce the relative magnitude compared to the pyrolysis rate. For analysis, the resulting trace species in compartments and filters can be converted back to original units multiplying by the scaling factor used. 


\section{Chapter 7}

\section{Fires}

A fire in CFAST is specified via a time-dependent heat release rate. The specified heat of combustion is used to calculate the mass loss rate of fuel, from which the production rate of combustion products can be calculated using specified product yields. The heat release and the corresponding product generation rates go to zero when the lower oxygen limit is reached, and are replaced by the appropriate production rate of unburned fuel gas which is transported from zone to zone until there is sufficient oxygen and a high enough temperature to support combustion.

The model can simulate multiple fires in one or more compartments. These fires are treated as totally separate entities, with no interaction of the plumes. These fires can be ignited at a prescribed time, or when a corresponding target (see Chapter 8) reaches a specified temperature or heat flux.

The combustion model is defined by the following one-step reaction:

$$
\begin{aligned}
& \mathrm{C}_{\mathrm{n}_{\mathrm{C}}} \mathrm{H}_{\mathrm{n}_{\mathrm{H}}} \mathrm{O}_{\mathrm{n}_{\mathrm{O}}} \mathrm{N}_{\mathrm{n}_{\mathrm{N}}} \mathrm{Cl}_{\mathrm{n}_{\mathrm{Cl}}}+\mathrm{v}_{\mathrm{O}_{2}} \mathrm{O}_{2} \rightarrow \\
& v_{\mathrm{CO}_{2}} \mathrm{CO}_{2}+v_{\mathrm{H}_{2} \mathrm{O}} \mathrm{H}_{2} \mathrm{O}+v_{\mathrm{CO}} \mathrm{CO}+v_{\mathrm{s}} \mathrm{Soot}+v_{\mathrm{HCl}} \mathrm{HCl}+v_{\mathrm{HCN}} \mathrm{HCN}
\end{aligned}
$$

It is assumed that all the nitrogen and chlorine in the fuel are converted to $\mathrm{HCN}$ and $\mathrm{HCl}$.

Two inputs on the Fire Tab are global, that is, they apply to all fires included in a simulation.

Lower Oxygen Limit (default units: \%, default value: $10 \%$ ): In the CFAST model, a limit is incorporated by limiting the burning rate as the oxygen level decreases until a "lower oxygen limit" (LOL) is reached. The lower oxygen limit is incorporated through a smooth decrease in the burning rate near the limit. Normally, this value would not be changed by the user.

Gaseous Ignition Temperature (default units: ${ }^{\circ} \mathrm{C}$, default value: ambient temperature plus 100 $\mathrm{K})$ : The lower temperature limit for burning unburned fuel gas generated in an oxygendepleted compartment.

\subsection{Adding Fires}

Fires are added to the simulation by clicking on the Add New or Add $\mathbf{t}^{2}$ button. The latter is useful because it has predefined quadratic growth rate options that are commonly used in fire analyses. See Section 7.3 for details. You may also Duplicate a listed fire, or select a fire From File of an existing case. For each fire, specify the following properties: 


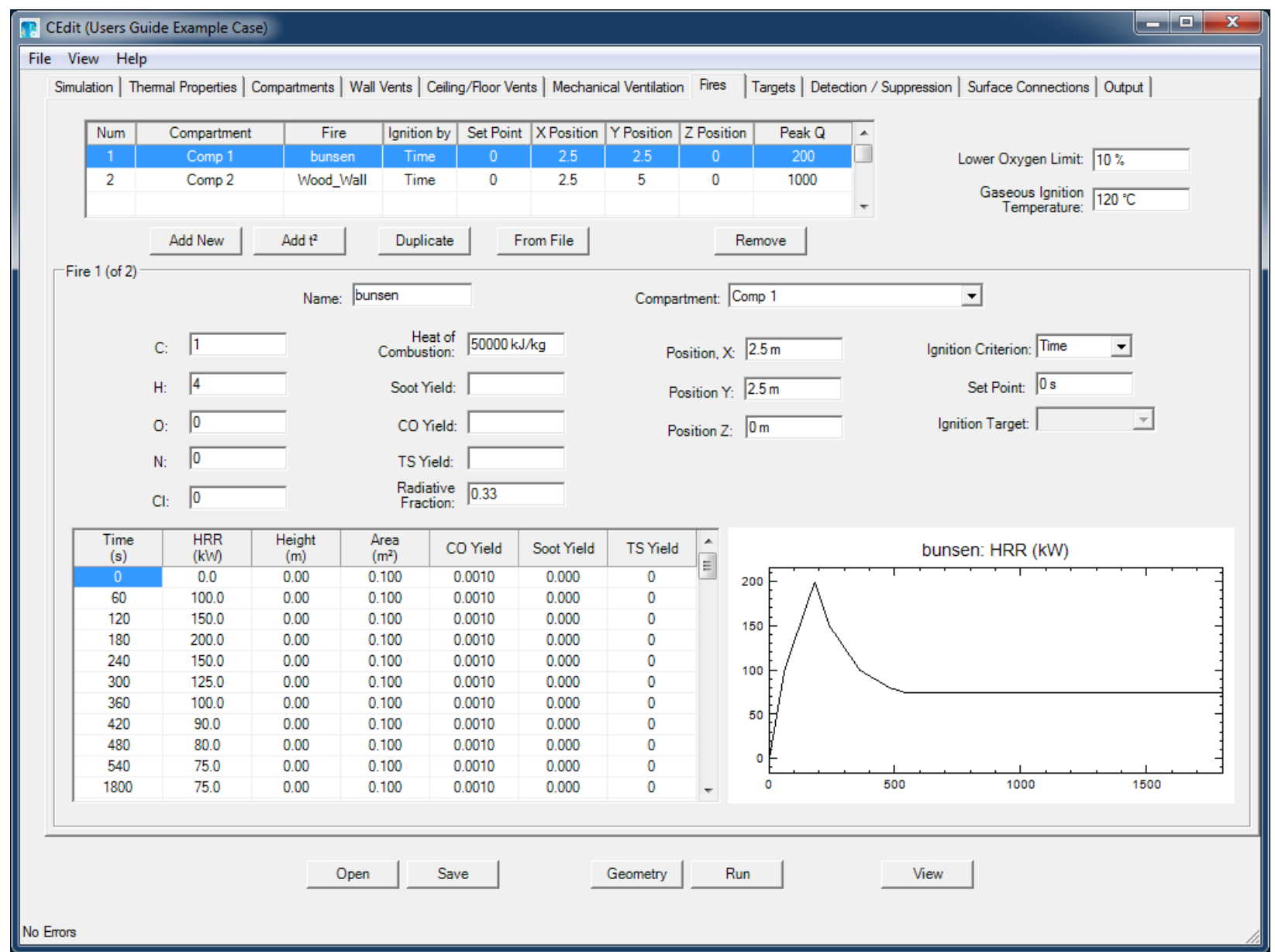

Figure 7.1: The CFAST Fires Tab.

Name The selected name must be unique (i.e., not the same as another fire in the same simulation).

Compartment where the fire occurs.

$\mathbf{C}, \mathbf{H}, \mathbf{O}, \mathbf{N}, \mathbf{C l}$ The number of each atom in the fuel molecule. Burning fuels in CFAST are assumed to be hydrocarbon fuels that contain at least carbon and hydrogen and optionally oxygen, nitrogen, and chlorine. All of the specified nitrogen and chlorine is assumed to completely react to form $\mathrm{HCN}$ and $\mathrm{HCl}$.

Heat of Combustion (default value: $50000 \mathrm{~kJ} / \mathrm{kg}$ ): The energy released per unit mass of fuel consumed.

Soot Yield (default value: $0 \mathrm{~kg} / \mathrm{kg}$ ): Mass of soot produced per unit mass of fuel consumed.

CO Yield (default value: $0 \mathrm{~kg} / \mathrm{kg}$ ): Mass of CO produced per unit mass of fuel consumed.

TS Yield (default value: $0 \mathrm{~kg} / \mathrm{kg}$ ): Mass of user-defined trace species per unit mass of fuel consumed. The trace species is transported along with the other products of combustion, but is 
assumed not to take part in the combustion reaction and is assumed not to be a significant source of overall mass for the system mass balance. This implies that the production rate of trace species specified should be much smaller than the total specified pyrolysis rate.

Radiative Fraction (default value: 0.35): The fraction of the combustion energy that is emitted in the form of thermal radiation. Values for various fuels are suggested by Beyler [8].

Position X, Y, Z (default units: m, default value: compartment center): Position of the center of the base of the fire relative to the front lower left corner of the compartment.

Ignition Criterion The time of ignition can be controlled by a user-specified time, or by a userspecified target's surface temperature or incident heat flux.

Set Point The critical value at which ignition will occur. If it is less than or equal to zero, the default value of zero is taken.

Ignition Target User-specified target used to calculate surface temperature or incident heat flux to ignite fire. Target is typically placed at the base of the fire to be ignited.

\subsection{Time-Dependent Properties}

Following is a list of fire properties that can be specified as a function of time. The properties are linearly interpolated between specified points. If the simulation time is longer than the total duration of the fire, the final values specified for the fire are continued until the end of the simulation. Normal copy (Ctrl-C), cut (Ctrl-X), and paste (Ctrl-V) keyboard shortcuts work for data editing. In addition, Alt-Insert will insert a complete row above the currently-selected row in the spreadsheet and Alt-Delete will delete the current row in the spreadsheet.

Time (default units: s, default values: none): Time from ignition.

HRR (default units: kW, default values: none): Heat release rate of the fire.

Height (default units: $\mathrm{m}$, default values: $0 \mathrm{~m}$ ): Height of the base of the fire.

Area (default units: $\mathrm{m}^{2}$, default values: $0.3 \mathrm{~m}^{2}$ ): Area of the base of the fire. The plume correlations used in CFAST generally regard the base to be circular. Do not set this value to zero because it is used in the various plume correlations.

CO, Soot, TS Yields (default units: $\mathrm{kg} / \mathrm{kg}$ ): Yields of carbon monoxide, soot, and trace species. The time-dependent values over-rides the constant values given above.

\subsection{Special Topic: t-Squared Fires}

Use the 'Add $\mathrm{t}^{2}$, button to create a new fire with a heat release rate that grows as a function of the time squared [9]:

$$
\dot{Q}(t)=\dot{Q}_{\text {peak }}\left(\frac{t}{t_{\text {peak }}}\right)^{2}
$$




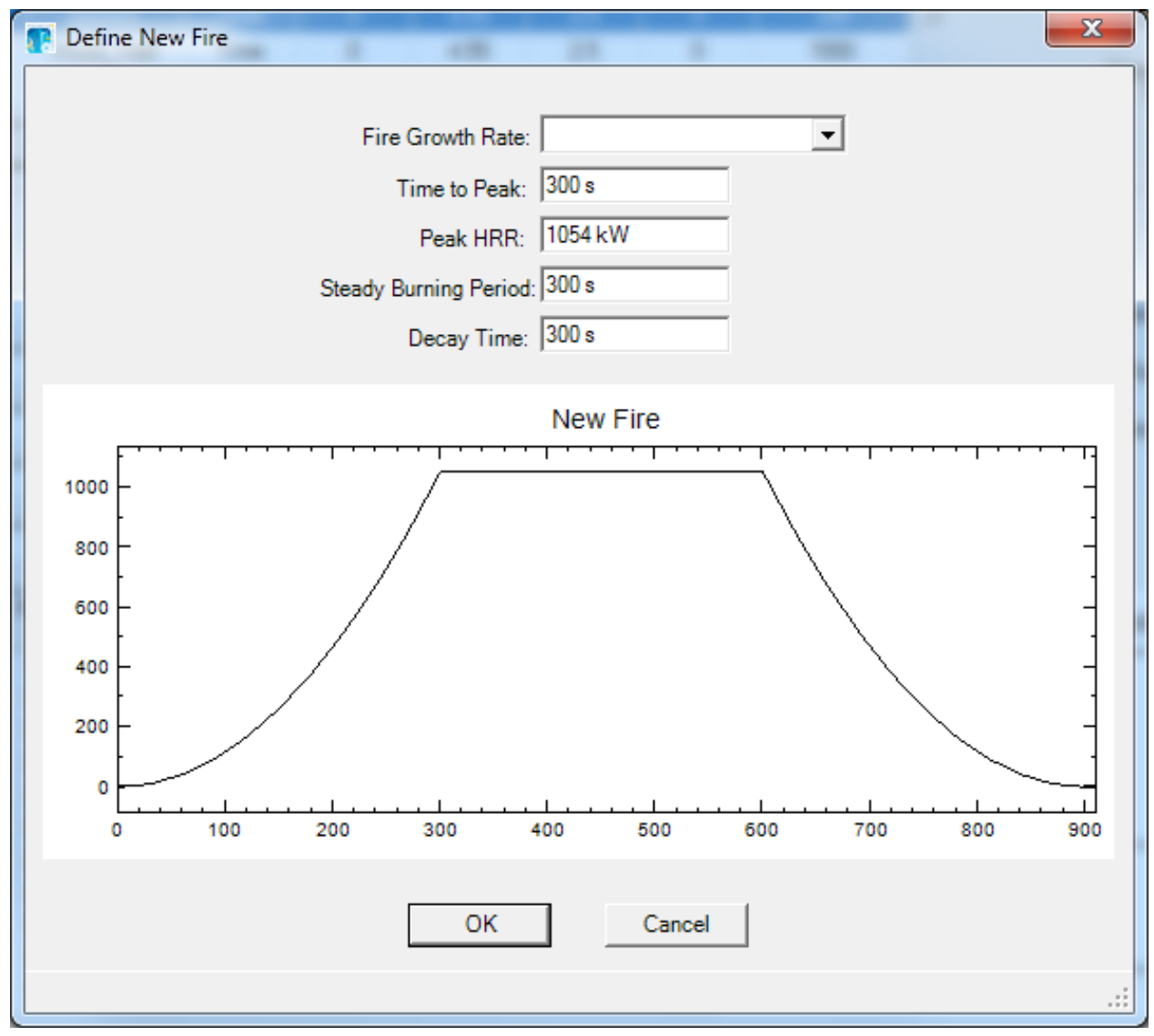

Figure 7.2: Inserting T-squared Fires in CFAST.

Fire Growth Rate A set of specific t-squared fires labeled slow, medium, fast, or ultra-fast such that the fire reaches $1054 \mathrm{~kW}(1000 \mathrm{BTU} / \mathrm{s})$ in $600 \mathrm{~s}, 300 \mathrm{~s}, 150 \mathrm{~s}$, and $75 \mathrm{~s}$. A custom selection allows you to define any growth or decay rate desired.

Time to Peak (default units: s, default value: 300 s): The time for the fire to reach the peak HRR.

Peak HRR (default units: $\mathrm{kW}$, default value: $1054 \mathrm{~kW}$ ): The peak heat release rate of the tsquared fire.

Steady Burning Period (default units: s, default value: $300 \mathrm{~s}$ ): Duration of time that the fire continues burning at the rate specified by the peak HRR.

Decay Time (default units: s, default value, $300 \mathrm{~s}$ ): Duration of time for the fire to decay back to a zero value. Decay follows the inverse of the t-squared growth rate. 


\section{Chapter 8}

\section{Defining Targets}

A target is any object in the simulation that can heat up via radiative and convective heat transfer. The heat conduction into the target is performed via a one-dimensional calculation in either cartesian or cylindrical coordinates.

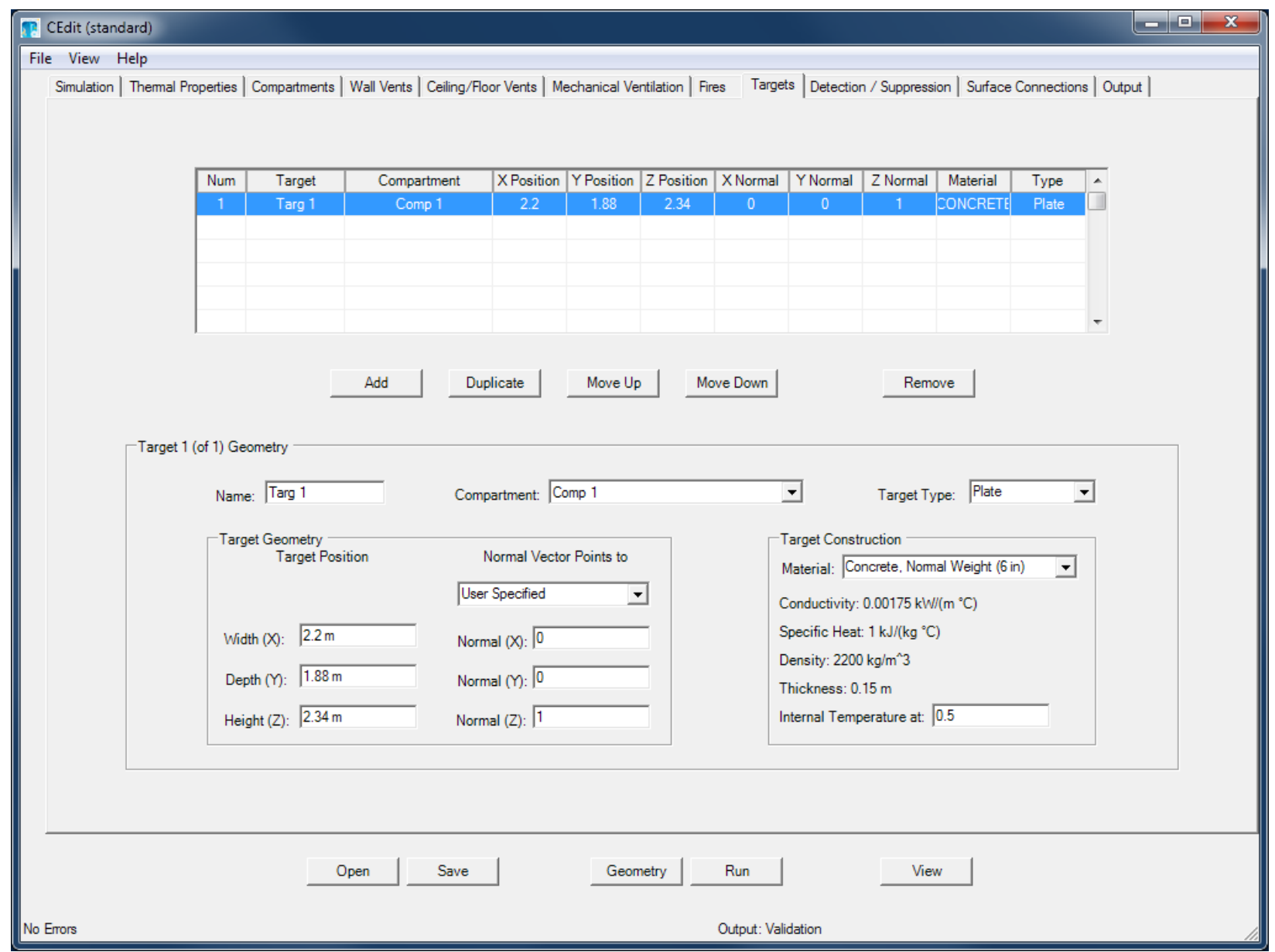

Figure 8.1: The CFAST Targets Tab. 
Name The selected name must be unique (i.e., not the same as another target in the same simulation).

Compartment The compartment in which the target is located.

Target Type Specify Plate, or Cylindrical. For plate targets, CFAST solves a partial differential equation in cartesian coordinates, and for cylindrical targets, a partial differential equation in cylindrical coordinates.

Width (X) (default units: $\mathrm{m}$ ): Distance from the left wall of the target compartment.

Depth (Y) (default units: m): Distance from the front wall of the target compartment.

Height (Z) (default units: $\mathrm{m}$ ): Height of the target above the floor.

Normal Vector $(\mathbf{X}, \mathbf{Y}, \mathbf{Z})$ : specifies a vector of unit length perpendicular to the exposed surface of the target. For example, the vector $(-1,0,0)$ indicates that the target is facing the left wall. The vector $(0,0,1)$ is facing the ceiling.

Material What the target is made of. Any existing material in the list of thermal properties may be used here. There can be only one material per target.

Internal Temperature at (default units: none, default value: 0.5): For each target, CFAST calculates the internal temperature at a number of node points within the target. By default, the reported internal temperature (in the printed and spreadsheet output) is the temperature at the center of the target, e.g., equidistant from the front and back faces of the target. This input allows the user to override this default position. The input represents the position as a fraction of the thickness from the front surface to the back surface of the material.

If the target is only needed to report the local gas temperature, which may include the plume or ceiling jet, then you may specify arbitrary properties and normal vector. The output spreadsheet file includes the local gas temperature in addition to the target temperature. 


\section{Chapter 9}

\section{Sprinklers and Detectors}

Sprinklers and detectors are both considered detection devices by the CFAST model and are handled using the same inputs. Detection is based upon heat transfer to the detector. Fire suppression by a user-specified water spray begins once the associated detection device is activated.

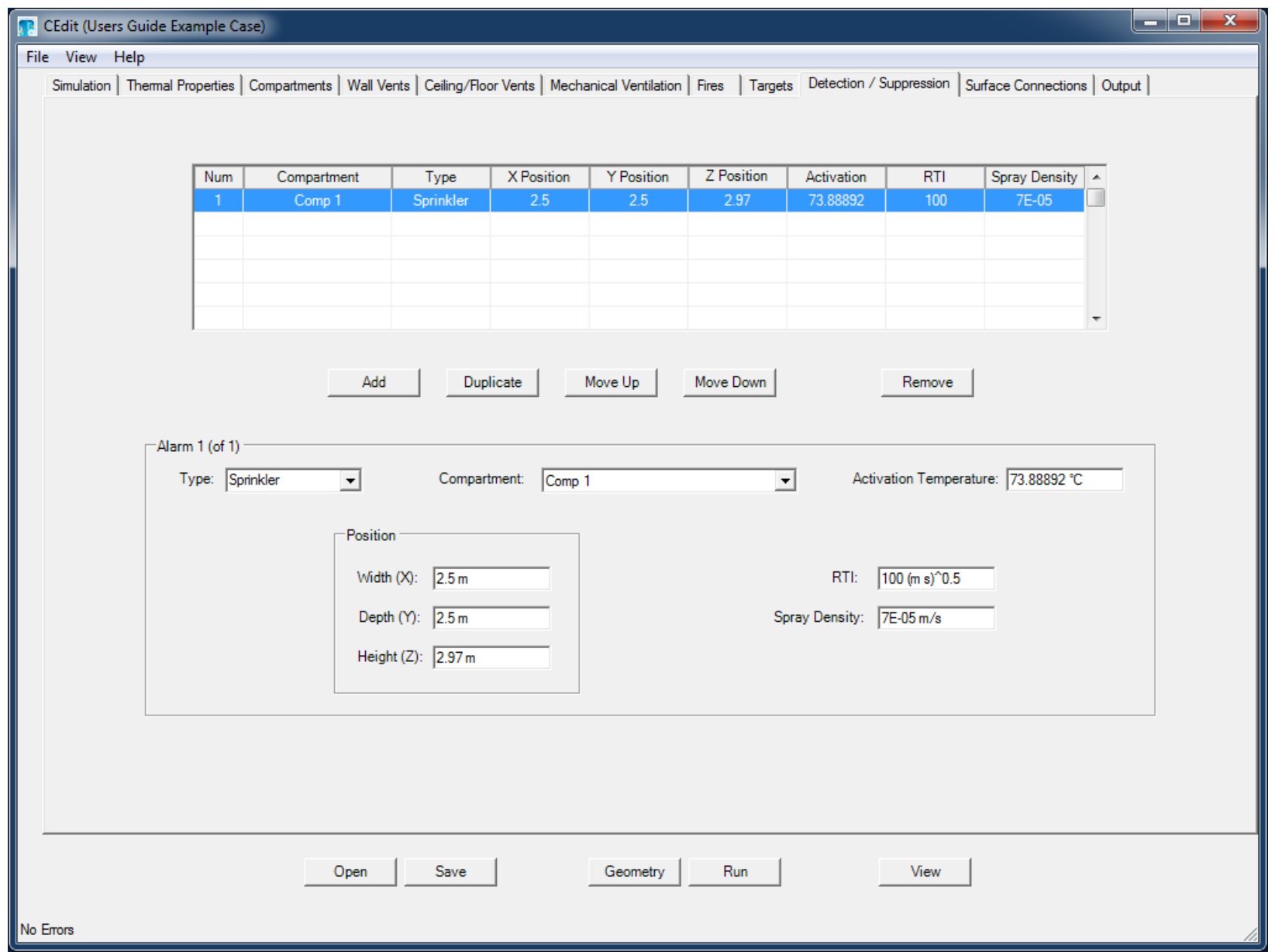

Figure 9.1: The CFAST Detection/Suppression Tab. 
Type type of detector, select smoke detector, heat detector, or sprinkler.

Compartment the compartment in which the detector or sprinkler is located.

Activation Temperature (default units: ${ }^{\circ} \mathrm{C}$, default value: dependent on type): the temperature at or above which the detector link activates.

Width (X) Position (default units: $\mathrm{m}$, default value: none): position of the object as a distance from the left wall of the compartment (X direction).

Depth (Y) Position (default units: m, default value: none): position of the detector or sprinkler as a distance from the front wall of the compartment (Y direction).

Height (Z) Position (default units: $m$, default value: none): position of the object as a distance from the floor of the compartment ( $\mathrm{Z}$ direction).

RTI (default units: $(\mathrm{m} \cdot \mathrm{s})^{1 / 2}$, default value: none): the Response Time Index (RTI) for the sprinkler or detection device.

Spray Density (default units: $\mathrm{m} / \mathrm{s}$, default value: none): the amount of water dispersed by a sprinkler. The units for spray density are length/time, derived by dividing the volumetric flow rate by the spray area. The suppression calculation is based upon an experimental correlation by Evans [10].

Often, the activation of smoke alarms is simulated with a temperature-based criterion, typically in the range of $5{ }^{\circ} \mathrm{C}$ to $10{ }^{\circ} \mathrm{C}$ above ambient. Davis and Notarianni studied the activation of heat and smoke alarms in small and large compartments [11]. They conclude that a temperature rise of approximately $5{ }^{\circ} \mathrm{C}$ corresponded to activation of ionization alarms for a range of fire sources and ceiling heights. The Nuclear Regulatory Commission includes a default value of $10{ }^{\circ} \mathrm{C}$ in NUREG-1805 [12].

Several cautions should be observed when using estimates of sprinkler suppression within the model: 1) The first sprinkler activated controls the effect of the sprinkler on the heat release rate of the fire. Subsequent sprinklers which may activate have no additional effect on the fire simulation. 2) The fire suppression algorithm assumes the effect of the sprinkler is solely to reduce the heat release rate of the fire. Any effects of the sprinkler spray on gas temperatures or mixing within the compartment are ignored. 3) The sprinkler always reduces the heat release rate of the fire. The ability of a fire to overwhelm an under-designed sprinkler is not modeled. 4) Since the dynamics of the sprinkler and direct effects of the spray on gas temperatures and velocities are not modeled, calculated times of activation of secondary sprinklers and / or detectors after the first sprinkler is activated should be not be modeled since the impact of the first sprinkler on the activation of additional sprinklers is not included in the CFAST model. 


\section{Chapter 10}

\section{Surface Connections}

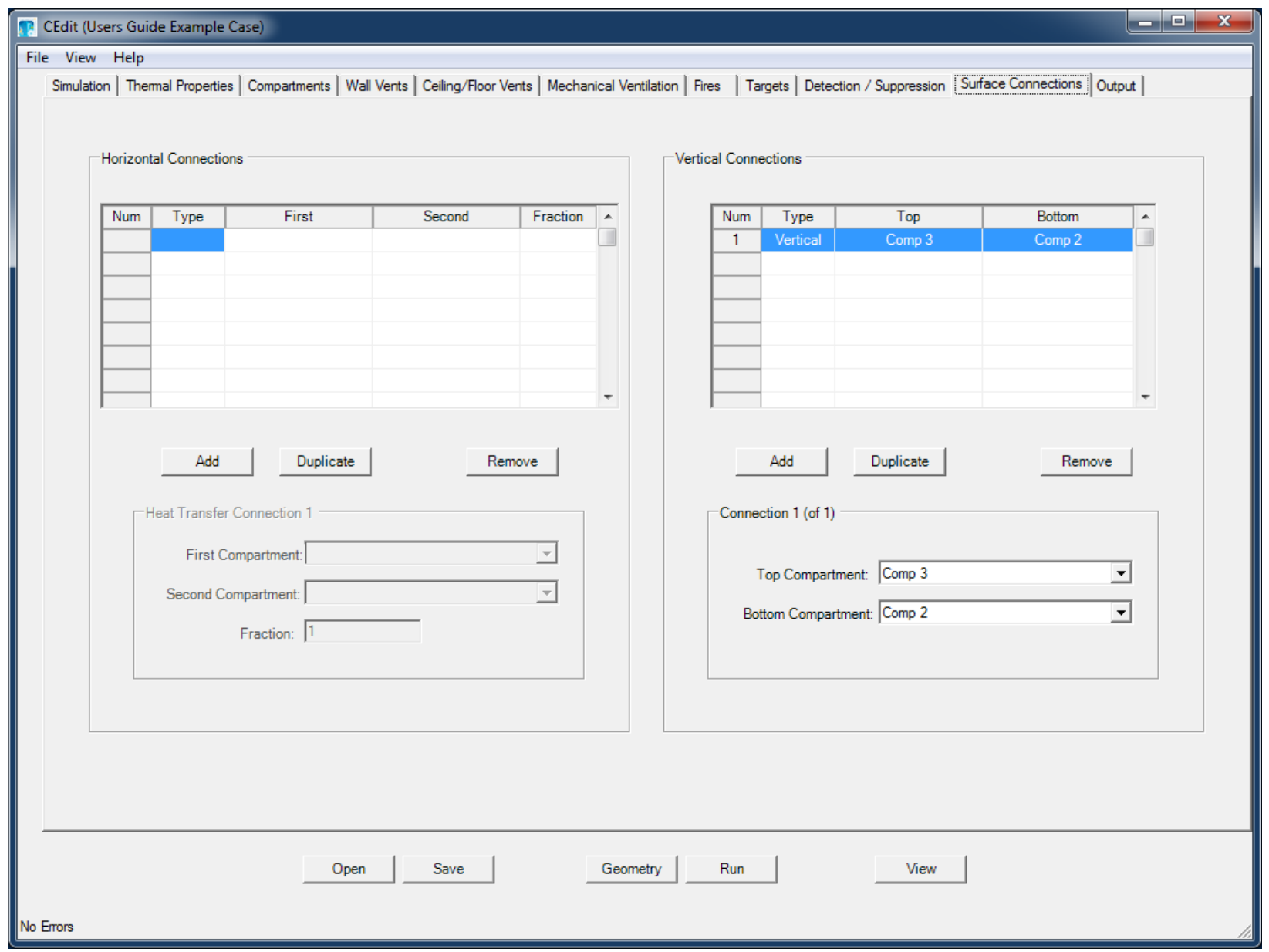

Figure 10.1: The CFAST Surface Connections Tab.

The Surface Connections page allows the user to define heat transfer between compartments in a simulation. Energy can be transferred from compartment to compartment through solid boundaries (walls, ceilings and floors) by means of conduction. The heat transfer between connected 
compartments is modeled by setting the boundary condition for the outside surface of a compartment to the temperature of the outside surface of the connected compartment. As before, temperatures are determined by the solver so that the heat flux striking the wall surface (both interior and exterior) is consistent with the temperature gradient at that surface.

First Compartment First of the connected compartments. Order of the inputs is not important.

Second Compartment Second of the connected compartments. Order of the inputs is not important.

Fraction Specifies the fraction of the vertical surface areas of the compartments which are connected can be specified. The fraction specifies the fraction of the vertical surface area connecting the first and second compartment pair.

Top Compartment The top or first of the two compartments to be connected by a vertical heat transfer connection. The connection is through the floor of this compartment.

Bottom Compartment The bottom or second of the two compartments to be connected by a vertical heat transfer connection. The connection is through the ceiling of this compartment. 


\section{Chapter 11}

\section{Visualization}

Calculated results from a CFAST simulation can be visualized using Smokeview [13]. This allows the user to see the compartment geometry and connections or view the results of the simulation visually. In addition to a simplified view of the layer temperatures and vent flows, more detailed estimates of gas temperature, gas velocity, vent flow velocity, target temperature, and detector status can be visualized.

\subsection{Adding Visualizations}

Visualization Type (default units: n/a, default value: 2-D): The type of visualization to be included. Choose from 2-D (a single plane slice of temperature at the position and axis specified), 3-D (a set of three animated slices whose position can be moved along its respective axis, or Isosurface (a fixed 3-D surface where the gas temperature is equal to the value specified. See the Smokeview documentation [13] for details on the use of Smokeview.

Compartment (default units: n/a, default value: All): Visualizations can be placed in a single compartment or at the same position and axis in all compartments.

Value (default units: $\mathrm{m}$, default value: $0 \mathrm{~m}$ ): Position along the specified axes where the slice is placed measured from the compartment origin for the selected axis $(0,0,0$ is the bottom left corner of the compartment. See page 12).

Axis (default units: n/a, default value: $X$-axis (Width)): Axis perpendicular to the specified slice. The slice is place perpendicular to the selected axis (the $\mathrm{Y}-\mathrm{Z}$ plane for the $\mathrm{X}-\mathrm{Axis}$; the $\mathrm{X}-\mathrm{Z}$ plane for the Y-Axis, and the X-Y plane for the Z-Axis)

Temperature (default units ${ }^{\circ} \mathrm{C}$, default value: none): Specified gas temperature for the selected isosurface.

Use the Add Defaults button to add a default set of visualizations for the current simulation. A slice file entry is created at the center of each compartment in the $x$ (width) and $y$ (depth) directions along with one near the ceiling in the $\mathrm{z}$ direction. A 3-D slice file entry is created for each compartment as well. 


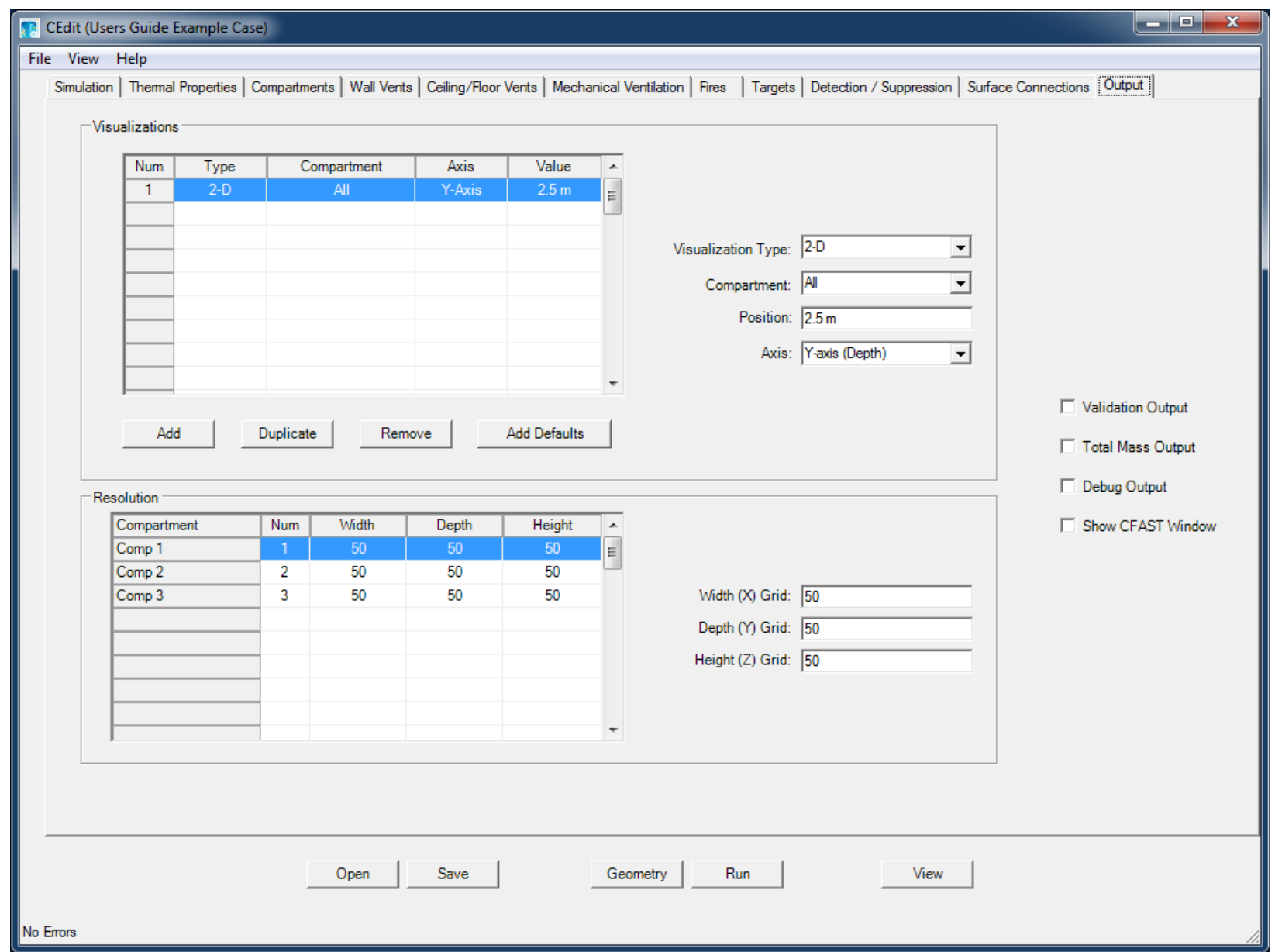

Figure 11.1: The CFAST Visualizations Tab.

\subsection{Visualization Resolution}

By default, slice files are generated with a grid of 50 data points in each direction for each compartment specified. If desired, the grid spacing can be adjusted up or down individually by compartment. Specifying a larger number of data points can dramatically slow program execution since the gas temperature and velocity are evaluated at each grid location every time a Smokeview output is specified. The default value should be appropriate for most simulations.

Width (X) Grid (default units: n/a, default value: 50): slices included along the $X$ axis for each compartment are uniformly divided into the specified number of data points.

Width (Y) Grid (default units: n/a, default value: 50): slices included along the Y axis for each compartment are uniformly divided into the specified number of data points.

Width (Z) Grid (default units: n/a, default value: 50): slices included along the $\mathrm{Z}$ axis for each compartment are divided into the specified number of data points.

Sample visualizations are included below. 

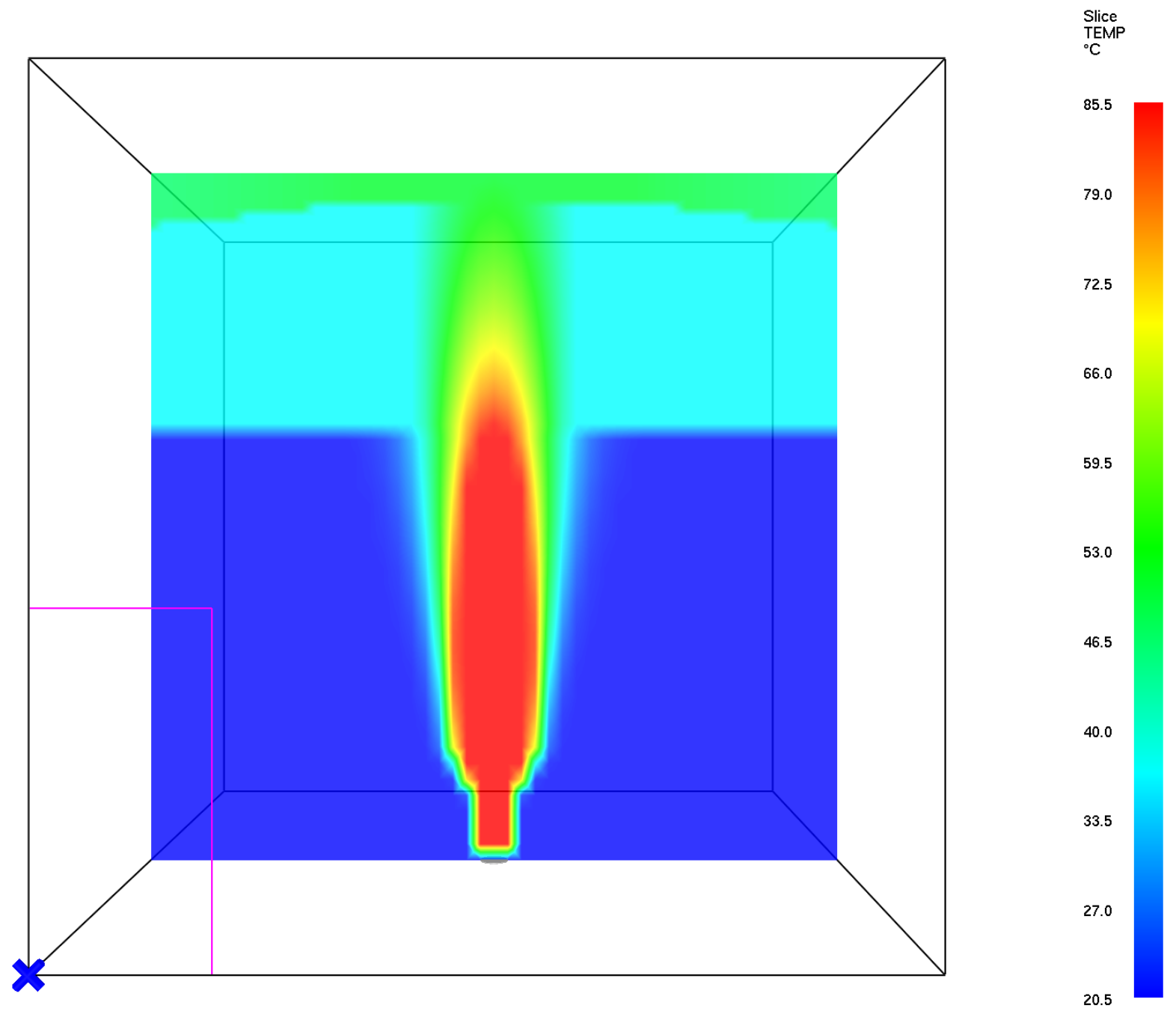

Figure 11.2: Smokeview Visualization of Gas Temperature with a Single Fire

\subsection{Output Options}

By default, CFAST generates a set of output files that includes a formatted readable output and a set of spreadsheet files. Options are available to modify the output files. The default output should be appropriate for most simulations.

CFAST Validation Output If checked, this item directs the CFAST model to output abbreviated headings for spreadsheet columns that are better for automated processing of the data.

Total Mass Output If checked, this item directs the CFAST model to replace the flow output with total mass flow through (mechanical) vents rather than the default flow rate values.

Debug Output If checked, CFAST will create a detailed output spreadsheet that contains values of all the solution variables at each successful solution time step. This file is typically only of use to model developers diagnosing a problem with the model. 


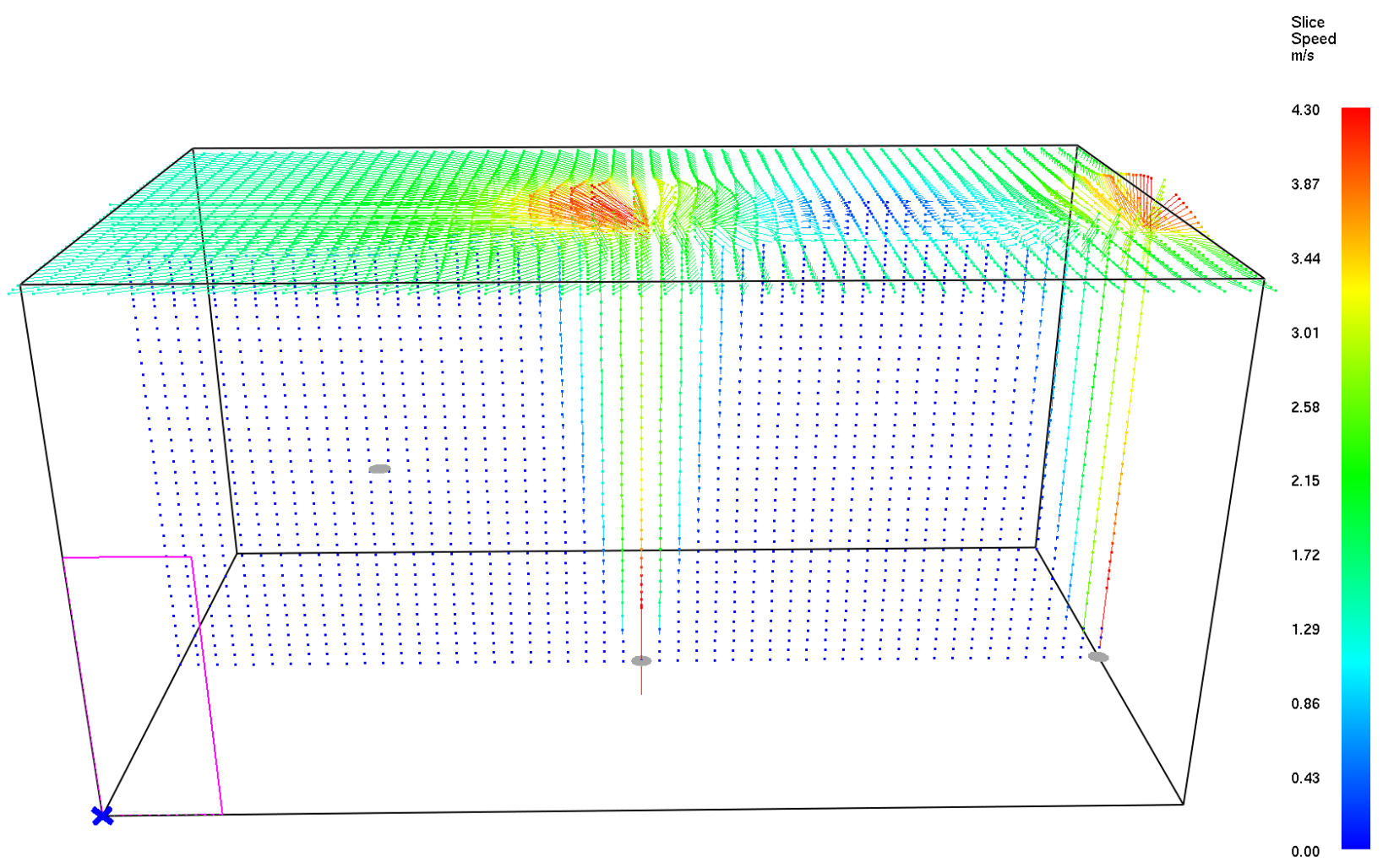

Figure 11.3: Smokeview Visualization of Gas Velocity with Two Fires

Show CFAST Window If checked, this item allows the user to see the windows command prompt that is used to execute the CFAST model when the Model Simulation, CFAST menu item is used. By default, this is not checked. Normally, this can be left unchecked. For troubleshooting, this can be selected to see additional details of the calculation as it progresses. 


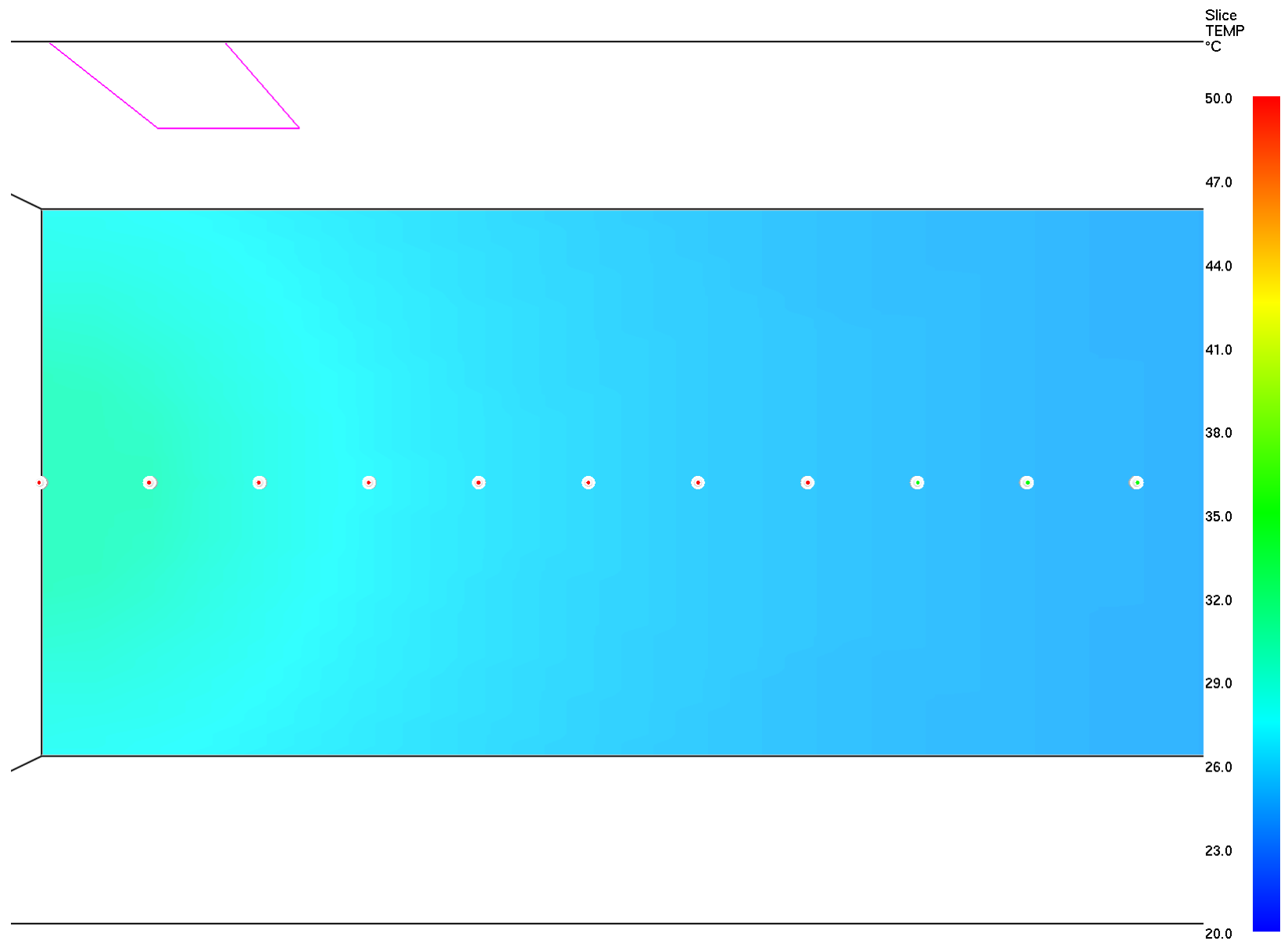

Figure 11.4: Smokeview Visualization of Detector Activation in a Corridor 


\section{Chapter 12}

\section{Output from CFAST}

The output of CFAST includes the temperatures of the upper and lower gas layers within each compartment, the ceiling/wall/floor temperatures within each compartment, the visible smoke and gas species concentrations within each layer, target temperatures and sprinkler activation time. The amount of information can be very large, especially for complex geometries and long simulations.

\subsection{Compact Output}

The default output to the console is called the compact form, and shows the basic information about a scenario, including layer temperatures and the size of fires. Default text output provides a simple overview for the user to make sure the case runs as expected.

\begin{tabular}{|c|c|c|c|c|c|c|c|}
\hline Compartment & $\begin{array}{l}\text { Upper } \\
\text { Temp. } \\
\text { (C) }\end{array}$ & $\begin{array}{l}\text { Lower } \\
\text { Temp. } \\
\text { (c) }\end{array}$ & $\begin{array}{l}\text { Inter. } \\
\text { Height } \\
(\mathrm{m})\end{array}$ & $\begin{array}{l}\text { Pyrol } \\
\text { Rate } \\
(\mathrm{kg} / \mathrm{s})\end{array}$ & $\begin{array}{l}\text { Fire } \\
\text { Size } \\
(W)\end{array}$ & $\begin{array}{l}\text { Pressure } \\
(\mathrm{Pa})\end{array}$ & $\begin{array}{l}\text { Ambient } \\
\text { Target } \\
\left(W / m^{\wedge} 2\right)\end{array}$ \\
\hline $\begin{array}{c}1 \\
\text { Outside }\end{array}$ & 113.4 & 33.3 & 1.4 & $1.393 \mathrm{E}-02$ & $\begin{array}{l}3.00 \\
0.00\end{array}$ & $5-0.790$ & 523. \\
\hline
\end{tabular}

The first column contains the compartment number. On each row with its compartment number from left to right is the upper layer temperature, lower layer temperature, the height of the interface between the two layers, the total pyrolysis rate, and finally the total fire size. The only value given for the outside is the total heat release rate of fires venting to the outside.

\subsection{Detailed Outputs}

The following sections describe each of the outputs from the model. Each section refers to a specific part of the print out and appears in the order the output appears. A description of each option follows. 


\subsubsection{Output for Initialization}

This option prints the initial conditions to the output before the actual run starts. This merely mimics the inputs specified by the user in the input data file The initial conditions break down into seven sections. Each is described below with the section name. The following explanation uses the output from the case STANDARD.IN. STANDARD.IN is included in the distribution. Please note, there are no mechanical ventilation, horizontal vents or detectors in this example, so the section discussing these phenomena are from additional data files.

\section{Overview}

The overview gives a general description of the case. The output is fairly self explanatory. "Doors, ..." is the total number of horizontal natural flow vent connections in all compartments of the simulation. "Ceil. Vents, ..." gives the total number of vertical natural flow vent connections in all compartments of the simulation. The last header on the line "MV Connections" has the total number mechanical flow connections to all compartments in the simulation. Times in these outputs come from the TIMES input. All times are in s.

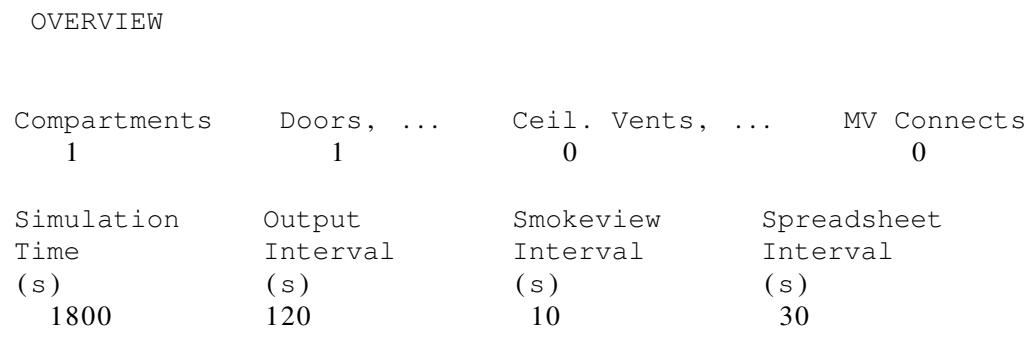

\section{Ambient Conditions}

This section, like the overview section, needs little elaboration. It gives the starting atmospheric conditions for the simulation both for outside and inside the structure. Data for these outputs come from the TAMB and EAMB inputs. Temperatures are in $\mathrm{K}$, pressure in $\mathrm{Pa}$, elevations in $\mathrm{m}$, and wind speed in $\mathrm{m} / \mathrm{s}$. Wind Power is the dimensionless power law coefficient from the WIND input.

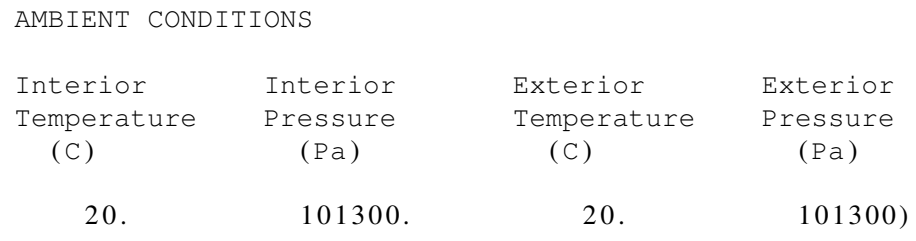

\section{Compartments}

The compartments section gives a summary of the geometry for the simulation. A simple table summarizes the geometry with compartments running down the page in numerical order. The various dimensions for each compartment are on the row with its compartment number. Two columns 
need explanation. The second to last column "Ceiling Height" gives the height of the ceiling relative to the station height in the Ambient Conditions section. Similarly the "Floor Height" refers to the height of the floor above the station height.

\begin{tabular}{|c|c|c|c|c|c|c|}
\hline Compartment & Name & $\begin{array}{l}\text { Width } \\
\text { (m) }\end{array}$ & $\begin{array}{l}\text { Depth } \\
\text { (m) }\end{array}$ & $\begin{array}{l}\text { Height } \\
\text { (m) }\end{array}$ & $\begin{array}{l}\text { Ceiling } \\
\text { Height } \\
\text { (m) }\end{array}$ & $\begin{array}{l}\text { Floor } \\
\text { Height } \\
(\mathrm{m})\end{array}$ \\
\hline 1 & Compartment 1 & 9.10 & 5.00 & 4.60 & 4.60 & 0.00 \\
\hline
\end{tabular}

\section{Horizontal Natural Ventilation}

This is the first table in the vent connections section. Each row in the table characterizes one vent. The first two columns contain the two compartments connected by the vent. Each vent is ordered first by the lower number of the two compartments and then the numeric order of the second compartment. The third column gives the vent number. Column four is the width of the vent. The next two columns report the sill and soffit height for the vent relative to the floor of the first compartment. The seventh and eighth columns have a second listing of the sill and soffit height, this time relative to the station height.

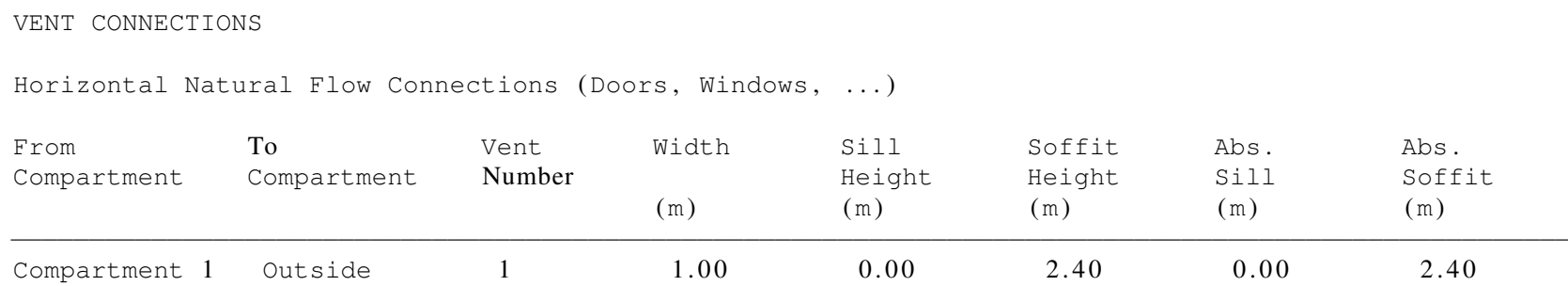

From compartment, to compartment, vent number, width, sill height, and soffit height all come directly from the HVENT specifications in the input data file. Absolute sill height is the station elevation + compartment floor height + sill height. Absolute soffit height is the station elevation + compartment floor height + soffit height.

\section{Vertical Natural Ventilation}

The first column is the upper compartment. The upper compartment is the compartment where the vent opens into the floor. The second column is the lower compartment where the vent is in the ceiling. The third column describes the shape of the vent, which can be either round or square. The fourth column gives the area of the vent. The last two columns are the height of the vent, relative to the floor of the lower room and relative to the station height respectively.

\begin{tabular}{|c|c|c|c|c|c|}
\hline $\begin{array}{l}\text { Top } \\
\text { Compartment }\end{array}$ & $\begin{array}{l}\text { Bottom } \\
\text { Compartment }\end{array}$ & Shape & $\begin{array}{l}\text { Area } \\
\left(m^{\wedge} 2\right)\end{array}$ & $\begin{array}{l}\text { Relative } \\
\text { Height } \\
\text { (m) }\end{array}$ & $\begin{array}{l}\text { Absolute } \\
\text { Height } \\
\text { (m) }\end{array}$ \\
\hline Outside & 1 & Round & 1.00 & 4.60 & 4.60 \\
\hline
\end{tabular}


Top compartment, bottom compartment, shape, and area come from the VVENT specifications in the input data file. Relative height is the height of the vent above the floor of the bottom compartment and absolute height is the height of the vent above the station elevation.

\section{Mechanical Flow Connections}

This section lists all connections to compartments and fans that connect between compartments. The table lists, in order, the number of the system the fan is a part, the "from" node and its height, the "to" node and its height. A fan actually draws air from the first or "from" node and pushes it to the second or "to" node. The sixth column is the cross-sectional area of the duct connection to the chosen compartment. The seventh column is the fan number as defined in CEdit. The next two columns are the minimum and maximum pressures at which the fan curve is defined. The rest of the row is made up of the one to five fan curve coefficients in the input file.

\begin{tabular}{|c|c|c|c|c|c|c|c|c|c|c|}
\hline System & From & & $\begin{array}{l}\text { From } \\
\text { Elev. } \\
\text { (m) }\end{array}$ & To & $\begin{array}{l}\text { To } \\
\text { Elev. } \\
\text { (m) }\end{array}$ & $\begin{array}{l}\text { Area } \\
\left(\mathrm{m}^{\wedge} 2\right)\end{array}$ & $\begin{array}{l}\text { Fan } \\
\text { Number }\end{array}$ & $\begin{array}{l}\text { Minimum } \\
(\mathrm{Pa})\end{array}$ & $\begin{array}{l}\text { Maximum } \\
(\mathrm{Pa})\end{array}$ & $\begin{array}{l}\text { Flowrate } \\
\left(\mathrm{m}^{\wedge} 3 / \mathrm{s}\right)\end{array}$ \\
\hline \multirow[t]{3}{*}{1} & Comp & 1 & 1.00 & Node 1 & 1.00 & 0.05 & \multirow{3}{*}{1} & \multirow{3}{*}{200.00} & \multirow{3}{*}{300.00} & \multirow{3}{*}{$3.80 \mathrm{E}-02$} \\
\hline & Node & 1 & 1.00 & Node 2 & 10.00 & & & & & \\
\hline & Node & 2 & 10.00 & Outside & 10.00 & 0.05 & & & & \\
\hline
\end{tabular}

\section{Thermal Properties}

The thermal properties section is broken into two parts. The first part is a table that lists the material for each surface of each compartment. The compartments appear as rows down the page in numerical order. From left to right next to the compartment number comes the material for the ceiling, wall and floor. The second part lists the properties of each material used in the simulation. For each listing of a material, the name is followed by the conductivity, specific heat, density, thickness and emissivity. In addition to materials for compartment surfaces, any thermal properties specified for targets are also listed (this may include thermal properties for gaseous materials specified as fire sources in a simulation.

\begin{tabular}{|c|c|c|c|c|c|c|}
\hline \multicolumn{2}{|c|}{ Compartment } & Ceiling & Wall & \multicolumn{2}{|l|}{ Floor } & \multirow[b]{3}{*}{ Emissivity } \\
\hline Compartme & ent 1 & GLASSE & CONCRETE & \multicolumn{2}{|c|}{ CONCRETE } & \\
\hline Name & \multicolumn{2}{|c|}{ Conductivity } & Specific heat & Density & Thickness & \\
\hline CONCRETE & & 1.75 & $1.000 \mathrm{E}+03$ & $2.200 \mathrm{E}+03$ & 0.150 & 0.940 \\
\hline GLASSFB3 & & $.600 \mathrm{E}-02$ & 795 & 105 & $1.300 \mathrm{E}-02$ & 0.900 \\
\hline HARDWOOD & & .160 & $1.255 \mathrm{E}+03$ & 720. & $1.900 \mathrm{E}-02$ & 0.900 \\
\hline DEFAULT & & .120 & 900 & 800 . & $1.200 \mathrm{E}-02$ & 0.900 \\
\hline
\end{tabular}

Material choices of the ceiling, walls, and floors come from the CEILI, WALLS, and FLOOR specifications in the input data file. Units for thermal properties are standard S.I. units. For thermal conductivity, W/m K ; for specific heat, $\mathrm{J} / \mathrm{kg} \mathrm{K}$; for density, $\mathrm{kg} / \mathrm{m}^{3}$; for thickness, $\mathrm{m}$; emissivity is dimensionless. 


\section{Targets}

The entry for targets shows the orientation of additional targets specified in the data file. Targets explicitly specified in the data file are listed first in the order they are included in the data file. Each target is numbered based on the order of the target specifications in the input data file. The compartment number, position of the target within the compartment, direction of the front face of the target object expressed as a normal unit vector to the surface, and object material. Additional targets, one for each compartment and one for each fire are automatically generated by the program and included in the list after the user-specified targets.

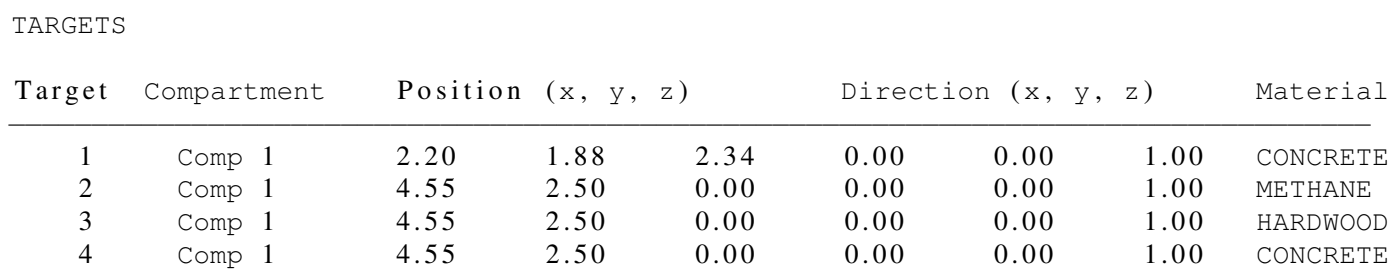

All of the inputs for targets come from the TARGE command in the input data file. Direction is specified as a unit vector as described in the section on target input. Units for position and direction are all in $\mathrm{m}$.

\section{Fires}

The fire section lists all the information about the main fire and any object fires that might exist. All the information for each fire is listed separately. If there is a main fire, it comes first. Each fire listing has the same form. First is the name of the fire followed by a list of general information. Listed left to right is the compartment the fire is in, the type of fire, the $\mathrm{x}, \mathrm{y}, \mathrm{z}$ position, the relative humidity, the lower oxygen limit, and finally the radiative fraction for the fire.

A table of time history curves for the fire follows. The table contains all the time history curves for the fire. Each row on the table is a specific time given in the left most column. The rest of the columns give the values at that particular time. The column headers indicate each input quantity and correspond to specific keywords in the fire definition. The headings are defined as follows: 'Fmdot' is pyrolysis rate; 'Hcomb' is the heat of combustion; 'Fqdot' is the heat release rate; 'Fheight' is height of fire; 'Soot' is the fraction of the fuel mass converted to soot during combustion; 'CO' is the fraction of the fuel mass converted to carbon monoxide during combustion; ' $\mathrm{HCN}$ ' is the fraction of the fuel mass converted to hydrogen cyanide during combustion; ' $\mathrm{HCl}$ ' is the fraction of the fuel mass converted to hydrogen chloride during combustion; ' $\mathrm{CT}$ ' is the concentration-time product; and 'TS' is the fraction of fuel mass converted to trace species during combustion.

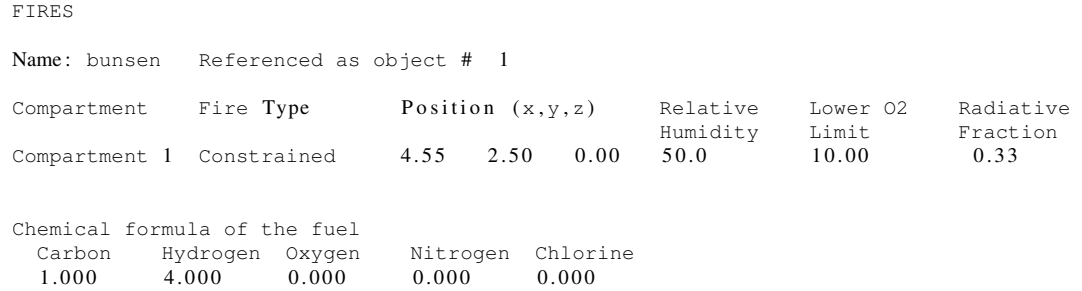




\begin{tabular}{|c|c|c|c|c|c|c|c|c|c|c|}
\hline $\begin{array}{l}\text { Time } \\
\text { (s) }\end{array}$ & $\begin{array}{l}\text { Fmdot } \\
(\mathrm{kg} / \mathrm{s})\end{array}$ & $\begin{array}{l}\text { Hcomb } \\
(\mathrm{J} / \mathrm{kg})\end{array}$ & $\begin{array}{l}\text { Fqdot } \\
\text { (W) }\end{array}$ & $\begin{array}{l}\text { Fheight } \\
\text { (m) }\end{array}$ & $\begin{array}{l}\text { Soot } \\
(\mathrm{kg} / \mathrm{kg})\end{array}$ & $\begin{array}{l}\mathrm{CO} \\
(\mathrm{kg} / \mathrm{kg})\end{array}$ & $\begin{array}{l}\mathrm{HCN} \\
(\mathrm{kg} / \mathrm{kg})\end{array}$ & $\begin{array}{l}\mathrm{HCl} \\
(\mathrm{kg} / \mathrm{kg})\end{array}$ & $\begin{array}{l}\mathrm{CT} \\
(\mathrm{kg} / \mathrm{kg})\end{array}$ & $\begin{array}{l}\text { TS } \\
(\mathrm{kg} / \mathrm{kg})\end{array}$ \\
\hline 0 . & 0.0 & $5.00 \mathrm{E}+07$ & 0.0 & 0.0 & 0.0 & $1.05 \mathrm{E}-03$ & 0.0 & 0.0 & 1.0 & 0.0 \\
\hline 60 . & $2.00 \mathrm{E}-03$ & $5.00 \mathrm{E}+07$ & $1.00 \mathrm{E}+05$ & 0.0 & 0.0 & $1.05 \mathrm{E}-03$ & 0.0 & 0.0 & 1.0 & 0.0 \\
\hline 120 . & $3.00 \mathrm{E}-03$ & $5.00 \mathrm{E}+07$ & $1.50 \mathrm{E}+05$ & 0.0 & 0.0 & $1.05 \mathrm{E}-03$ & 0.0 & 0.0 & 1.0 & 0.0 \\
\hline 180. & $4.00 \mathrm{E}-03$ & $5.00 \Xi+07$ & $2.00 \mathrm{E}+05$ & 0.0 & 0.0 & $1.05 \mathrm{E}-03$ & 0.0 & 0.0 & 1.0 & 0.0 \\
\hline 240 . & $3.00 \mathrm{E}-03$ & $5.00 \mathrm{E}+07$ & $1.50 \mathrm{E}+05$ & 0.0 & 0.0 & $1.05 \mathrm{E}-03$ & 0.0 & 0.0 & 1.0 & 0.0 \\
\hline 300 . & $2.50 \mathrm{E}-03$ & $5.00 E+07$ & $1.25 \mathrm{E}+05$ & 0.0 & 0.0 & $1.05 \mathrm{E}-03$ & 0.0 & 0.0 & 1.0 & 0.0 \\
\hline 360 . & $2.00 \mathrm{E}-03$ & $5.00 \mathrm{E}+07$ & $1.00 \mathrm{E}+05$ & 0.0 & 0.0 & $1.05 \mathrm{E}-03$ & 0.0 & 0.0 & 1.0 & 0.0 \\
\hline 420. & $1.80 \mathrm{E}-03$ & $5.00 E+07$ & $9.00 \mathrm{E}+04$ & 0.0 & 0.0 & $1.05 \mathrm{E}-03$ & 0.0 & 0.0 & 1.0 & 0.0 \\
\hline 480 . & $1.60 \mathrm{E}-03$ & $5.00 E+07$ & $8.00 \mathrm{E}+04$ & 0.0 & 0.0 & $1.05 \mathrm{E}-03$ & 0.0 & 0.0 & 1.0 & 0.0 \\
\hline 540. & $1.50 \mathrm{E}-03$ & $5.00 \mathrm{E}+07$ & $7.50 \mathrm{E}+04$ & 0.0 & 0.0 & $1.05 \mathrm{E}-03$ & 0.0 & 0.0 & 1.0 & 0.0 \\
\hline 1800 . & $1.50 \mathrm{E}-03$ & $5.00 \mathrm{E}+07$ & $7.50 \mathrm{E}+04$ & 0.0 & 0.0 & $1.05 \mathrm{E}-03$ & 0.0 & 0.0 & 1.0 & 0.0 \\
\hline \multicolumn{3}{|c|}{ Name: Wood_Wall } & object \# & 2 & & & & & & \\
\hline Compartment & 1 Constr & ained & 4.55 & 0.00 & 50.0 & 10.00 & \multicolumn{2}{|c|}{$\begin{array}{l}\text { Radiative } \\
\text { Fraction } \\
0.33\end{array}$} & & \\
\hline \multicolumn{11}{|c|}{ Chemical formula of the fuel } \\
\hline Carbon & Hydrogen & Oxygen & Nitrogen & Chlorine & & & & & & \\
\hline 6.000 & 10.000 & 5.000 & 0.000 & 0.000 & & & & & & \\
\hline $\begin{array}{l}\text { Time } \\
(\mathrm{s})\end{array}$ & $\begin{array}{l}\text { Fmdot } \\
(\mathrm{kg} / \mathrm{s})\end{array}$ & $\begin{array}{l}\text { Hcomb } \\
(\mathrm{J} / \mathrm{kg})\end{array}$ & $\begin{array}{l}\text { Fqdot } \\
(\mathrm{W})\end{array}$ & $\begin{array}{l}\text { Fheight } \\
\text { (m) }\end{array}$ & $\begin{array}{l}\text { Soot } \\
(\mathrm{kg} / \mathrm{kg})\end{array}$ & $\begin{array}{l}\mathrm{CO} \\
(\mathrm{kg} / \mathrm{kg})\end{array}$ & $\begin{array}{l}\mathrm{HCN} \\
(\mathrm{kg} / \mathrm{kg})\end{array}$ & $\begin{array}{l}\mathrm{HCl} \\
(\mathrm{kg} / \mathrm{kg})\end{array}$ & $\begin{array}{l}\mathrm{CT} \\
(\mathrm{kg} / \mathrm{kg})\end{array}$ & $\begin{array}{l}\mathrm{TS} \\
(\mathrm{kg} / \mathrm{kg})\end{array}$ \\
\hline 0 . & 0.0 & $1.81 \mathrm{E}+07$ & 0.0 & 0.0 & $2.00 \mathrm{E}-02$ & $2.00 \mathrm{E}-02$ & 0.0 & 0.0 & 1.0 & 0.0 \\
\hline 8000 . & $5.52 \mathrm{E}-02$ & $1.81 \mathrm{E}+07$ & $1.00 \mathrm{E}+06$ & 3.0 & $2.00 \mathrm{E}-02$ & $2.00 \mathrm{E}-02$ & 0.0 & 0.0 & 1.0 & 0.0 \\
\hline
\end{tabular}

All of the inputs for the main fire come from the fire specifications in the input data file. Data for the object fire comes from the object data file included with the CFAST software. Units for most values are included in the output. Fire position is in $\mathrm{m}$, relative humidity is in \%, lower oxygen limit is in volume percent, and pyrolysis temperature is in $\mathrm{K}$.

\subsubsection{Output for Main Variables}

The normal print out is the first information printed at each time interval. This information includes the layer temperatures, interface height, volume of the upper layer, layer absorption coefficients, and compartment pressure (relative to ambient).

\begin{tabular}{llllllll} 
Time $=$ & 1800.0 seconds. \\
Compartment & $\begin{array}{l}\text { Upper } \\
\text { Temp. } \\
(\mathrm{C})\end{array}$ & $\begin{array}{l}\text { Lower } \\
\text { Temp. } \\
(\mathrm{C})\end{array}$ & $\begin{array}{l}\text { Inter. } \\
\text { Height } \\
(\mathrm{m})\end{array}$ & $\begin{array}{l}\text { Upper } \\
\text { Vol. } \\
\left(\mathrm{m}^{\wedge} 3\right)\end{array}$ & $\begin{array}{l}\text { Upper } \\
\text { Absorb } \\
\left(\mathrm{m}^{\wedge}-1\right)\end{array}$ & $\begin{array}{l}\text { Lower } \\
\text { Absorb } \\
\left(\mathrm{m}^{\wedge}-1\right)\end{array}$ & $\begin{array}{l}\text { Pressure } \\
(\mathrm{Pa})\end{array}$ \\
\hline Comp 1 & 113.4 & 33.30 & 1.410 & $1.45 \mathrm{E}+02(69 \%)$ & 0.124 & $8.817 \mathrm{E}-02$ & -0.790
\end{tabular}

The second table of the normal print out has information about the fires. In essence it is two tables joined. The first part lists information by fire. It starts with the main fire, if there is one, and then the object fires down the page. The fires are listed in the second column followed by the plume flow rate, the pyrolysis rate, the fire size, and flame height. The next three columns are then skipped. The next column with information is the amount of heat given off by each fire convectively, followed by the amount of heat given off radiantly. The last two columns give the total mass pyrolyzed and the amount of trace species produced. The second part starts after all the fires have been individually listed. It gives the totals for all fires in each compartment. The first column has the compartment number. The compartments start at one and are listed down the page in order. The third to fifth columns are the same as the first part except the values are totals for the compartment and not just for one fire. The sixth column has the total heat release rate that occurs 
in the upper layer. The next column has the same total in the lower layer. The eighth column has the total size of vent fires in the compartment.

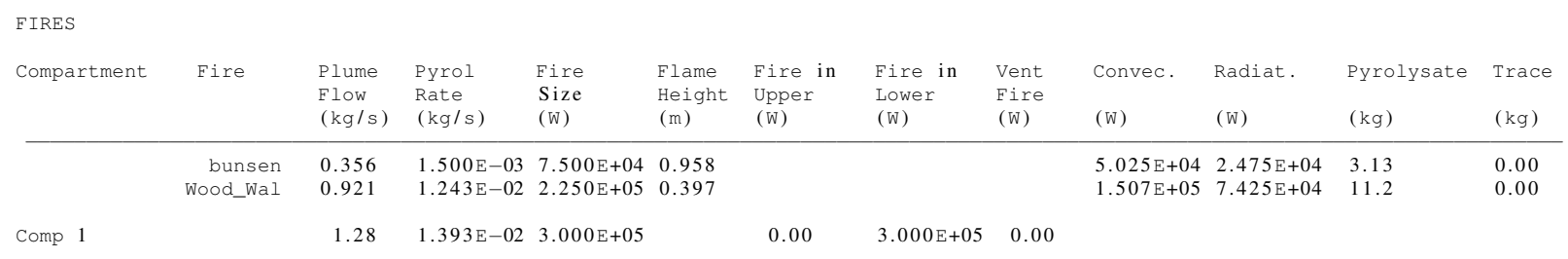

Flame height is calculated from the work of Heskestad [14]. The average flame height is defined as the distance from the fuel source to the top of the visible flame where the intermittency is 0.5 . A flame intermittency of 0.5 means that the visible flame is above the mean $50 \%$ of the time and below the mean $50 \%$ of the time.

\subsubsection{Output for Wall Surfaces, Targets, and Detectors/Sprinklers}

The printed output provides two tables displaying information about wall surface or target temperatures and fluxes, and heat detectors or sprinklers. The left most column specifies the compartment number; followed by four columns providing the temperatures of the bounding surfaces of the compartment in contact with the ceiling, upper wall surface (in contact with the upper layer gases), lower wall surface (in contact with the lower layer gases), and floor, in that order. Next comes information about targets in the compartment, with each target listed on a separate line. Information in the columns includes the surface temperature of the target, net heat flux to the target, and the percentage of that net flux that is due to radiation from the fire, radiation from compartment surfaces, radiation from the gas layers, and convection from the gas surrounding the target. CFAST includes one target in the center of the floor for all compartments. Information on additional targets specified by the user in the input data file are also included, in the order specified in the input file.

For smoke detectors, heat detectors, and sprinklers, the temperature of the device, its current state (activated or not), and the nearby gas temperature and velocity are included.

SURFACES AND TARGETS

\begin{tabular}{|c|c|c|c|c|c|c|c|c|c|c|c|c|c|}
\hline Compartment & $\begin{array}{l}\text { Ceiling } \\
\text { Temp. } \\
\text { (C) }\end{array}$ & $\begin{array}{l}\text { Up wall } \\
\text { Temp. } \\
\text { (C) }\end{array}$ & $\begin{array}{l}\text { Low wall } \\
\text { Temp. } \\
\text { (C) }\end{array}$ & $\begin{array}{l}\text { Floor } \\
\text { Temp. } \\
\text { (C) }\end{array}$ & Target & $\begin{array}{l}\text { Gas } \\
\text { Temp } \\
\text { (C) }\end{array}$ & $\begin{array}{l}\text { Surface } \\
\text { Temp. } \\
\text { (C) }\end{array}$ & $\begin{array}{l}\text { Center } \\
\text { Temp. } \\
\text { (C) }\end{array}$ & $\begin{array}{l}\text { Flux To } \\
\text { Target } \\
(\text { W/m^2) }\end{array}$ & $\begin{array}{l}\text { Fire } \\
\text { Rad. } \\
\left(\mathrm{W} / \mathrm{m}^{\wedge} 2\right)\end{array}$ & $\begin{array}{l}\text { Surface } \\
\text { Rad. } \\
\left(W / \mathrm{m}^{\wedge} 2\right)\end{array}$ & $\begin{array}{l}\text { Gas } \\
\text { Rad. } \\
\left(\mathrm{W} / \mathrm{m}^{\wedge} 2\right)\end{array}$ & $\begin{array}{l}\text { Convect. } \\
\left(\mathrm{W} / \mathrm{m}^{\wedge} 2\right)\end{array}$ \\
\hline \multirow[t]{4}{*}{ Comp 1} & \multirow[t]{4}{*}{23.0} & \multirow[t]{4}{*}{22.5} & \multirow[t]{4}{*}{21.6} & \multirow[t]{4}{*}{22.6} & Floor & & 22.6 & & 17.8 & $2.817 \mathrm{E}-02$ & 13.3 & 1.25 & 3.23 \\
\hline & & & & & 1 & 23.7 & 21.7 & 20.9 & 23.2 & 0.00 & 12.0 & 1.54 & 9.67 \\
\hline & & & & & 2 & 21.2 & 21.7 & 21.7 & 16.6 & $1.341 \mathrm{E}-04$ & 12.0 & 1.46 & 3.23 \\
\hline & & & & & 3 & 21.2 & 25.0 & 25.0 & 16.6 & $1.341 \mathrm{E}-04$ & 12.0 & 1.46 & 3.23 \\
\hline
\end{tabular}

DETECTORS / ALARMS / SPRINKLERS

\begin{tabular}{ccccccc} 
Number & Compartment & Type & $\begin{array}{l}\text { Sensor } \\
\text { Temp (C) }\end{array}$ & Activated & Temp (C) & \multicolumn{2}{c}{ Vmoke (m/s) } \\
\hline 1 & 1 & HEAT & $2.627 \mathrm{E}+01$ & YES & $2.518 \mathrm{E}+01$ & $6.617 \mathrm{E}-01$
\end{tabular}

In all cases, the flux to/from a target is net radiation or net convection. That is, it is the incoming minus the outgoing. So while a target or object is heating, the flux will be positive, and once it starts to cool, the flux will be negative. Values for radiation from fires (fire rad.), radiation from surfaces (surface rad.), radiation from the gas layers (gas rad.), and convection from surfaces (convect) are 
expressed as the net flux to target (flux to target). Positive values indicate heat gains by the target and negative values indicate heat losses.

\subsubsection{Output for Gas Species}

The output has two tables displaying information about the amounts of species in each layer. The species information follows the normal print out. The first table gives species volume fractions for the upper layers of all the compartments and the second reports the same for the lower layers of all the compartments. Again the compartments are listed down the page and the information across the page. The species are each given in one of several different terms. Below each header are the units for the given value. Most of the headers are simply the chemical formula for the species being tracked. However, several are not obvious. "TUHC" is the total unburned hydrocarbons or the pyrolyzed fuel that hasn't burned yet. "OD" is the optical density, which is a measure of the amount of smoke. "TS" is trace species.

\begin{tabular}{|c|c|c|c|c|c|c|c|c|c|c|c|}
\hline compartment & $\begin{array}{l}\mathrm{N} 2 \\
(\%)\end{array}$ & $\begin{array}{l}\mathrm{O} 2 \\
(\%)\end{array}$ & $\begin{array}{l}\mathrm{CO} 2 \\
(\%)\end{array}$ & $\begin{array}{l}\mathrm{CO} \\
(\mathrm{ppm})\end{array}$ & $\begin{array}{l}\mathrm{HCN} \\
(\mathrm{ppm})\end{array}$ & $\begin{array}{l}\mathrm{HCL} \\
(\mathrm{ppm})\end{array}$ & $\begin{array}{l}\text { TUHC } \\
(\%)\end{array}$ & $\begin{array}{l}\mathrm{H} 2 \mathrm{O} \\
(\%)\end{array}$ & $\begin{array}{l}\mathrm{OD} \\
(1 / \mathrm{m})\end{array}$ & $\begin{array}{l}\mathrm{CT} \\
(\mathrm{g}-\mathrm{min} / \mathrm{m} 3)\end{array}$ & $\begin{array}{l}\text { TS } \\
\mathrm{kg}\end{array}$ \\
\hline Compartment & 179.2 & 20.5 & $9.055 \mathrm{E}-02$ & 2.98 & 0.00 & 0.00 & 0.00 & 0.180 & $1.086 \mathrm{E}-02$ & 51.8 & 0.00 \\
\hline \multicolumn{12}{|c|}{ LOWER LAYER SPECIES } \\
\hline compartment & $\begin{array}{l}\mathrm{N} 2 \\
(\%)\end{array}$ & $\begin{array}{l}\mathrm{O} 2 \\
(\%)\end{array}$ & $\begin{array}{l}\mathrm{CO} 2 \\
(\%)\end{array}$ & $\begin{array}{l}\mathrm{CO} \\
(\mathrm{ppm})\end{array}$ & $\begin{array}{l}\mathrm{HCN} \\
(\mathrm{ppm})\end{array}$ & $\begin{array}{l}\mathrm{HCL} \\
(\mathrm{ppm})\end{array}$ & $\begin{array}{l}\text { TUHC } \\
(\%)\end{array}$ & $\begin{array}{l}\mathrm{H} 2 \mathrm{O} \\
(\%)\end{array}$ & $\begin{array}{l}\mathrm{OD} \\
(1 / \mathrm{m})\end{array}$ & $\begin{array}{l}\mathrm{CT} \\
(\mathrm{g}-\mathrm{min} / \mathrm{m} 3)\end{array}$ & $\begin{array}{l}\mathrm{TS} \\
\mathrm{kg}\end{array}$ \\
\hline Compartment & 179.3 & 20.7 & $6.412 \mathrm{E}-03$ & 0.211 & 0.00 & 0.00 & 0.00 & 0.029 & $7.750 \mathrm{E}-04$ & +4.00 & 0.00 \\
\hline
\end{tabular}

The report by species for nitrogen, oxygen, hydrogen chloride and the total unburned hydrocarbons (fuel vapor in the layer) are percent by volume. Carbon dioxide, carbon monoxide and hydrogen cyanide are in parts per million, which is proportional to the volume fraction. Optical depth per meter is a measure of the visibility in the smoke. This is covered in detail in the comment on visibility in the section on fires and species specification. The concentration-time (CT) calculation is an integration of the species input for type CT (See section 7.1 for the input of CT) and is intended to represent a relative dose of toxic gas species. Trace species (TS) is the total kilograms of the trace species that is present in the compartment. It is an absolute measure and not percent or density.

\subsubsection{Output for Vent Flows}

Information about vent flow is obtained by using this option. It includes a section detailing mass flow through horizontal, vertical, and mechanical vents. There are two forms for the vent flow. The first is flow through the vents as mass per second. The alternative, obtained with the total mass flow output option on the 'Run!,' 'Output Options' menu, gives the total mass which has flowed through the vent(s) and the relative mass of trace species divided by the total mass of trace species produced up to the current time.

The section for vent flow is titled "FLOW THROUGH VENTS $(\mathrm{kg} / \mathrm{s})$." Because flow is always given in positive values, each vent is listed twice, once for flow going from compartment $A$ to 
compartment B (labelled as "Flow relative to "from"') and a second time for flow from B to A (labelled as "Flow relative to "To"". As the example below shows, the first column specifies the vent, including the type of vent (an " $\mathrm{H}$ " in this column stands for horizontal flow, such as through a doorway or window; a "V" here would mean vertical flow, such as through an opening in the ceiling, and an " $\mathrm{M}$ " stands for a mechanical ventilation connection) and the compartment from which the flow comes. The second column lists the name of the compartment. Up to six additional columns detail the flow at this vent. Flow into and out of the compartment through the vent in the upper and lower layers are included.

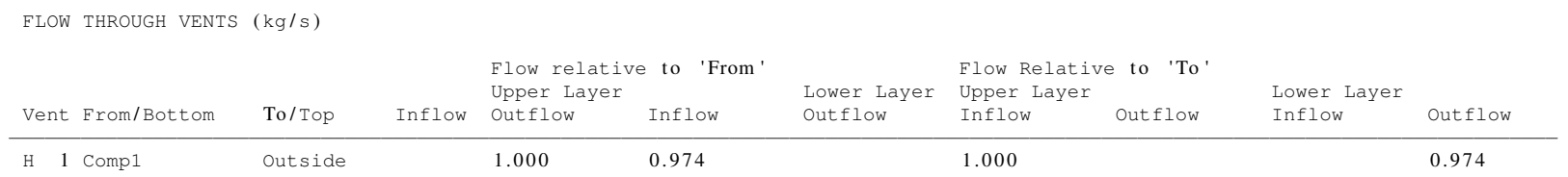

The mass balance is the sum of the flow in minus the flow out. (Note that this is an extended run to achieve results close to steady state.) For any compartment, this is just

$$
\left(\dot{m}_{u, \text { in }}+\dot{m}_{l, \text { in }}+\dot{m}_{f}\right)-\left(\dot{m}_{u, \text { out }}+\dot{m}_{l, \text { out }}\right)
$$

with the inflow and outflow summed for each vent. For the above example, the mass balance is:

$$
(0.974+0.01393) \mathrm{kg} / \mathrm{s}-(1.000) \mathrm{kg} / \mathrm{s}=-0.012 \mathrm{~kg} / \mathrm{s}
$$

where the pyrolysis rate (from the "normal" output) is $0.01393 \mathrm{~kg} / \mathrm{s}$. The result is about the right magnitude (about $1 \%$ of the mass flow into or out of the vent) for net mass loss given the default equation solver tolerances for CFAST. The mass loss should still be slightly negative since the compartment continues to heat.

An alternative printout is provided by use of the total mass flow output option on the 'Run!,' 'Output Options' menu. This shows total (mass) flow through vents. At present this is confined to mechanical ventilation. It applies only to vents which can be filtered, in this case mechanical ventilation. The last column is obtained by summing the outflow/inflow for each vent and then dividing that sum by the total trace species produced by all fires. For details on this value, see the section on output listing for fires.

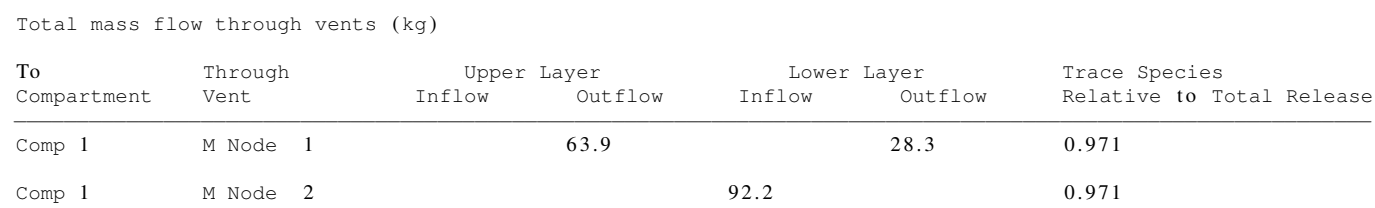

\subsection{Spreadsheet Output}

CFAST can generate a number of output files in a plain text spreadsheet format. These files capture a snap shot of the modeling data at an instant of time. This instance is determined by the fourth entry on the TIMES line of the data file. However, there are events which can occur in between these reporting periods. Examples are the ignition of objects and the activation of detectors or sprinklers. These are not reported in these output files. 


\subsubsection{Primary Output Variables (project_n.csv)}

There are two sets of information in this file. The first includes compartment information such as layer temperature. This is output by compartment and there are eight entries for each compartment plus a column that indicates the current simulation time:

Time (s)

Upper Layer Temperature $\left({ }^{\circ} \mathrm{C}\right)$

Lower Layer Temperature $\left({ }^{\circ} \mathrm{C}\right)$

Layer Height (m)

Upper Layer Volume $\left(\mathrm{m}^{3}\right)$ : total volume of the upper layer. This is just the floor area times the difference between the ceiling height and the layer height.

Pressure $(\mathrm{Pa})$ : pressure at compartment floor relative to the outside at the absolute height of the floor.

Ambient Temp Target Flux $\left(\mathrm{W} / \mathrm{m}^{2}\right)$ : net heat flux to the center of the floor assuming the floor is at ambient temperature. This is largely useful to estimate the tenability of the compartment.

Floor Temp Target Flux $\left(\mathrm{W} / \mathrm{m}^{2}\right)$ : net heat flux to the center of the floor.

HRR Door Jet Fires (W): total heat release rate of all door jet fires adding heat to this compartment.

The second set of information is for fires. There are seven entries per fire. This information is displayed for each fire :

Plume Entrainment Rate (kg/s): current mass entrained from the lower layer into the plume for this fire.

Pyrolysis Rate (kg/s): current rate of mass loss for this fire.

HRR (W): current total heat release rate for this fire. This is just the sum of the heat release rate for the lower layer and upper layer for this fire.

HRR Lower (W): current heat release rate for burning in the lower layer for this fire.

HRR Upper (W): current heat release rate for burning in the upper layer for this fire.

Flame Height (m): current calculated flame height for this fire.

Convective HRR (W): current rate of heat release by convection for this fire. The remainder is released by radiation to the surroundings.

Total Pyrolysate Released (kg): total mass released by the fire up to the current time.

Total Trace Species Released $(\mathrm{kg})$ : total mass of trace species released by the fire up to the current time. 


\subsubsection{Species Output (project_s.csv)}

At present, there are nine outputs in this file: oxygen $(\mathrm{O} 2)$, carbon dioxide $(\mathrm{CO} 2)$, carbon monoxide (CO), hydrogen cyanide $(\mathrm{HCN})$, hydrogen chloride (HCL), water vapor $(\mathrm{H} 2 \mathrm{O})$, optical depth $(\mathrm{OD})$, concentration-time dose (CT) and trace species (TS). This set of nine is enumerated for the upper and lower layer, and are done sequentially by compartment.

Time (s)

O2 Upper/Lower Layer (mol \%): oxygen concentration in the upper (or lower) layer in the current compartment

CO2 Upper/Lower Layer (mol \%): carbon dioxide concentration in the upper (or lower) layer in the current compartment

CO Upper/Lower Layer (ppm by volume): carbon monoxide concentration in the upper (or lower) layer in the current compartment

HCN Upper/Lower Layer (ppm by volume): HCN concentration in the upper (or lower) layer in the current compartment

HCL Upper/Lower Layer (ppm by volume): $\mathrm{HCl}$ concentration in the upper (or lower) layer in the current compartment

H2O Upper/Lower Layer (mol \%): water vapor concentration in the upper (or lower) layer in the current compartment

Optical Density Uppe/Lowerr Layer $\left(\mathrm{m}^{-1}\right)$ : optical density in the upper (or lower) layer in the current compartment

C-T Product Upper/Lower Layer $\left(\mathrm{g}-\mathrm{min} / \mathrm{m}^{3}\right)$ : integrated concentration-time product in the upper (or lower) layer in the current compartment

Trace Species Upper/Lower Layer (kg): total mass of trace species in the upper (or lower) layer in the current compartment

\subsubsection{Vent Flow (project_f.csv)}

The first columns in this file pertain to the horizontal flow through vertical vents such as windows and doors. There are two types of output, first to and from the outside, and second for interior compartments. The flow is broken down to flow in and out of the compartments. For flow to and from the outside (compartment $\mathrm{N}$ ) there are two entries.

Time (s)

HVENT Inflow Vent \# 1 Outside-1 $(\mathrm{kg} / \mathrm{s})$ : mass flow into the current compartment through the current horizontal flow (door/windows) vent connected to the current compartment

HVENT Outflow Vent \# 1 Outside-1 (kg/s): mass flow out of the current compartment through the current horizontal flow (door/windows) vent connected to the current compartment 
The second set of columns pertain to the vertical flow through horizontal vents. There are two entries for each vent in each compartment, showing the total flow into or out of each vent in each compartment.

VVENT Inflow Vent \# 1-Outside (kg/s): mass flow into the current compartment through the current vertical flow (ceiling/floor) vent connected to the current compartment

VVENT Outflow Vent \# 1-Outside Vent Connection at Node 1-2 (kg/s): mass flow out of the current compartment through the current vertical flow (ceiling/floor) vent connected to the current compartment

The third set of columns pertain to the mechanical ventilation. Once again, there will be an entry for each node/compartment pair, showing the total flow into or out of the compartment through this node. In addition, the total amount of trace species through filters and captured on filters in mechanical ventilation connected to the compartment is included.

MVENT Inflow Vent Connection at Node 1-2 $(\mathrm{kg} / \mathrm{s})$ : mass flow into the current compartment through the current mechanical flow (HVAC) vent connected to the current compartment

MVENT Outflow (kg/s): current mass flow out of the compartment through the current mechanical flow (HVAC) vent connected to the current compartment

MVENT Trace Species Flow Fan at Node $2(\mathrm{~kg} / \mathrm{s})$ : current total mass of trace species flowing through the filter at the fan in the current mechanical vent connected to the current compartment

MVENT Trace Species Filtered Fan at Node $2(\mathrm{~kg} / \mathrm{s})$ : total mass of trace species captured on the filter at the fan in the current mechanical vent connected to the current compartment

\subsubsection{Surface and Target Temperature and Heat Flux (project_w.csv)}

This file provides information on surface and target temperatures and flux, and reports on the current state of detectors and sprinklers (as a sub-set of detectors). The output is in three sections, one for wall surface temperatures, one for target temperature and heat flux, and one for detector/sprinkler temperature and activation. The first set of columns pertain to the temperature of compartment surfaces.

Time (s)

Ceiling Temperature $\left({ }^{\circ} \mathrm{C}\right)$ : temperature of the ceiling surface in the current compartment

Upper Wall Temperature $\left({ }^{\circ} \mathrm{C}\right)$ : temperature of the wall surface adjacent to the upper layer in the current compartment

Lower Wall Temperature $\left({ }^{\circ} \mathrm{C}\right)$ : temperature of the wall surface adjacent to the lower layer in the current compartment

Floor Temperature $\left({ }^{\circ} \mathrm{C}\right)$ : temperature of the floor surface in the current compartment 
The second set of columns pertain to the user-defined targets included in the simulation.

Target Surrounding Gas Temperature $\left({ }^{\circ} \mathrm{C}\right)$ : gas temperature nearby the current target

Target Surface Temperature $\left({ }^{\circ} \mathrm{C}\right)$ : temperature of the surface of the current target

Target Center Temperature $\left({ }^{\circ} \mathrm{C}\right)$ : interior temperature of the current target

Target Total Flux (kW/m2): total net heat flux to the front surface of the current target

Target Convective Flux $\left(\mathrm{kW} / \mathrm{m}^{2}\right)$ : convective heat flux to the front surface of the current target

Target Radiative Flux $\left(\mathrm{kW} / \mathrm{m}^{2}\right)$ : total net radiative heat flux to the front surface of the current target

Target Fire Radiative Flux $\left(\mathrm{kW} / \mathrm{m}^{2}\right)$ : radiative heat flux from fires to the front surface of the current target

Target Surface Radiative Flux $\left(\mathrm{kW} / \mathrm{m}^{2}\right)$ : radiative heat flux from compartment surfaces to the front surface of the current target

Target Gas Radiative Flux $\left(\mathrm{kW} / \mathrm{m}^{2}\right)$ : radiative heat flux from the upper and lower gas layers to the front surface of the current target

Target Radiative Loss Flux $\left(\mathrm{kW} / \mathrm{m}^{2}\right)$ : radiative heat flux from the current target to surroundings at the calculated temperature of the target

Target Total Gauge Flux $(\mathrm{kW} / \mathrm{m} 2)$ : total net heat flux to the front surface of the current target assuming the target radiative losses are at ambient temperature

Target Radiative Gauge Flux $\left(\mathrm{kW} / \mathrm{m}^{2}\right)$ : total net radiative heat flux to the front surface of the current target assuming the target radiative losses are at ambient temperature

Target Radiative Loss Gauge Flux $\left(\mathrm{kW} / \mathrm{m}^{2}\right)$ : radiative heat flux from the current target to surroundings assuming the target radiative losses are at ambient temperature

The third set of columns pertain to the detector/sprinkler output.

Sensor Temperature $\left({ }^{\circ} \mathrm{C}\right)$ : temperature of the current detector / sprinkler

Sensor Activation (none): indicator of activation of the current detector / sprinkler; takes a value of zero if the sensor has not activated and one if it has

Sensor Surrounding Gas Temperature $\left({ }^{\circ} \mathrm{C}\right)$ : gas temperature nearby the current detector / sprinkler. This is the ceiling jet temperature at the device location if the device is in the ceiling jet or the appropriate gas layer temperature if the device is lower in the compartment

Sensor Surrounding Gas Velocity (m/s): gas velocity nearby the current detector / sprinkler. This is the velocity of the ceiling jet at the device location if the device is in the ceiling jet or a default value of $0.1 \mathrm{~m} / \mathrm{s}$ if the device is lower in the compartment 


\subsection{Error Messages}

In some (hopefully rare) cases, a simulation will fail to complete. In those cases, an error message provides guidance to the user on possible reasons for the failure. The message will contain an error number which provides a reference to additional information from the table below. Most often, these errors result from improper information in the input data files. During initialization of the program for a simulation, CFAST may stop with an error message if the simulation cannot be initialized due to a missing or incorrect file specification. The error codes are as follows:

100 program called with no arguments (no input file)

101 internal error in fire input; code for a free burning fire should not be reachable

102 project file does not exist

103 total file name length including path is more than 256 characters

104 one of the output files is not accessible (for example, if a CFAST case with this name is already running)

105 error writing to an output file (openoutputfiles)

106 a system fault has occurred. Applies to all open/close pairs once the model is running

107 incompatible options

108 not currently used

109 cannot find/open a file

110 error in handling the status input/output

Error codes from 1 to 99 are from the routine which parses the input and will be reported in the .log file. The first set indicates a command with the wrong number of arguments. These errors indicate an error in a particular input command as follows:

1 TIMES command

2 TAMB command

3 EAMB command

4 LIMO2 command

5 THERMAL or FIRE commands

7 MAINF command

8 COMPA command

10 HVENT command 
11 EVENT command

12 MVENT command

23 VVENT command

24 WIND command

25 INTER command

26 MVOPN command

28 MVDCT command

29 MVFAN command

32 OBJECT command

34 CJET and DETEC command

35 STPMAX command

37 VHEAT command

39 ONEZ command

41 TARGE command

46 HALL command

47 ROOMA command

51 ROOMH command

55 DTCHE command

56 SETP command

58 HHEAT command

65 HEATF command

The second set of errors related to parsing the input indicate specific errors with a command as follows:

9, compa Compartment out of range

26, inter Not a defined compartment

27, mvopn Specified node number too large for this system

30, mvfan Fan curve has incorrect specification 
31, mvfan Exceeded allowed number of fans

33, object Object must be assigned to an existing compartment

35, detect Invalid DETECTOR specification

36, detect A referenced compartment is not yet defined

38, vheat VHEAT has specified a non-existent compartment

42, target Too many targets are being defined

43, target The compartment specified by TARGET does not exist

44, target Invalid TARGET solution method specified

45, target Invalid equation type specified in TARGET

49, rooma Compartment specified by ROOMA does not exist

52, roomh Compartment specified by ROOMH is not defined

53, roomh ROOMH error on data line

54, roomh Data on the ROOMA (or $\mathrm{H}$ ) line must be positive

57, setp Trying to reset the SETP parameters

61, hheat HHEAT specification error in compartment pairs

62, hheat Error in fraction for HHEAT

63, object Fire type out of range

64, object The fire must be assigned to an existing compartment

66, heatf The heat source must be assigned to an existing compartment

67, mvent Compartment has not been defined

68, mvent Exceed one of the array bounds, ierror=68 (external), 69 (internal) and 70 (fan)

71, event Undefined vent type

72, inter Specification for interface height is outside of allowable range

73, inter Compartments must be defined in pairs

74, setp The requested SETP command does not exists

75, setp Incorrect file reference

76, setp Cannot read the parameter file 
77, setp Unsupported parameter

Errors 400 and above are failures while the model is running. 610 through 685 are failures in the numerical routines; these are rarely seen, but typically result from an internal error in the model. 


\section{Chapter 13}

\section{Scenario and Sofware Limits}

CFAST is intended for use with a wide variety of fire scenarios. A number of limits to the inputs in the software implementation of the model are noted below.

\begin{tabular}{|l|c|}
\hline Maximum simulation time in seconds & 86400 \\
\hline & 100 \\
\hline Maximum number of compartments & 2500 \\
\hline $\begin{array}{l}\text { Maximum number of horizontal flow (door/window) vent connections that can be in- } \\
\text { cluded in a single test case }\end{array}$ & 25 \\
\hline $\begin{array}{l}\text { Maximum number of horizontal vent connections between a pair of compartments that } \\
\text { can be included in a single test case }\end{array}$ & 200 \\
\hline $\begin{array}{l}\text { Maximum number of vertical flow (ceiling/floor) vent connections which can be included } \\
\text { in a single test case }\end{array}$ & 1 \\
\hline $\begin{array}{l}\text { Maximum number of vertical vent connections between a pair of compartments that can } \\
\text { be included in a single test case }\end{array}$ & 200 \\
\hline $\begin{array}{l}\text { Maximum total number of connections between compartments and mechanical ventila- } \\
\text { tion systems which can be included in a single test case }\end{array}$ & 100 \\
\hline Maximum number of fans that can be included in a single test cases & 200 \\
\hline Maximum number of fires which can be included in a single test case & 199 \\
\hline Maximum number of data points for a single fire definition & 21 \\
\hline $\begin{array}{l}\text { Maximum number of data points in a variable cross-sectional area definition for a single } \\
\text { compartment }\end{array}$ & 125 \\
\hline $\begin{array}{l}\text { Maximum number of material thermal property definitions which can be included in a } \\
\text { single thermal database file }\end{array}$ & 1000 \\
\hline $\begin{array}{l}\text { Maximum number of targets which can be included in a single test case. In addition, the } \\
\text { CFAST model includes a target on the floor of each compartment in the simulation and } \\
\text { one for each object fire in simulation. }\end{array}$ & 1000 \\
\hline Maximum number of detectors/sprinklers which can be included in a single test case. \\
\hline
\end{tabular}




\section{References}

[1] R.D. Peacock, K.B. McGrattan, G.P. Forney, and P.A. Reneke. CFAST - Consolidated Fire And Smoke Transport (Version 7) Volume 1: Technical Reference Guide. Technical Note xxxx, National Institute of Standards and Technology, Gaithersburg, Maryland, July 2015. 1, 69,71

[2] R. D. Peacock and P. A. Reneke. CFAST - Consolidated Fire And Smoke Transport (Version 7) Volume 3: Software Development and Model Evaluation Guide. Technical Note xxxx, National Institute of Standards and Technology, Gaithersburg, Maryland, July 2015. 1

[3] American Society for Testing and Materials, West Conshohocken, Pennsylvania. ASTM E 1355-04, Standard Guide for Evaluating the Predictive Capabilities of Deterministic Fire Models, 2004. 1

[4] U.S. Government Printing Office, Washington, DC. U.S. Standard Atmosphere, 1976. 6

[5] J. H. Klote and J. A. Milke. Principles of Smoke Management. American Society of Heating, Refrigerating, and Air-Conditioning Engineers, Inc, Atlanta, GA, 2002. 22

[6] 2001 ASHRAE Handbook - HVAC Systems and Equipment. American Society of Heating, Refrigerating, and Air-Conditioning Engineers, Inc, Altanta, Georgia, 2001. 22

[7] J. H. Klote. A Computer Model of Smoke Movement by Air Conditioning Systems. NBSIR 87-3657, National Bureau of Standards, 1988. 22

[8] C.L. Beyler. SFPE Handbook of Fire Protection Engineering, chapter Fire Hazard Calculations for Large Open Hydrocarbon Fires. National Fire Protection Association, Quincy, Massachusetts, 4th edition, 2008. 27

[9] R.L.P. Custer, B.J. Meacham, and R.P. Schifiliti. SFPE Handbook of Fire Protection Engineering, chapter Design of Detection Systems. National Fire Protection Association, Quincy, Massachusetts, fourth edition, 2008. 27

[10] D. D. Evans. Sprinkler Fire Suppression for HAZARD. NISTIR 5254, National Institute of Standards and Technology, 1993. 32

[11] W. D. Davis and K. A. Notarianni. NASA Fire Detector Study. NISTIR 5798, National Institute of Standards and Technology, Gaithersburg, Maryland, November 1996. 32 
[12] N. Iqbal and M.H. Salley. Fire Dynamics Tools (FDTs), Quantitative Fire Hazard Analysis Methods for the U.S. Nuclear Regulatory Commission Fire Protection Inspection Program. NUREG 1805, U. S. Nuclear Regulatory Commission, Office of Nuclear Regulatory Research, Rockville, MD, 2004. 32

[13] G. P. Forney. Smokeview (Version 6) - A Tool for Visualizing Fire Dynamics Simulation Data, Volume I: User's Guide. Special Publication 1017-1, National Institute of Standards and Technology, Gaithersburg, Maryland, June 2012. 35

[14] G. Heskestad. SFPE Handbook of Fire Protection Engineering, chapter Fire Plumes, Flame Height, and Air Entrainment. National Fire Protection Association, Quincy, Massachusetts, fourth edition, 2008. 47

[15] R. D. Peacock, G. P. Forney, and P. A. Reneke. CFAST - Consolidated Model of Fire Growth and Smoke Transport (Version 6): Technical Reference Guide. Special Publication 1026r1, National Institute of Standards and Technology, Gaithersburg, Maryland, October 2011. 65 


\section{Appendix A}

\section{Structure of the CFAST Input File}

The purpose of this appendix is to describe the format of the text-based input file that is generated by the CEdit graphical user interface. A simple input file is listed below. The input values may be integers, real numbers, or text. The input file is a comma-separated ASCII text file and may be edited with a spreadsheet program or any text editor. It is possible to use a word processor but it is important to save the file in ASCII text format and not in a word processing format. Note that some word processors will save punctuation and other characters incorrectly for the simple ASCII text file used by CFAST. It is recommended that the input files be created with the input editor, CEdit, provided as part of the CFAST distribution. In addition to checking the input data for errors, it includes typical ranges for input values to assist in appropriate use of the model.

Each line of the input file consists of a label followed by one or more alphanumeric parameters associated with that input label, separated by commas. The label must always begin in the first space of the line and be in capital letters. Following the label, the values may start in any column, and all values must be separated by a comma. Values may contain decimal points if needed or desired. They are not required.

Inputs are in standard SI units. The maximum line length is 1024 characters, so all data for each keyword must fit in this number of characters.

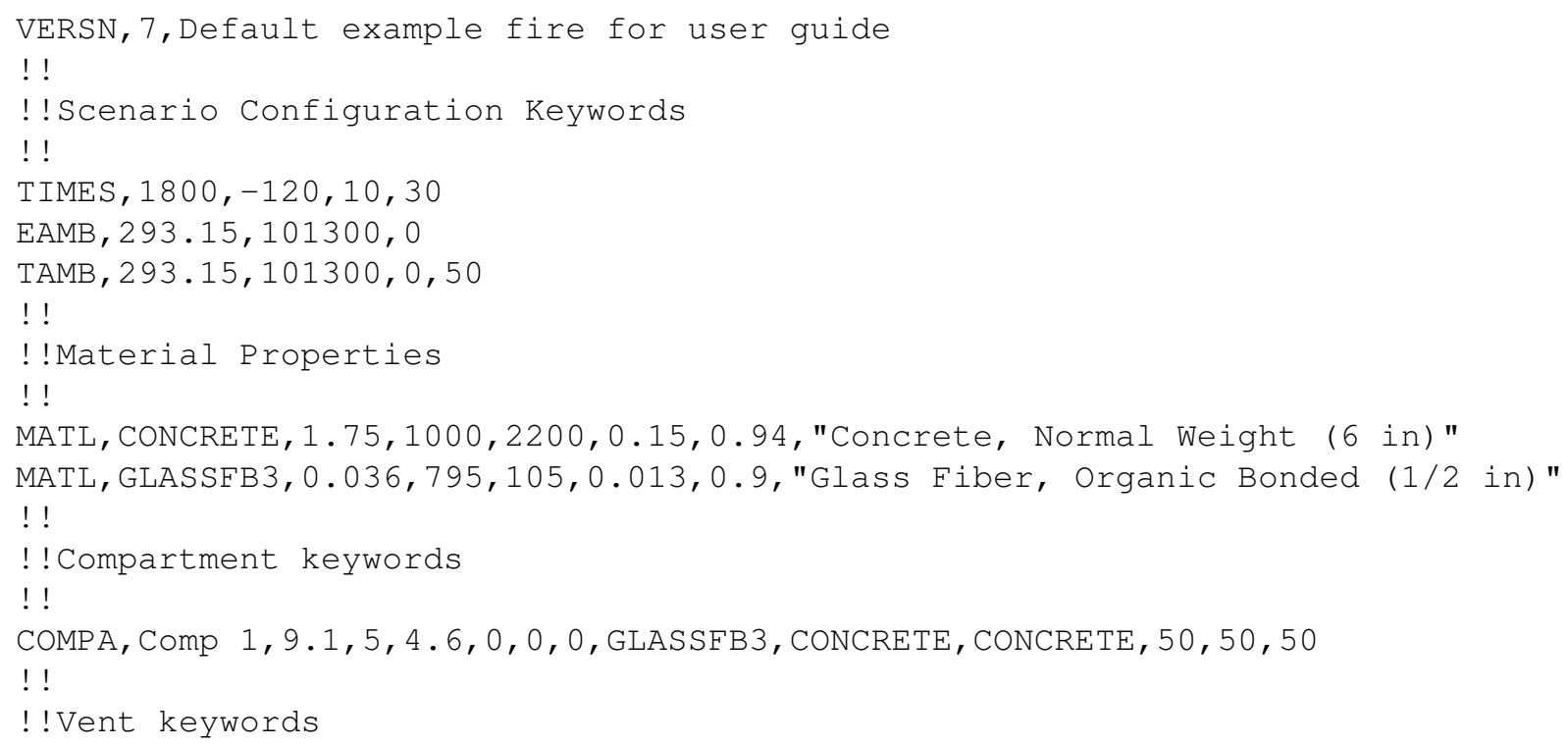




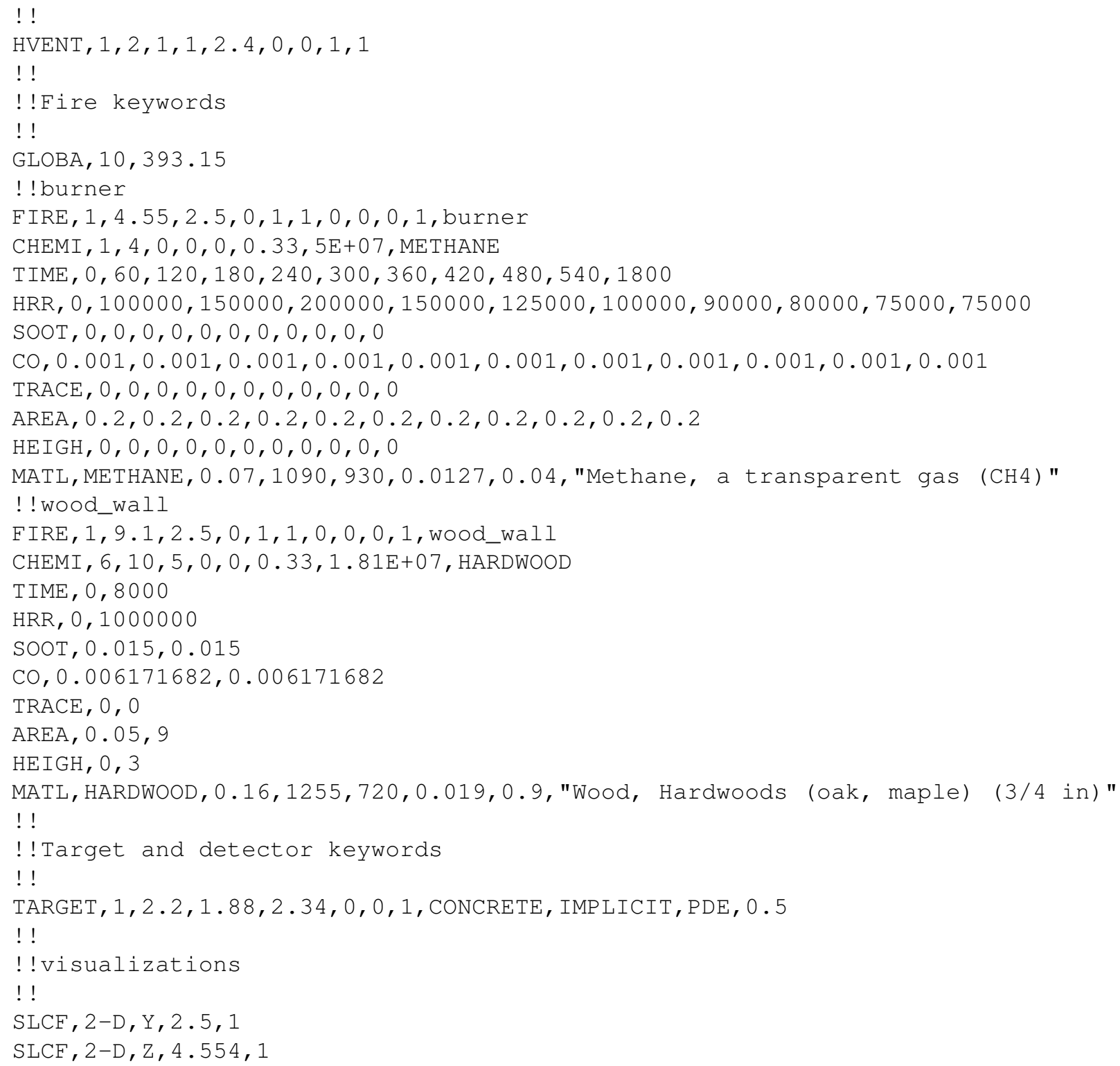

\section{A.1 COMPA}

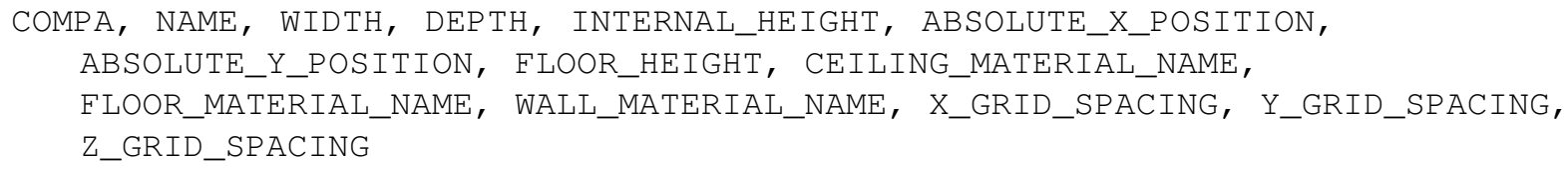

The compartments are numbered internally as they are read in. The other key words which refer to compartment numbers then refer to these ordinals. Compartments must be defined before they are referenced by other commands. Example: 
COMPA, hallway, 9.1, 5.0,4.6, 0.,0.,0 ., CONCRETE, CONCRETE, CONCRETE, 50, 50,50

\section{A.2 DEADROOM}

DEADROOM，DEAD_ROOM_NUMBER，CONNECTED_ROOM_NUMBER

The DEADROOM command specifies a compartment that is only connected to another compartment that in turn is not connected to the outside. Compartment pressure is not calculated for the "dead" room. Pressure for this room is assumed to be the same as that of the connected room.

\section{A.3 DETEC}

DETEC, TYPE, COMPARTMENT, ACTIVATION_TEMPERATURE,E DEPTH, WIDTH, HEIGHT, RTI, SUPPRESSION， SPRAY_DENSITY

The DETEC keyword is used for both detectors and sprinklers. Sprinklers and detectors are both considered detection devices and are handled using the same input keywords. Detection is based upon heat transfer to the detector. Fire suppression by a user-specified water spray begins once the associated detection device is activated.

For the type of detector, use 1 for smoke detector and 2 for heat detector or sprinklers. If suppression is set to a value of 1 , a sprinkler will quench the fire with the specified spray density of water. If turned off (a value of 0 ), the device is handled as a heat or smoke detector only - values entered for activation temperature, RTI, and spray density are ignored.

The spray density is the amount of water dispersed by a water sprinkler. The units for spray density are length/time. These units are derived by dividing the volumetric rate of water flow by the area protected by the water spray. The suppression calculation is based upon an experimental correlation by Evans, and depends upon the RTI, activation temperature, and spray density to determine the behavior of the sprinkler.

Example:

DETECT $, 2,1,344.2,1.5,1.5,2.29,98,1,7.00 \mathrm{E}-05$

\section{A.4 DJIGN}

DJIGN， 373.15

This entry sets the ignition temperature for door jet fires. Please read the technical reference manual for the meaning and implication of modifying these two parameters [15].

This entry is superseded by the two-entry key word GLOBA which replaces both LIMO2 and DJIGN.

Example:

DJIGN, 488 


\section{A.5 DTCHE}

DTCHE, MINIMUM_TIME, COUNT

The purpose of DTCHE is to prevent excessive computation with a very small time step. This often appears to users as though the program has frozen, when it is simply the set of equations has reached a point that requires very small time steps for the solver to converge. A negative entry on DTCHE turns off the time step checking algorithm. A positive value for the minimum time input sets the software for a maximum number of iterations (COUNT) below a minimum time step (MINIMUN_TIME) before producing an error and stopping.

Example:

DTCHECK, 1.E-9, 100

\section{A.6 EAMB and TAMB}

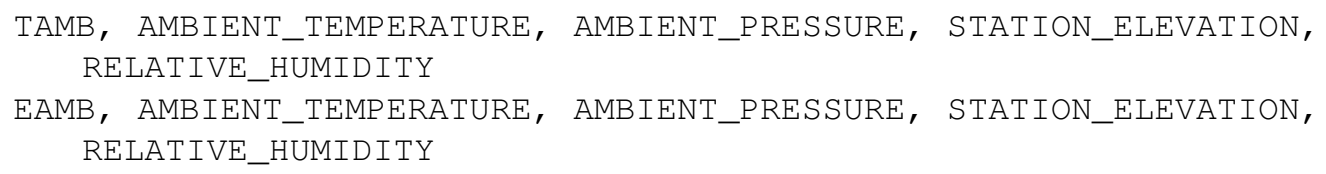

This keyword sets ambient conditions, TAMB for the internal and EAMB for outside the building. For the internal ambient, relative humidity sets the initial water concentration in the ambient air. For the external ambient, it sets the water content for air flowing into compartments through vents connecting to the exterior. Temperatures are in Kelvin, pressure in Pascals, and relative humidity in percent. Default values for temperature, pressure, and relative humidity are $20{ }^{\circ} \mathrm{C}$, $101300 \mathrm{~Pa}$, and $50 \%$, respectively.

Example:

$\mathrm{EAMB}, 300,101300,0,50$

TAMB $, 300,101300,0,50$

\section{A.7 EVENT}

EVENT, TYPE, FIRST_COMPARTMENT, SECOND_COMPARTMENT, VENT_NUMBER, TIME, FINAL_FRACTION

Type indicates the vent type associated with this EVENT action. " $\mathrm{H}$ " indicates a horizontal flow event that changes the vent opening, "V" a vertical flow event, "M" a mechanical flow event, and " $F$ " for filtering of mechanical ventilation flow. Final_Fraction is the percent of the full opening width expressed as a fraction for vents and fraction of trace species and soot removed for filters.

EVENT is used to open or close a vent or to change filtering. This replaces the earlier CVENT and applies to all vents for vertical flow (V), horizontal flow $(\mathrm{H})$ mechanical flow $(\mathrm{M})$, and filtering of mechanical ventilation $(\mathrm{F})$. The intent is to allow these events to be triggered by time, 
temperature or flux as is done with detectors. However, at the moment, time is the only option.

The form for EVENT is

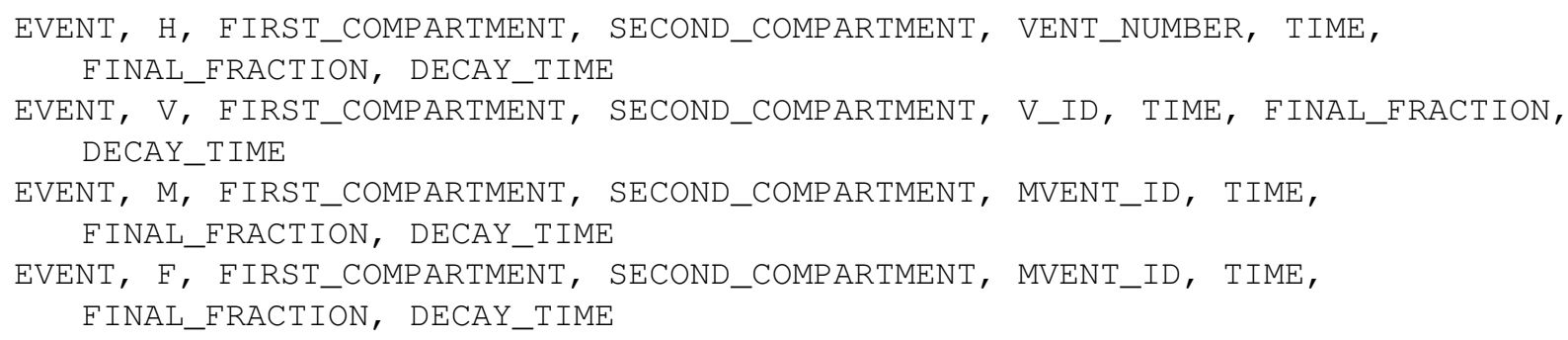

Decay time is the duration of the event and the units are seconds.

Example:

EVENT, H, 1, 2, 1, 10., 0.3,1

The convention for vent fractions is the 1 is $100 \%$ open, and 0 is closed. Filtering applies only to trace species and particulate (soot) and only to mechanical ventilation vents. For filtering, 0 indicates no filtering and 1 indicates that all soot and trace species flowing through the fan is removed.

\section{A.8 FIRE}

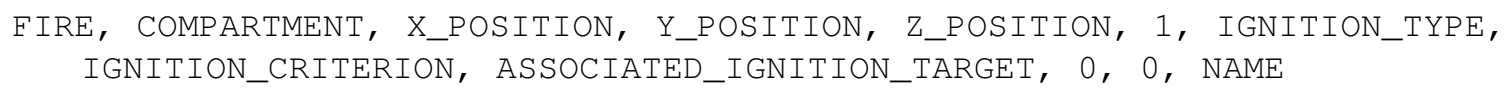

This key word places a fire into a compartment. The associated keywords CHEMI, TIME, HRR, SOOT, CO, TRACE, AREA, and HEIGH completely specify the fire for the current simulation. IGNITION_TYPE can be TIME, FLUX, or TEMP. IF FLUX or TEMP is specified, an existing, user-specified target specified in the ASSOCIATED_IGNITION_TARGET field is used to determine the ignition time.

\section{Example:}

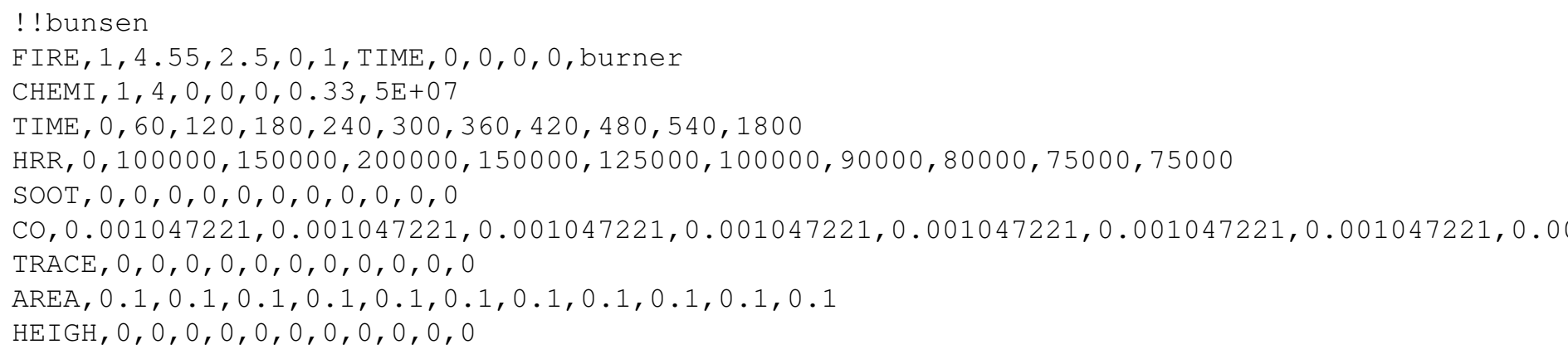

\section{A.8.1 CHEMI}

CHEMI, FORMULA_C, FORMULA_H, FORMULA_O, FORMULA_N, FORMULA_Cl, 
RADIATIVE_FRACTION, HEAT_OF_COMBUSTION

The CHEMI input defines the chemical formula of the burning material (FORMULA_C,_H, ${ }_{-} \mathrm{O},{ }_{-} \mathrm{N}$, and $\_\mathrm{Cl}$ ), its heat of combustion, and fraction of its head given off by radiation.

\section{A.8.2 TIME}

TIME, T_1, T_2, T_3, ..., T_N-1, T_N

The TIME input defines a series of time points which correspond to entries on the other fire inputs HRR, SOOT, CO, TRACE, AREA, and HEIGH. These define the time-based variation of the fire size, fire area, and species yields for the specified fire.

\section{A.8.3 HRR}

HRR, Q_1, Q_2, Q_3, . , Q_N-1, Q_N

The HRR input defines a series of heat release rates which correspond to entries on the TIME input. These define the time-based variation of the fire size for the specified fire.

\section{A.8.4 SOOT, CO, TRACE}

SOOT, S_1, S_2, S_3, .... S S_N-1, S_N

CO, C_1, C_2, C_3,$\ldots$, C_N -1, C_N

TRACE, TR_1, TR_2, TR_3, ..., TR_N-1, TR_N

These three inputs define a series of species yields which correspond to entries on the TIME input. These define the time-based variation of the soot, carbon monoxide, and trace species yields for the specified fire.

\section{A.8.5 AREA}

AREA, A_1, A_2, A_3, $\ldots$, A_N-1, A_N

The AREA input defines a series of areas which correspond to entries on the TIME input. These define the time-based variation of the cross-sectional area of the base of the fire for the specified fire.

\section{A.8.6 HEIGH}

HEIGH, H_1, H_2, H_3, ... , H_N-1, H_N

The HEIGH input defines a series of height values which correspond to entries on the TIME input. These define the time-based variation of the vertical position of the base of the fire (measured from the floor of the current compartment) for the specified fire.

\section{A.9 GLOBA}


This parameter is global and applies to all fires. Here, with two parameters, the command sets the lower oxygen limit and the ignition temperature for door jet fires. The first entry sets the lower oxygen limit for combustion in a layer. The second entry sets the ignition temperature for door jet fires. Please read the technical reference manual for the meaning and implication of modifying these two parameters [1].

This two-entry key word replaces LIMO2 and DJIGN.

Example:

GLOBA, 10,488

This sets the limiting oxygen index to $10 \%$ and the ignition temperature to $488 \mathrm{~K}$. These are the default values.

\section{A.10 HALL}

HALL, COMPARTMENT

This command invokes the corridor flow ceiling jet algorithm for the chosen compartment.

Example:

HALL, 3

\section{A.11 HHEAT}

HHEAT, FIRST_COMPARTMENT, NUMBER_OF_PARTS, N PAIRS OF \{SECOND_COMPARTMENT, FRACTION\}

Used to allow heat conduction between pairs of compartments which have a contiguous vertical partition between them. There are two forms of this command. The first form is to use only a compartment number. In this case, CFAST will calculate the conductive heat transfer to all compartments connected to this compartment by horizontal convective flow. The second form specifies the compartments to be connected and what fraction of the compartment is connected to an adjacent compartment. This latter is particularly useful for rooms which are connected to adjacent rooms as well as hallways. The user of the model is responsible for the consistency of these pairings. The model does not check to insure that the specified compartment pairs are located next to one another.

Example:

HHEAT $, 1,1,2,0.5$

specifies that compartment one has one connection to compartment two and the fraction of wall 
surface through which heat is transferred is one half of the wall surface of compartment one.

\section{A.12 HVENT}

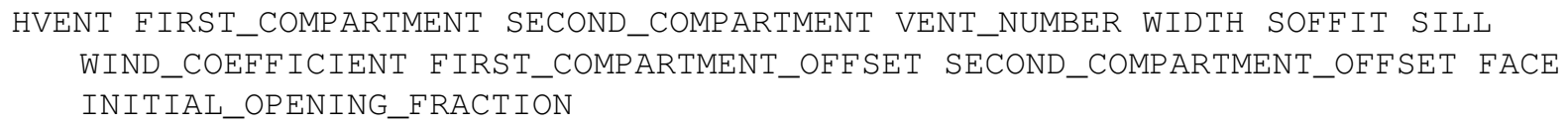

Vent which allows horizontal flow of gases through vents such as doors and windows. Compartment offsets are triplets from the compartment origin. FACE is an integer from 1 to 4 counterclockwise from the origin defining which wall face to place the vent on when visualizing with Smokeview. It doesn't affect the dynamics of the calculation, just the way it looks. The size of the opening can be modified by EVENT. This changes the Opening Fraction from the initial value (set above) to some other value. Typical use is to start with the door open (Initial_Opening_Fraction = 1) and use EVENT to close the door (Final_Fraction =0).

Example:

HVENT $, 1,2,1,2.4,1.0,0 ., 0 ., 0 ., 0 ., 1,0.9$

\section{A.13 INTER}

INTER INITIAL_INTERFACE_HEIGHT_I INITIAL_INTERFACE_HEIGHT_2 ...
INITIAL_INTERFACE_HEIGHT_N

This is used to set the initial interface height below the top of the compartment. A great deal of care is needed to use this, as the model has only rudimentary checks for the limits imposed (for example, the initial value must specify a height not greater than the compartment height. This does change the nature of a zone in the context of a zone model.

Example:

INTER $21.2 \quad 3 \quad 2.0$

\section{A.14 ISOF}

ISOF, VALUE, COMPARTMENT (S)

The ISOF command creates 3-dimensional animated contours of gas temperature in one or more compartments. For example, a $300{ }^{\circ} \mathrm{C}$ temperature isosurface is a 3-D surface on which the gas temperature is $300{ }^{\circ} \mathrm{C}$. The output frequency of the slice files is controlled by the SMOKEVIEW_OUTPUT INTERVAL input on the TIMES input line. Note that 3-D isosurface files can be quite large if the output interval is small. Computational time can also increase significantly with specification of isosurface files.

ISOF, $300,1,2$ 
The first example specifies a $300{ }^{\circ} \mathrm{C}$ temperature isosurface in compartments 1 and 2 . The last example specifies $600{ }^{\circ} \mathrm{C}$ isosurfaces in all compartments.

\section{A.15 LIMO2}

LIMO2, LOWER_OXYGEN_INDEX

This parameter is global and applies to all fires. The single entry sets the lower oxygen limit for combustion. Please read the technical reference manual for the meaning and implication of modifying these parameters [1].

This entry is superceded by the two-entry key word GLOBA which replaces both LIMO2 and DJIGN.

\section{A.16 MATL}

MATL, SHORT_NAME, CONDUCTIVITY, SPECIFIC_HEAT, DENSITY, THICKNESS, EMISSIVITY, LONG_NAME

This command defines the thickness and thermal properties for a single material that may be referenced as a compartment surface material, target material, or fire object. Each name must be unique within a single input file.

MATL, CONCRETE, 1.75,1000,2200,0.15,0.94, "Concrete, Normal Weight (6 in)"

MATL, GLASSFB3, 0.036, 795, 105,0.013,0.9,"Glass Fiber, Organic Bonded (1/2 in)"

\section{A.17 MVENT}

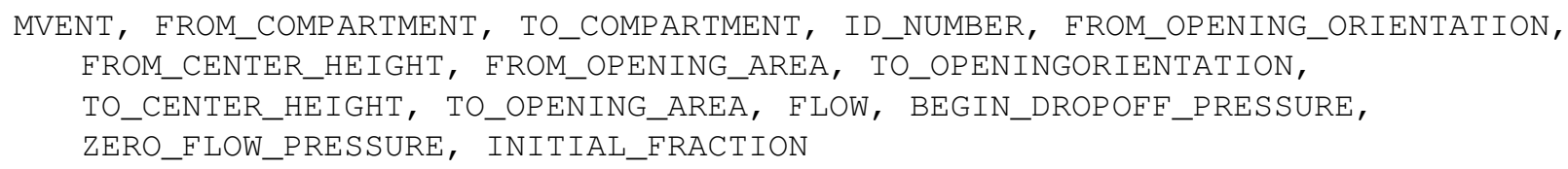

This replaces the more complex mechanical ventilation commands with a constant flow fan connection. The original commands MVOPN MVFAN MVDCT and INELV are not supported in this version. The command specifies a pair of openings connected by a constant volume flow fan. The fan flow can be modified with the EVENT key word.

Example:

MVENT, $5,7,1, \mathrm{~V}, 0.50,1.00, \mathrm{H}, 2.40,1.10,2.00,200 ., 300 ., 1.0$

\section{A.18 ONEZ}


For tall compartments or those removed from the room of fire origin, the compartment may be modeled as a single, well-mixed zone rather than the default two-zone assumption. A single zone approximation is appropriate for smoke flow far from a fire source where the two-zone layer stratification is less pronounced than in compartments near the fire. This is used in situations where the stratification does not occur. Examples are elevators, shafts, complex stairwells, and compartments far from the fire.

Example:

ONEZ, 2

\section{A.19 ROOMA and ROOMH}

ROOMA AND ROOMH, COMPARTMENT, NUMBER_OF_VALUES, AREA(OR HEIGHT) VALUES

These key words allow the user to define non-rectangular rooms by specifying cross-sectional area as a function of height. One set of values is included for each compartment that has a variable cross-sectional area. The format in both cases is the key followed by an index of the number of values. These key words must be used in pairs.

Example:

ROOMA $1 \quad 3 \quad 10.0 \quad 5.0 \quad 3.0$

ROOMH $13 \quad 3 \quad 0.0 \quad 1.0 \quad 2.0$

The example specifies that compartment 1 has a cross-sectional area of $10 \mathrm{~m}^{2}, 5 \mathrm{~m}^{2}$ and $3 \mathrm{~m}^{2}$ at elevations $0.0 \mathrm{~m}, 1.0 \mathrm{~m}$ and $2.0 \mathrm{~m}$ respectively.

\section{A.20 SLCF}

SLCF, DOMAIN, LOCATION, COMPARTMENT(S)

With Smokeview, CFAST can display animations of various gas phase quantities in a plane or volume in one or more compartments, depending on the inputs. For 2-D slices, the DOMAIN input is 2-D, followed by the selected plane (either $\mathrm{X}, \mathrm{Y}$, or Z), and a position within the compartment along the respective axis. For 3-D slices, the DOMAIN input 3-D is selected. One, several, or all compartments can be specified. As many SLCF commands as needed can be used in a CFAST input file. The output frequency of the slice files is controlled by the SMOKEVIEW_OUTPUT_INTERVAL input on the TIMES input line. Note that 3-D slice files can be quite large if the output interval is small. Computational time can also increase significantly with specification of 3-D slice files.

Example:

SLCE, 3-D, 1, 2, 3

SLCE, 2-D, X, 2.5, 3, 5 
SLCF, 3-D

SLCF, 2-D

$\backslash$

The first SLCF example specifies a 3-D slice file output for compartments 1, 2, and 3. The second SLCF example specifies a 2-d slice file output parallel to the X (depth) axis, $2.5 \mathrm{~m}$ from the axis origin in compartments 3 and 5. The last two examples specify default 3-D and 2-D slice file output for all compartments.

\section{A.21 STPMAX}

STPMAX, MAXIMUM_TIME_STEP

This specifies the largest time step that the model will take. The default value is one second. In most cases, the numerical routines adjust the time step appropriately; however, for long simulation times and slowly varying conditions, a larger value is appropriate. In cases where the fire height and vent soffits interact, the time step may need to be smaller.

Example:

STPMAX, 0.2

\section{A.22 TARGE}

TARGE, COMPARTMENT, WIDTH, DEPTH, HEIGHT, NORMAL_DEPTH, NORMAL_BREADTH, NORMAL_HEIGHT, MATERIAL, METHOD, EQUATION_TYPE, INTERNAL_LOCATION

CFAST can track and report calculations of the net heat flux striking arbitrarily positioned and oriented targets and the temperature of these targets. A non-zero normal vector must be specified as must a material from the thermophysical database. METHOD can be set to STEADY for steady state solution, XPLICIT for explicit solution, and MPLICIT for an implicit solution. Equation_Type can be PDE for cartesian coordinates or CYL for cylindrical coordinates.

Example:

TARGE $, 1,2.20,1.88,2.34,0.00,0.00,1.00$, CONCRETE, IMPLICIT, PDE

\section{A.23 TIMES}

TIMES, SIMULATION_TIME, PRINT_INTERVAL, SPREADSHEET_OUTPUT_INTERVAL, SMOKEVIEW_OUTPUT_INTERVAL

Example:

TIMES, $360,-120,130,140,150$, 
Printed output will be on the screen or in a file named project.out. The four spreadsheet listings are in project.(project_n.csv, project_w.csv, project_f.csv and project_s.csv). The Smokeview output interval are for graphical output using the companion program Smokeview.

\section{A.24 THRMF}

THRMF，THERMOPHYSICAL_PROPERTIES_FILE

By default, thermophysical properties are obtained from the thermal.csv which is located in the directory where the model executables reside. This allows for another file to be used.

Example:

THRMF, NEWTHERMALF ILE

\section{A.25 VERSN}

VERSN, version number, Title

This input must be the first line in a CFAST input and largely specifies a title for the simulation. The major version number from the file must match the major version number kept internally (7 at the moment).

Example

VERSN, 6,"Simple test of the object file input"

\section{A.26 VHEAT}

VHEAT, FIRST_COMPARTMENT, SECOND_COMPARTMENT

Heat transfer between the ceiling and floor of specified compartments can be incorporated with the VHEAT key word. Ceiling to floor heat transfer occurs between interior compartments of the structure or between an interior compartment and the outdoors. The model checks to make sure that the ceiling and floor are reasonably contiguous (within $0.01 \mathrm{~m}$ ), and the assumption is made that this is true for the entire ceiling and floor.

Example:

VHEAT, 1, 2

The floor properties of the top compartment ( 1 in this case) and the ceiling properties of the bottom compartment ( 2 in this case) must be defined by COMPA and included in the thermophysical file.

\section{A.27 VVENT}


VVENT, FROM_COMPARTMENT, TO_COMPARTMENT, AREA, SHAPE, INITIAL_FRACTION

This key word describes horizontal openings between compartments connected with a vent in the floor/ceiling between the compartments. Each VVENT line in the input file describes one horizontal vent. There are four parameters, the connected compartments, the shape of the opening, and the effective area of the vent.

Example:

VVENT $, 1,2,4.0,2,0.9$

\section{A.28 Running CFAST from a Command Prompt}

The model CFAST can also be run from a Windows command prompt. CFAST can be run from any folder, and refer to a data file in any other folder. The fires and thermophysical properties have to be in either the data folder, or the executable folder. The data folder is checked first and then the executable folder.

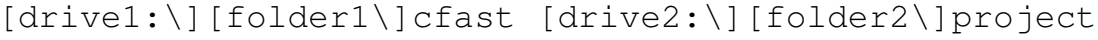

The project name will have extensions appended as needed (see below). For example, to run a test case when the CFAST executable is located in c: $\backslash$ nist $\backslash$ cfast 6 and the input data file is located in $\mathrm{c}: \backslash$ data, the following command could be used:

$c: \backslash$ nist \cfast6\cfast $c: \backslash$ data \testfire0 $\quad<<$ note there is no extension.

If the command is entered as $\backslash$ bin $\backslash$ cfast $\backslash$ bin $\backslash$ data $\backslash$ testfire0.in, then CFAST will try to open testfire 0. in.in

The database files for thermal properties and fire objects may be located either in the folder with the input data file or in the folder with the CFAST executable. The model checks first in the data file folder and then in the CFAST executable folder. If the files do not exist in either location, the simulation is not run. By default, names for these files are thermal.csv for the thermal properties file and *.o for the fire object files.

Command line options

- k - no keyboard access

- i - initialization only

- c - compact output

- $\mathrm{f}$ - full output (c and $\mathrm{f}$ are exclusive). Note the interaction of the $\mathrm{f}$ and c option. The default for the console output is /c. The default for the file output is /f. This default action can be overwritten by explicitly including the /f or /c option. Output goes to the screen if the print interval (second entry on the TIMES line) is positive and to the output file if the interval is negative.

- $\mathrm{t}$ - replace the flow output with total flow through (mechanical) vents. 
- $\mathrm{n}$ - net heat flux option

- v - validation output (outputs a modified set of spreadsheet files with different column headers designed to facilitate automated analysis of the output) 